$$
\begin{aligned}
& \text { INBORN FRRORS } \\
& \text { OI METABOL.ISM }
\end{aligned}
$$$$
\text { A.E.GARROD }
$$

lifornia ional lity 
Digitized by the Internet Archive in 2007 with funding from

Microsoft Corporation 

INBORN ERRORS OF METABOLISM 


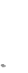




\title{
INBORN ERRORS OF METABOLISM
}

The Croonian Lectures delivered before the Royal College of Physicians of London, in June, I 908

\author{
By \\ ARCHIBALD E. GARROD \\ D.M., M.A. OXON.
}

Fellow of the Royal College of Physicians. Assistant Physician to, and Lecturer on Chemical Pathology at St. Bartholomew's Hospital. Physician to the Hospital for Sick Children, Great Ormond Street

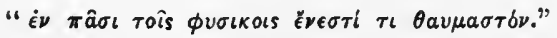

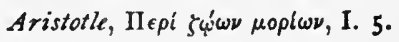

\section{LONDON}

HENRY FROWDE HODDER \& STOUGHTON Oxford University Press 20, Warwick Sevare, E.C. I909 



\section{Preface}

Since they were delivered in June, and published in the Lancet in July 1908, these Croonian Lectures have undergone revision. The results of some important investigations which have been since published have been incorporated, and this has rendered necessary some rearrangement and expansion of the text, and also some additions to the tables.

It has been thought better to substitute a division into chapters for the original division into lectures.

I desire to offer, once more, to the authorities of the Royal College of Physicians, my sincere thanks for the honour conferred upon me in the invitation to deliver these lectures before the College; and also to express my gratitude to those who have lent most valuable and willing aid in their preparation, among whom I would specially name Dr. W. H. Hurtley and Mr. T. Shirley Hele. 
The motto printed upon the title page was that adopted by Dr. Croon, in memory of whom these lectures were founded, for his tract $D e$ ratione motus musculorum. To the subjects here discussed it seems particularly appropriate; for if it be true that in every phenomenon of Nature there is something of the marvellous, surely that factor is nowhere more in evidence than in the workings of the metabolic processes in living things.

January, 1909. 


\section{Contents}

PAGE

Preface

CHAPTER I

INBorN Errors of Metabolism . . . . . 1

CHAPTER II

AlbINISM

CHAPTER III

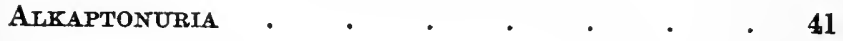

CHAPTER IV

$\begin{array}{llll}\text { Cystentara } & \cdot \\ & \text { CHAPTER V }\end{array}$

CHAPTER IV

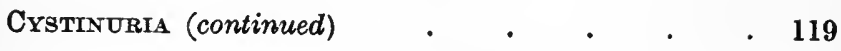

CHAPTER VI

Pentosuria.

INDEX . 



\section{CHAPTER I}

\section{The Inborn Errors of Metabolism}

The differences of structure and form which serve to distinguish the various genera and species of animals and plants are among the most obvious facts of nature. For their detection no scientific training is needed, seeing that they cannot escape the notice of even the least cultivated intelligence. Yet with the growth of knowledge we have learned to recognize the uniformity which underlies this so apparent diversity, and the genetic relationship of form to form. With regard to the chemical composition of the tissues of living organisms, and the metabolic processes by which those tissues are built up and broken down, the advance has been in the opposite direction, for the progress of chemical physiology is teaching us that behind a superficial uniformity there exists a diversity which is no less real than that of structure, although it is far less obvious.

The differences of ultimate composition and crystalline form which distinguish the hæmoglobins of animals of distinct genera have long been known. That the fats of animals are not alike in composition is 


\section{INBORN ERRORS OF METABOLISM}

well recognized, as also are the differences of their bile acids, to quote only a few of the most conspicuous examples. As instances of distinctive end-products of metabolism may be mentioned kynurenic acid, which is present in the urine of animals of the canine tribe and bears witness to a generic peculiarity in the manner of dealing with the tryptophane fraction of proteins, and the excretion by birds and reptiles of the bulk of their nitrogenous waste in the form of uric acid, whereas in the urine of mammals urea is the chief nitrogenous constituent.

A more extended study, even by strictly chemical methods, will doubtless serve to reveal innumerable minor differences, such as are foreshadowed by Przibram's ${ }^{1}$ work on muscle proteins. The delicate ultra-chemical methods which the researches of recent years have brought to light, such as the precipitin test, reveal differences still more subtle, and teach the lesson that the members of each individual species are built up of their own specific proteins, which resemble each other the more closely the more nearly the species are allied.

Obviously it is among the highly complex proteins that such specific differences are to be looked for, rather than in the simple end-products of their disintegration. The many amino-acids which enter into the structure of the protein molecules are capable of almost innumerable groupings and proportional representations, and each fresh grouping will produce a distinct protein; but all alike, in

1 Hofmeister's Beiträge zur chem. Physiol. u. Pathologie, 1902, Band ii, p. 143. 
their breaking down, will yield the same simple end-products, such as urea and carbon dioxide.

Nor can it be supposed that the diversity of chemical structure and process stops at the boundary of the species, and that within that boundary, which has no real finality, rigid uniformity reigns. Such a conception is at variance with any evolutionary conception of the nature and origin of species. The existence of chemical individuality follows of necessity from that of chemical specificity, but we should expect the differences between individuals to be still more subtle and difficult of detection. Indications of their existence are seen, even in man, in the various tints of skin, hair, and eyes, and in the quantitative differences in those portions of the end-products of metabolism which are endogenous and are not affected by diet, such as recent researches have revealed in increasing numbers. Even those idiosyncrasies with regard to drugs and articles of food which are summed up in the proverbial saying that what is one man's meat is another man's poison presumably have a chemical basis.

Upon chemical as upon structural variations the factors which make for evolution have worked and are working. Evidences of this are to be detected in many directions, as, for example, in the delicate selective power of the kidneys, in virtue of which they are enabled to hold back in the circulation the essential proteins of the blood but at the same time allow free passage to other proteins which are foreign to the plasma, such as hæmoglobin 
and the Bence-Joncs protein, when these are present in any but quite small amounts. The working of these factors is also seen in the various protective mechanisms against chemical poisons, such as that which averts the depletion of the fixed alkalies of the organism, by the neutralization of acids present in excess by ammonia. This mechanism is well developed in the carnivora and in man, but in vegetivorous animals, which from the nature of their diet are little exposed to acidosis, it appears to be wanting.

Even in the normal metabolic processes the working of such influences may be traced, as in the power which the organism possesses of destroying the benzene ring of those aromatic amino-acids which enter into the composition of proteins, and cannot therefore be regarded as substances foreign to the body, whereas the benzene ring of foreign aromatic compounds, with very few exceptions, are left intact. Such compounds require to be rendered innocuous by being combined with sulphuric acid to form aromatic sulphates, or with glycocoll to form the acids of the hippuric group and, so combined, are excreted in the urine and got rid of. The few exceptions referred to are compounds which so closely resemble the protein fractions in their structure that they fall victims with these to the normal destructive processes.

The great strides which recent years have witnessed in the sciences of chemical physiology and pathology, the newly-acquired knowledge of the constitution of proteins and of the part played by 
enzymes in connexion with the chemical changes brought about within the organism, have profoundly modified our conceptions of the nature of the metabolic processes, and have made it easier to understand how these changes may differ in the various genera and species. It was formerly held that many derangements of metabolism which result from disease were due to a general slackening of the process of oxidation in the tissues. The whole series of catabolic changes was looked upon as a simple combustion, and according as the metabolic fires burnt brightly or burnt low, the destruction of the products of the breaking down of food and tissues was supposed to be complete or imperfect. A very clear setting forth of such views will be found in the lectures of Bence-Jones 2 on Diseases of Suboxidation, delivered and published in the year 1865, but the thesis in question is chiefly associated with the name of Bouchard, ${ }^{3}$ who expounded it in his well-known lectures on Maladies par Ralentissement de la Nutrition, published in 1882. The so frequent clinical association of such maladies as gout, obesity, and diabetes was invoked in its support, nor was it regarded as a serious obstacle to the acceptance of such views that there is but scanty evidence to show that failure to burn any particular metabolic product, such as glucose, is associated with inability to deal with others.

Nowadays, very different ideas are in the ascend-

2 Medical Times and Gazette, 1865, vol. ii, pp. 29,83, etc.

- Maladies par Ralentissement de la Nutrition, Paris, 1882. 


\section{INBORN ERRORS OF METABOLISM}

ant. The conception of metabolism in block is giving place to that of metabolism in compartments. The view is daily gaining ground that each successive step in the building up and breaking down, not merely of proteins, carbohydrates, and fats in general, but even of individual fractions of proteins and of individual sugars, is the work of special enzymes set apart for each particular purpose. Thus the notion of general suboxidation is reduced to very narrow limits, to the recognition of controlling influences exercised by certain glandular organs, such as the thyroid, upon metabolism as a whole. For example, it is known that lævulose is not dealt with in the human organism in the same way as dextrose is, but follows its own path. A patient whose power of burning dextrose is seriously impaired may yet utilize lævulose in the normal manner. Again, there is evidence to show that the several fractions of proteins, tyrosin, cystin, tryptophane, and the rest, do not merely serve as fuel for a common furnace, but are dealt with each in a special manner and in successive stages.

It may well be that the intermediate products formed at the several stages have only momentary existence as such, being subjected to further change almost as soon as they are formed; and that the course of metabolism along any particular path should be pictured as in continuous movement rather than as series of distinct steps. If any one step in the process fail the intermediate product in being at the point of arrest will escape further change, just as when the film of a biograph is brought 
to a standstill the moving figures are left foot in air. All that is known of the course of catabolism tends to show that in such circumstances the intermediate product in being is wont to be excreted as such, rather than that it is further dealt with along abnormal lines. Indeed, it is an arguable question whether, under abnormal conditions, the metabolic processes are ever thrown out of their ordinary lines into entirely fresh paths, with the result that products are formed which have no place in the normal body chemistry. It is commonly assumed that this happens, but if the conception of metabolism in compartments, under the influence of enzymes, be a correct one, it is unlikely, à priori, that alternative paths are provided which may be followed when for any reason the normal paths are blocked. It is far easier to suppose that in such circumstances normal intermediate products are excreted without further change, and that processes which in health play but small parts in metabolism are called into unwonted activity.

This conception of the permanency of the metabolic paths is no new one, for it may be read between the lines in the writings of some physiologists of the last century, and especially in those of Claude Bernard, ${ }^{4}$ from which the following passage is translated :-

"It used to be supposed that in diabetes wholly new conditions were developed in the economy, under the influence of the morbid state, and that there resulted therefrom a

4 Pathologie Expérimentale, second edition, 1880, p. 15. 


\section{INBORN ERRORS OF METABOLISM}

special morbid product-namely, glucose. But it is admitted nowadays that the observed phenomena are to be explained by an augmentation, pure and simple, of a normal function in virtue of which glucose is formod in all subjects, oven in health. It is clear that the malady is nothing more than a physiological phenomenon perturbed and exaggorated."

\section{Still more striking is the following passage ${ }^{5}$ :}

“ Et maintonant oserait-on soutenir qu'il faut distinguer les lois de la vie à l'état pathologique des lois de la vie à l'état normal ? Ce serait vouloir distinguer les lois do la mécanique dans une maison qui tombe, des lois de la mécanique dans une maison qui tient debout."

To prove the truth of the contention put forward it would be necessary to show that every abnormal product found in the tissues or in the excreta, under morbid conditions, can be ascribed to other causes than the deflexion of the metabolic processes into new and unwonted paths. It must be admitted that this cannot yet be asserted of all such products. For example, we are still ignorant of the parent substance and mode of origin of the remarkable Bence-Jones protein, which is excreted in the urine of patients with multiple myeloma, nor is there any evidence as yet forthcoming that it is a normal intermediate product of protein metabolism. Nevertheless, when an endeavour is made to classify the unusual constituents which are occasionally present in that most important animal excretion, the urine, it is found that there are few of them which cannot be accounted for as intermediate products incompletely burnt, or as exaggeration of traces normally present, if we exclude such as are

- Pathologie Expérimentale, second odition, 1880, p. 568. 
merely foreign substances absorbed from the alimentary canal or derivatives of these, or are products of bacterial life and action in the intestines or in the tissues.

A number of unusual constituents of urine, and of normal constituents also, are derived from the alimentary canal. Thus foreign substances administered in food or as drugs may be excreted unchanged or may undergo oxidation or reduction in the intestine or after absorption, or again may appear in the urine in combination with products of metabolism. These last compounds, which result from the working of the chemical protective mechanisms, cannot be regarded as abnormal excreta. Even in health some tenth part of the total sulphuric acid of the urine is in combination with aromatic substances as ethereal sulphates. Traces of compound glycuronates are also normally present, and the aromatic constituents of vegetable foods are in part excreted in combination with glycocoll, as hippuric acid-and its allies. When other harmful substances, with which these protective mechanisms are competent to deal, are introduced in abnormal quantities the protective processes are stimulated to unwonted activity.

It does not necessarily follow that the substances which are utilized for such combinations are themselves intermediate products of normal metabolism, for it may well happen that combination has preceded oxidation. Thus the glycuronic acid which is excreted in compound glycuronates may not represent an intermediate stage in the breaking down 
of glucose as it has been supposed to do; for, as Emil Fischer has pointed out, the oxidation of the alcohol grouping of dextrose, whilst the less stable grouping remains intact, is more easily explained on the supposition that the primary combination of the foreign substance is with glucose itself, and that, the aldehyde group being thus protected from change, oxidation to glycuronic acid occurs as a subsequent event.

Some excreta are products of the action of bacteria in the alimentary canal upon the proteins of food or upon constituents of the bile. Thus urobilin, is formed by the intestinal bacteria from bilirubin and is abundantly present in the fæces so long as bile enters the intestine. From the intestine some urobilin is absorbed, and is excreted in part in the bile and in part in the urine, whilst some of it is probably destroyed in the tissues. Again, from the tryptophane of ingested proteins the intestinal bacteria form indol, which after absorption is oxidized to indoxyl and is excreted in the urine, mainly as indoxyl sulphate, but in part in combination with glycuronic acid. Disease of the actual organs of excretion has conspicuous effects upon the excreta. Thus diseased kidneys may hold back in part some constituents of the urine or, on the other hand, may allow passage to the normal proteins of the blood serum which it is their function to retain in the circulation. Again, by the blockage of a duct, as in jaundice, the products of glandular activity may be thrown back into the blood and appear in the urine, but the presence of such abnor- 
mal constituents is in no sense due to errors of metabolism.

Actual derangements of the metabolic processes follow almost any deviations from the normal of health, but our interpretation of the urinary changes which result is, in many instances, greatly hampered by the scantiness of our knowledge of the intermediate steps of the paths of metabolism. Such knowledge as we have of these steps is derived from casual glimpses afforded when, as the outcome of one of Nature's experiments, some particular line is interfered with, and intermediate products are excreted incompletely burnt. Many of the substances which rank as abnormal constituents are present in traces in normal urine, as by-products of the metabolic processes, and it may safely be assumed that we are not cognizant of all the traces which so occur. Exceptional methods will reveal traces previously unsuspected. Thus Dombrowski, working with enormous volumes of normal urine (100 litres), was able to demonstrate the presence of minute quantities of cadaverin; and that very delicate instrument the spectroscope reveals traces of hæmatoporphyrin in normal urine which would escape detection by rougher means. Only recently it has been shown that certain sulphur-containing acids, previously unknown, occur in no inconsiderable quantities in normal urine, and even now we do not know with any certainty all the constituents which go to make up the so-called neutral sulphur and residual nitrogen.

The effects of disease of the great laboratory 
glands, of which the liver is the chief, upon the chemical processes of which they are the seats, are less conspicuous than might be expected. This is perhaps due to the power of a small intact residue of an organ to carry on the functions of the whole, nor must it be forgotten that any very grave interference with the metabolic activities of the liver is incompatible with life. On the other hand, the phenomena of exophthalmic goitre, and of myxœdema bear witness to the profound effects of atrophy or disease of a gland which exerts a controlling influence over the metabolic processes as a whole. Some abnormal constituents of urine are believed to be products of undue breaking down of tissues, of autolysis intra vitam. Such an origin is now usually ascribed to the tyrosin and leucin excreted in acute yellow atrophy of the liver, and to the albumoses met with in urine.

There is a group of maladies in which metabolic disturbances are by far the most conspicuous features, whereas the structural changes behind them are scanty or even inappreciable. Of such "diseases of metabolism," diabetes, gout, and obesity are the most important. It is still uncertain how far the accumulation of uric acid in the blood and the deposition of sodium biurate in the tissues, which are the characteristic features of gout, are actually due to derangement of metabolism, as distinct from a mere excretory defect. In diabetes mellitus, under which name we probably include more than one morbid condition attended by persistent glycosuria, the metabolic derangements, 
primary and secondary, dominate the clinical picture. At the outset sugar may be excreted in very small quantity and only after a meal rich in carbohydrates; at a later stage the glycosuria tends to become continuous and the percentage of glucose in the urine rises until, in grave cases, the excretion almost ceases to be controlled by diet and the tissue proteins are called upon to supply sugar. By the destruction of fats and proteins the acetone bodies, and especially $\beta$-oxybutyric acid, are formed in increasing amounts, and to them the fatal ending is commonly attributed at the present day, although the accumulation of unburnt glucose in the blood is itself productive of serious evils. The liability to develop diabetes or gout is often inherited, but the diseases themselves are not inherited for they are never congenital. Developing at any period of life, the mischief, once begun, tends to become aggravated as time goes on, but the rate of aggravation differs widely in individual cases and is often conspicuously controlled by appropriate treatment.

Quite unlike that of the above metabolic diseases is the course of the anomalies of which I propose to treat and which may be classed together as inborn errors of metabolism. Some of them are certainly, and all of them are probably, present from birth. The chemical error pursues an even course and shows no tendency to become aggravated as time goes on. With one exception they bring in their train no serious morbid effects, do not call for treatment, and are little likely to be influenced by any 


\section{INBORN ERRORS OF METABOLISM}

therapeutic measures at our disposal. Yet they are characterized by wide departures from the normal of the species far more conspicuous than any ordinary individual variations, and one is tempted to regard them as metabolic sports, the chemical analogues of structural malformations. It is interesting to note that as far back as the earlier years of the nineteenth century, one of them, albinism, was classed by Mansfield ${ }^{6}$ and by Meckel ? as a "Hemmungsmissbildung" or malformation by arrest.

It may be pointed out that the epithets inborn and congenital are by no means synonymous. Structural abnormalities may be present at birth which owe their origin to intra-uterine disease or intra-uterine injury and are in no senso developmental errors. Again, an infective disease may be congenital but cannot be inborn. It has merely been acquired in utero. Even true developmental errors are of several distinct kinds. In some there is malposition or transposition of organs, partial or complete ; in others doubling of parts or inclusion of twin structures. Some struetural anomalies are malformations by excess, such as polydactyly, and some are malformations by defect, such as absence of the middle phalanx of each digit. In one large class, the so-called malformations by arrest, the process of development meets with a cheek and some portion of the body is left unfinished.

- Archiv für Anatomie und Physiologie, 1826, p. 96.

- Handbuch der pathologischen Anatomie, 1816, Band ii, 2, p. 3. 
To this group belong such abnormalities as harelip, cleft-palate, and spina bifida. Speaking of such arrests Professor J. A. Thomson writes: ${ }^{8}$ "These abnormalities occasionally recur repeatedly in a family tree, but it seems probable that what is really inherited is a deficiency in 'developmental vigour' accentuated by nutritive defects on the parts of the mothers during the period of gestation." No extraneous causes, such as intra-uterine injury or disease, can be assigned to the metabolic errors which are under discussion. As far as our present knowledge of them enables us to judge they apparently result from failure of some step or other in the series of chemical changes which constitute metabolism, and are in this respect most nearly analogous to what are known as malformations by defect. Nor is it only in the field of metabolism that inborn derangements of function are met with, for Daltonism and night-blindness may be quoted as examples of such anomalies having no obvious chemical basis.

At first sight there appears to be little in common between inborn derangements of function and structural defects, but on further consideration the difference is seen to be rather apparent than real. Almost any structural defect will entail some disorder of function ; sometimes this is almost inappreciable, but, on the other hand, the resulting functional disorder may be so conspicuous that it completely overshadows the defect to which it is due. Very slight structural changes may lead to profound

' Heredity, London, 1908, p. 289. 
functional derangements, as witness the effects of atrophy of the thyroid gland, whether congenital or acquired in later life, and the stormy metabolic disorders which may ensue upon comparatively insignificant morbid changes in the pancreas. By selective breeding there has been produced a race of waltzing mice, but their bizarre dance is merely the functional manifestation of an inborn and hereditary malformation of the semicircular canals. In the same way beneath each chemical sport may well exist some abnormality of structure, so slight that it has hitherto escaped detection. Among the complex metabolic processes of which the human body is the seat there is room for an almost countless variety of such sports, but the examples which can be adduced are very few in number. Indeed, up to now the only known anomalies which can, with any good show of reason, be assigned to this class are albinism, alkaptonuria, cystinuria, and pentosuria, and even as regards these the grounds for their inclusion in the group are not of equal cogency.

We should naturally expect that among such abnormalities those would earliest attract attention which advertize their presence in some conspicuous way, either by some strikingly unusual appearance of surface tissues or of excreta, by the excretion of some substance which responds to a test habitually applied in the routine of clinical work, or by giving rise to obvious morbid symptoms. Each of the known inborn errors of metabolism manifests itself in one or other of these ways, and this suggests 
that others, equally rare, which do not so advertize their presence, may well have escaped notice until now. One man in 20,000 whose urine of twenty-four hours habitually contained a few grammes of aspartic acid might well be overlooked.

Theoretically any anomaly which claims a place in the group should be present from birth and should persist throughout life, but it must be confessed at the outset that this cannot as yet be definitely asserted of all the four metabolic errors which $\mathbf{I}$ have mentioned. Some of them produce no obvious effects which compel attention, and may be only accidentally detected in adult life, and neither the evidence of the patient himself nor that of his parents can be of any help in endeavouring to trace back the peculiarity to infancy.

That albinism is congenital and persists through life is self-evident, and admits of no dispute, for the condition is as obvious as any structural malformation and much more so than many such. Its rarity in man is also evident, although by artificial selection it may be reproduced indefinitely in lower animals.

As regards alkaptonuria its lifelong persistence is equally well established, although it may be that this error, which is in the great majority of instances inborn, may occasionally occur as a temporary phenomenon in disease. The remarkable staining property of alkapton urine allows of its recognition at the very beginning of life, and I have been able to obtain reliable evidence with regard to two cases that the staining of clothing 
was noticed on the second day of life, and in one of these instances had an opportunity of examining some urine passed during the first ten days after birth. ${ }^{9}$ On the other hand an individual who exhibits the anomaly may reach adult life without being aware of any special peculiarity of his urine, and the condition may only attract attention when he is an applicant for life insurance or comes under treatment on account of some illness. Winternitz ${ }^{10}$ has recorded the interesting fact that the mother of seven children, three of whom were alkaptonuric, was convinced that whereas two of her children had passed alkapton urine from the earliest days of life, this had not been the case with the youngest child, in whom she had only noticed the peculiarity from the age of five years. Such information, supplied by a mother familiar with the symptoms of alkaptonuria, carries as much weight as any hearsay evidence can carry, but nothing short of actual chemical examination of the urine would suffice to prove a point of so much importance.

Turning now to cystinuria, the evidence of its congenital occurrence is much more difficult to obtain, for this anomaly is little likely to attract attention in a young infant. Seeing that cystinuria is not infrequently transmitted from parent to child, examination of the urine of the infant children of those who manifest the peculiarity

- The Lancet, 1901, vol. ii, p. 1484; Transactions of the Royal Medical and Chirurgical Society, 1902, vol. lxxxv, p. 69.

10 Münchener medicinische Wochenschrift, 1899, Band xlvi, p. 749 . 
offers the most likely means of settling the point. That it may be present in early childhood there is abundant evidence to show. The first cystin calculus ever examined ${ }^{11}$ was taken from the bladder of a child of five years. Abderhalden ${ }^{12}$ has placed on record the detection of cystinuria in two children of the same family at the ages of twenty-one months and fourteen months respectively, and Ultzmann ${ }^{13}$ the case of a child of two with a cystin calculus who had exhibited symptoms of stone from the age of twelve months. Not a few cases in older children have been described. As affording evidence of the long persistence of cystinuria a case which came under the observation of the late Sir Henry Thompson ${ }^{14}$ may be quoted, that of an old man, aged eighty-one years, for whom a cystin calculus was crushed, and who had passed a stone of the same nature thirty-nine years previously. There is reason to believe that cystinuria, like alkaptonuria, is occasionally temporary or intermittent.

No direct evidence of the congenital occurrence of pentosuria, the latest discovered and least known member of the group, is yet forthcoming, and its inclusion is to be justified on other grounds. That it may persist unchanged for years is certain, but

11 Philosophical Transactions of the Royal Society, 1810, vol. c, p. 223.

${ }_{12}$ Zeitschrift für physiologische Chemie, 1903, Band xxxviii, p. 557.

${ }_{13}$ Wiener medicinische Wochenschrift, 1871, Band xxi, pp. 286, 307.

${ }_{14}$ Transactions of the Pathological Society, 1870, vol. xxi, p. 272. 
the youngest pentosuric yet observed was a boy aged fiftcen years. ${ }^{15}$

It is probable that the rarity of albinism in man, of which each of us is able to judge from personal observation, is no greater than that of the other inborn errors. My belief is that cystinuria is decidedly the least rare of the four, but C. E. Simon ${ }^{16}$ met with only one cystin sediment among some 15,000 urines examined, and Primavera ${ }^{17}$ one in 20,000 urines. Another feature which all four anomalies share in common is their more frequent occurrence in males than in females. Of 38 cases of alkaptonuria, presumably congenital, 31 were in males and only 7 in females. Of 93 cystinurics collected from the records by Simon 63 were males and 30 females. Of 26 pentosurics, 19 were males and 7 females. That males preponderate among albinos has often been stated, but among the cases collected by Ascoleo ${ }^{18}$ in Sicily the disparity was comparatively slight, the numbers being 34 males and 28 females. It does not appear that there is any such unequal liability of the sexes to structural malformations, as far as can be judged from figures collected from the records of two hospitals, and in the remarkable family described by Farabee ${ }^{19}$ in which many members exhibited a curious

15 Chobola: Centralblatt für innere Medicin (abstract), 1907. Band xxviii, p. 864 .

10 American Journal of the Medical Sciences, 1900, vol. cxix, p. 39.

17 Quoted by Piccini e Conti, Lo Sperimentale, 1891, vol. xlv, p. 353 .

18 Archivio per l'Anthropologia, 1871, vol. i, p. 367.

10 Papers of the Peabody Museum of American Archaoology and Ethnology, Harvard, 1905. 
malformation by defect-namely, absence of the middle phalanges-the majority of the affected members were females. In a similar family recorded by Drinkwater ${ }^{20}$ male cases slightly preponderated.

To be harmless is no essential attribute of an inborn abnormality, but it stands to reason that an error of metabolism which persists from birth into adult, and even into advanced life must needs be relatively innocuous. Albinism, although inconvenient, is certainly harmless, and the most serious direct result of alkaptonuria is the peculiar pigmentation, a variety of ochronosis, which some of its subjects develop in later life. Evidence is accumulating of the harmlessness of pentosuria, and that the excretion of a sugar with five carbon atoms in its molecule has none of the sinister significance of glycosuria. Only cystinuria can be classed as actually injurious, but even its ill effects, serious as they often are, are not due to deranged metabolism as such, but are secondary, and result from the unsuitability of so sparingly soluble a substance as cystin for excretion by way of a urinary apparatus constructed upon the mammalian plan. Even in the single recorded instances in which death may possibly have resulted from cystinuria, apart from urinary complications, that of an infant aged twenty-one months, which Abderhalden describes, the deposition of cystin in the tissues was the conspicuous lesion found at the necropsy.

${ }^{20}$ Proceedings of the Royal Society of Edinburgh, 1908, vol. Xxviii, p. 35. 


\section{INBORN ERRORS OF METABOLISM}

There remains to be mentioned yet another feature which the abnormalities under discussion possess in common-namely, the liability for each of them to occur in several members of a family, most often in collaterals of the same generation, born of normal parents. In this respect, of course, they do not stand alone. In connexion with many actual diseases, as well as with structural malformations, hereditary influences come into play, and among diseases with none more strikingly than with such metabolic disorders as diabetes and gout. Only when taken in conjunction with all the other common features which have already been discussed can their mode of incidence be adduced in support of the view here taken of their nature.

To the students of heredity the inborn errors of metabolism offer a promising field of investigation, but their adequate study from this point of view is beset with many difficulties. Save in the case of albinism one is driven to rely upon the casual mating of human beings, and the conclusions based thereon cannot be checked by experimental breeding of animals. It is true that cystinuria is known to occur in dogs. A calculus obtained from a dog was described by Lassaigne ${ }^{21}$ in 1823 , and other examples have since been recorded, ${ }^{22}$ but hitherto the diagnosis has only been made after the death of the animal and no opportunity has presented itself of utilizing this fact for the advancement of

21 Annales de Chimie, 1823, $2^{\circ}$ s., tome xxiii, p. 328.

22 Gross, S.W.: North American Medico-Chirurgical Review, 1861, vol. v, p. 311 . 
the study of the anomaly. Whether alkaptonuria and pentosuria occur among lower animals is unknown. If they do they are little likely to be recognized.

Again it is naturally far more difficult to collect information as to the occurrence of chemical than of structural anomalies in past generations of a family, save in the case of albinism and possibly of alkaptonuria. Even as regards the relative numbers of normal and abnormal members, a knowledge of which is so important in connexion with questions of heredity, the information available is scanty and unreliable unless based upon personal examination. However, one point which stands out clearly is the remarkable similarity of the modes of incidence of alkaptonuria and albinism, which suggests that the manifestation of both is governed by the same laws. Both are apt to occur in several brothers and sisters of a family whose parents do not exhibit the anomaly, and direct transmission of either from parent to child is very rare. It has been repeatedly stated that a considerable proportion of human albinos are the offspring of consanguineous marriages. Thus Ascoleo found that of 24 families which included 60 albino members 5 were the offspring of the mating of first cousins. In only two instances was albinism directly transmitted from parent to child. I am indebted to Professor Karl Pearson for the information that the pedigrees of albinism collected by Messrs. Nettleship and Usher and himself show a high percentage of consanguineous 
marriages, and that although the exact proportions cannot yet be stated, it may safely be asserted that 20 per cent. of families containing albino members have consanguineous parents. Of the cases of alkaptonuria, concerning which the necessary information is forthcoming, a very large proportion have been in children of first cousin marriages. In a paper published in $1902^{23} \mathrm{I}$ called attention to this point and more recent cases, although they have somewhat lowered the proportion, have borne out the fact, as will be seen from the following table, in which the more recent cases have been incorporated.

Familes the OFFspring of First Cousins.
Names of Observers.
1. Pavy .
R. Kirk $\cdot \cdot \cdot 4$
R. Kirk $\cdot \cdot \cdot \cdot 3$
3. Garrod . . . 2
4. Erich Meyer . . . 1
5. Ogden . . . . 1
6. Hammarsten . . 2
7. Grutterink and van der Bergh . . . 1
8. Cronvall . . . 1
Number of families, $8 \cdot \overline{15}$

Familes of Parents who were not Blood RelaTIONS.

Names of

Observers.

Number of.

Alkaptonuric Members.
1. W. Smith and Gar-

$\operatorname{rod} \cdot$. . 2

2. Ewald Stier . . . 1

3. Noccioli and Domenici . . . . 1

4. Marshall and Futcher 3

5. Langstein and E. Meyer . . . 1

6. Garrod and T. W. Clarke . . . . 1

7. Grutterink and van der Bergh . . . 2

8. Grutterink and van der Bergh . . 4

9. Schumm . . $\quad 1$

10. Fromherz . . . 3

Number of families, $10.19^{*}$

2a The Lancet, 1902, vol. ii, p. 1616.

* In some instances private information has supplemented 
Thus of 18 families 8 were the offspring of first cousins and 10 were the children of parents who were not related, and of the total of 34 cases 15 fall into the first group. There appears to be a close connexion between the occurrence of an anomaly in several children of normal parents and consanguinity of the parents, a connexion which has been emphasized by Feer ${ }^{24}$ in a recent paper. No one would suggest nowadays that the mere fact that the parents are of one blood would cause an anomaly to appear de novo in their children, but it is obvious that the reappearance of a latent character which both parents tend to transmit is likely to be favoured by the mating of members of certain families.

The statistics as to the proportion of first-cousin marriages in this country are very scanty. Sir George Darwin has calculated ${ }^{25}$ that less than 3 per cent. of all marriages are of this class, and Professor Karl Pearson ${ }^{26}$ has recently collected some figures which give a percentage of 4.9 first-cousin marriages among the professional classes, a figure which, for reasons which he states, he regards as probably somewhat too high, and of 0.86 among the classes from which patients in London hospitals are drawn. The totals of consanguineous mar-

the published records. For some of the more recent cases the required information is not forthcoming. The new references will be found in the bibliography of Chapter III. 24 Jahrbuch für Kinderheillunde, 1907, vol. lxvi, p. 188.

25 Journal of the Statistical Society, 1875, vol. xxxviii, p. 153.

26 Brit. Med. Jour., 1908, vol. i, p. 1395. 
riages of all degrees in the two classes were $7 \cdot 76$ per cent. and 1.3 per cent. respectively. Hence it is obvious that the proportion of such marriages among the parents of alkaptonuric families is altogether abnormal. On the other hand, the proportion of alkaptonurics among children of such marriages must be very small indeed. Only some 50 to 60 cases of alkaptonuria have been recorded in Europe and America, whereas in London alone there are probably many thousands of children of first cousins.

It was pointed out by Bateson, ${ }^{27}$ and has recently been emphasized by Punnett, ${ }^{28}$ that the mode of incidence of alkaptonuria finds a ready explanation if the anomaly in question be regarded as a rare recessive character in the Mendelian sense. Mendel's law asserts that as regards two mutually exclusive characters, one of which tends to be dominant and the other recessive, cross-bred individuals will tend to manifest the dominant character, but when they interbreed the offspring of the hybrids will exhibit one or other of the characters and will consist of dominants and recessives in definite proportions. Mendel's theory explains this by the supposition that the germinal cells or gametes of each generation are pure as regards the qualities in question, and accounts for the numerical results observed by the production

27 Report of the Evolution Committee of the Royal Society, 1902 , No. 1, p. 133, note.

${ }^{28}$ Proceedings of the Royal Society of Medicine, 1908, vol. i, Epidemiological Section, p. 148. 
of dominant and recessive gametes in equal numbers. Of the offspring of two hybrids, one quarter will result from the union of two dominant gametes and will produce such gametes only; another quarter will result from the union of recessive gametes and will produce only recessive gametes. The remaining half will themselves manifest the dominant character, but will be hybrids like their parents and will produce gametes of both varieties. Only when two recessive gametes meet in fertilization will the resulting individual show the recessive character.

If the recessive character be a rare one many generations may elapse before the union of two such gametes occurs, for the families in which they are produced will be few in number and the chance that in any given marriage both parents will contribute such gametes will be very small. When, however, intermarriage occurs between two members of such a family the chance will be much greater, and of the offspring of such a marriage several are likely to exhibit the peculiarity. The rarer the anomaly the more conspicuous should be the influence of consanguinity. When a recessive individual mates with an apparent dominant, who produces gametes of both kinds; a larger proportion of the offspring will be recessives, and we should expect that recessive children of a recessive parent, but whose other parent is apparently normal, will occasionally be met with. Of such direct transmission of alkaptonuria from parent to child, the other parent not being alkaptonuric, two examples 
are known. One of these was observed by Osler. ${ }^{29}$ An alkaptonuric father whose brother also showed the anomaly had an alkaptonuric son. The second case, which was recorded by Orsi, ${ }^{30}$ was that of a mothor and her son and daughter, all alkaptonuric. ${ }^{31}$ Lastly when recessive mates with recessive all the offspring should manifest the recessive character, but no such marriage of alkaptonurics is known to have occurred. Whereas in animals, such as mice, which produce a numerous progeny the proportions of dominants and recessives among their offspring can be readily observed, the results of the chance matings of human beings, who are so far less prolific, are far less demonstrative.

It must be confessed, indeed, that as regards human characteristics the relative numbers of dominant and recessive offspring have often departed widely from these required by Mendel's law, but a number of sources of error will tend to vitiate such results. Experience has shown that the information supplied as to the normality or otherwise of other members of a patient's family can seldom be relied upon, and this is especially the case with chemical anomalies. An individual in middle life seldom knows much about his brothers and sisters who died in infancy. Miscarriages must be taken into account, and again the figures supplied may relate to incomplete families and

29 See Garrod, The Lancet, 1902, vol. ii, p. 1617.

so Gazzetta Medica Lombarda, 1889, vol. xlviii, p. 115.

11 In Fromherz' family the mother appears to be an intermittent alkaptonuric, but he was not able to satisfy himself fully that this was the case. 
may be profoundly modified by subsequent births. For the above reason little importance is to be attached to the figures available with regard to alkaptonuria, but those contained in the following table, which relate to $\mathbf{1 8}$ families, are given for what they are worth :-

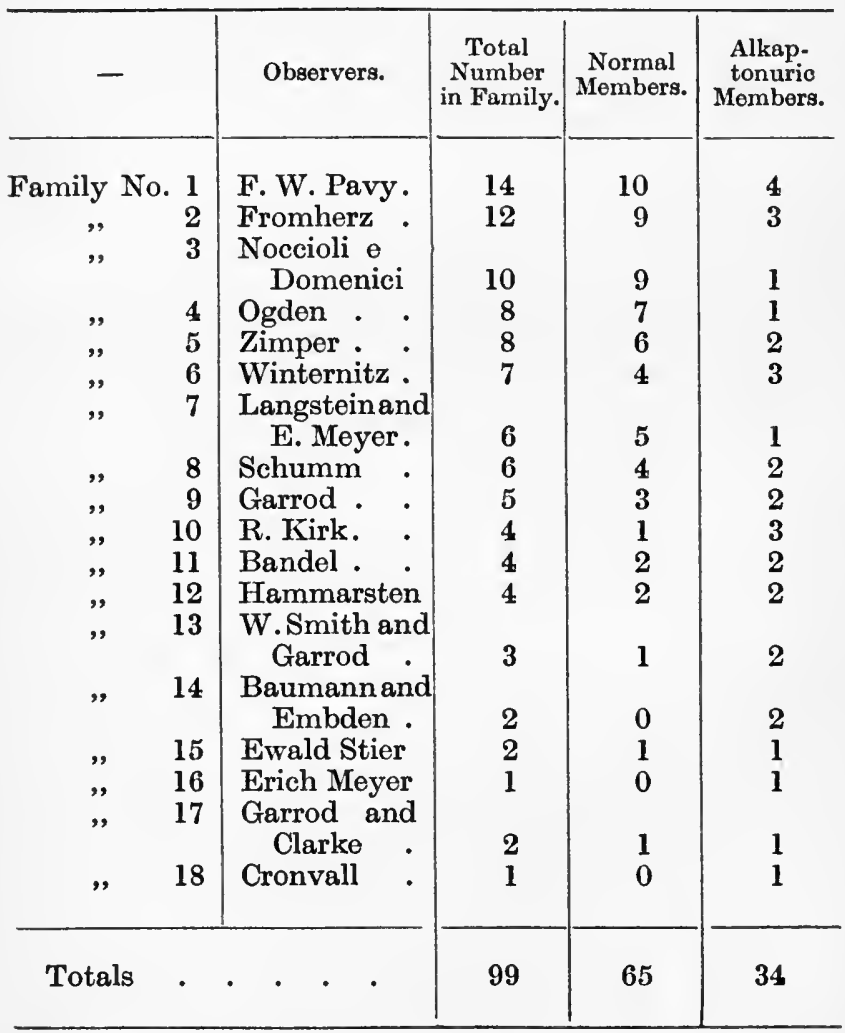

Although the totals show that the normal members 


\section{INBORN ERRORS OF METABOLISM}

largely preponderate they do not approach the requirements of Mendcl's law, according to which a recessive character should appear in one quarter of the offspring; the alkaptonurics should number 24 or 25 instead of 34 . It is clear that the figures as they stand are not fair to Mendel, for in the last three families the affected members were single children. One would expect to obtain a more accurate estimate by confining our attention to the larger families, and it is noteworthy that if one takes families 1 to 9 , each containing five or more children, the totals work out in strict conformity to Mendel's law, i.e. $76: 57: 19$ in the proportions $4: 3: 1$. However, to draw the line at families of five and upwards is a purely arbitrary proceeding.

The patients of Baumann and Embden were a brother and sister born out of wedlock, but it is not quite clear from the record whether they were the only children of the union. Both parents subsequently married away and had children, none of whom were alkaptonuric. Three recorded alkaptonurics were twins; and in one case the second twin was certainly and in the two others was probably normal. ${ }^{32}$ In each instance the normal twin died and the alkaptonuric survived. The twins were of the same sex in two cases.

It appears to me that the strongest argument

32 Noccioli e Domenici : Gazette degli Ospedali, 1898, vol. xix, p. 303. D. Gerhardt: Münchener medicinische Wochenschrift. 1904, Band li, p. 176. Fromherz: Dissertation, Frieburg, i. Br. 1908. 
which can be adduced in favour of this view that alkaptonuria is a Mendelian recessive character is afforded by the fact that albinism, which so closely resembles it in its mode of incidence in man, behaves as a recessive character in the experimental breeding of animals. ${ }^{33}$ Nor do the figures quoted by Bateson, ${ }^{34}$ relating to the proportion of albino members in human families, show any more close conformity to the requirements of Mendel's law than do those above quoted for alkaptonuric families.

Evidence is accumulating of the occurrence of pentosuria in brothers and sisters, ${ }^{35}$ and no instance of its transmission from parent to child has yet been recorded. Of consanguinity of parents of the subjects of this abnormality nothing is yet known. There is some evidence of a special liability of the Jewish race.

The available evidence regarding the inheritance of cystinuria is much more scanty than that relating to alkaptonuria. This is largely due to the less obvious character of the anomaly, for it is only by careful examination of the urine of each member of a family that any certainty can be reached as to the numbers of cystinuric and normal members. A cystinuric does not necessarily form calculi, and at any given time his urine may deposit no

${ }^{33}$ Castle and Allon: Proceedings of the American Academy of Arts and Sciences, 1903, vol. xxxviii, p. 603.

${ }^{34}$ Brit. Med. Jour. 1908, vol. i, p. 1252.

${ }^{35}$ Brat: Zeitschrift für klinische Medicin, 1902, Band xlvii, p. 499. Bial: Berliner klinische Wochenschrift, 1904, Band xli, p. 552, and others. 
crystals, nor are the statements of patients as to other members of their familics of any value in this connexion, save that a history of several cases of stone may be suggestive. Such information as is forthcoming points to a greater frequency of direct transmission from parent to child than is met in connexion with the other metabolic errors, and cystinuria has been traced with certainty in three successive generations. Thus in the family investigated by Abderhalden the paternal grandfather and father were cystinuric, whereas the mother was normal. Of five children one had died with symptoms of inanition at twenty-one months, and deposits of cystin were found in its tissues; two others had died with like symptoms at nine and seventeen months respectively, but were not known to excrete cystin. The surviving children, aged five and a half years and fourteen months, respectively, were both cystinuric. Such large proportion of cystinuric members as was here met with has been observed in other families. In one which Cohn ${ }^{36}$ described a cystinuric mother and a normal father had twelve children. The urine of two of them could not be obtained, but of the remaining ten no less than seven excreted cystin. Again, Pfeiffer ${ }^{37}$ records four children of normal parents who were, as he has informed me, first cousins, all of whom were cystinuric. The

so Berliner klinische Wochenschrift, 1899, Band xxxvi, p. 503.

37 Centralblatt für Krankheiten der Harn- und SexualOrgane, 1897, Band viii, p. 173. 
two children of one of the affected daughters were normal. In another family which has come under my notice, in which two out of six children were cystinuric, the parents were the children of halfbrothers. The frequency of direct inheritance and the large proportion of the offspring affected suggest that, if cystinuria be transmitted on Mendelian lines, it is probably a dominant rather than a recessive characteristic.

Hitherto we have been considering these inborn errors of metabolism collectively, the points which they have in common, and the grounds for regarding them as constituting a distinct group of anomalies. But each one of them presents peculiar features of much interest which amply repay detailed consideration, if only on account of the light which their study throws upon the chemical processes at work in the normal human organism. 


\section{CHAPTER II}

\section{ALBINISM}

OF albinism I propose to speak very briefly, for its study from the chemical side has scarcely been begun. In the fairly extensive literature of the subject much space is devoted to the ocular troubles which are connected with it; some authors have treated of its hereditary aspects; the question whether albinism carries with it any impairment of bodily or mental powers has been widely discussed, but the actual nature of the anomaly has hardly been touched upon. Clearly it is an abnormality of a different kind from the others here under discussion which manifest themselves by errors of excretion. In albinism there is a defect of substances which are normal constituents of certain specialized tissues, and which serve purposes of much utility to the organism. It is not necessary to enter upon any discussion of the question whether it should be classed as an error of anabolism or of catabolism. The work of F. G. Hopkins ${ }^{1}$ upon the utilization of excretory products in ornament, as exemplified in the employment of uric acid in

1 Philosophical Transactions of the Royal Society, 1895, clxxxvi, p. 661. 
the pigmentation of white butterflies of the genus Pieris, is of interest in this connexion, but it is probable that in insects, as in birds and reptiles, the excreted uric acid is largely formed by synthesis, as the breaking-down of nuclein does not provide an adequate source for the yield.

The essential phenomenon of albinism is the absence of the pigments of the melanin group, which play the chief part in the colouration of man and lower animals, and which serve the important function of rendering the eye a dark chamber. There are various kinds of melanins, but all alike are wanting in albinos, as witness the white hair, pink eyes, and unpigmented skin which characterize such individuals. Pigments of other kinds are not wanting, such as the lipochromes which impart their yellow tints to fats and blood serum, and hæmoglobin and its derivatives. In the urine of albinos I have found the same pigments as are ordinarily present. The fact that albinos of certain birds, such as the peacock, which are normally characterized by the brilliancy of the colouring of their plumage, are quite white, does not invalidate the truth of this statement. Their brilliant tints are interference colours, due to physical structure and not to pigmentation, and the absence of such colours is merely due to the lack of a dark background for their display, for such a background the melanins with their sombre hues provide. In the feathers of the albino peacock the iridescent tints are faintly visible in certain lights.

Our knowledge of the chemistry of melanins is 


\section{INBORN ERRORS OF METABOLISM}

still very imperfect. Their sulphur content varies widely; some contain iron, others do not. The presence of iron has been held to indicate an origin from hæmoglobin, but the trend of opinion at the present day is towards the view that they are derived from proteins in general, perhaps by the action of a tyrosinase upon tyrosin, and that the natural melanins are allied to the melanoid substances which are formed during the hydrolysis of proteins. If, as has been suggested, white hair contains a white chromogen and is pigmented and not merely devoid of colour; if also this is true of albino hair as well as that of white animals not albinos, we may suppose that the chromogen merely fails to be converted into the dark pigments in the ordinary way.

Three possible explanations of the phenomenon of albinism suggest themselves. We might suppose that the cells which usually contain pigment fail to take up melanins formed elsewhere; or that the albino has an unusual power of destroying these pigments; or again that he fails to form them. Some experiments of Kobert, ${ }^{2}$ who injected solutions of melanin into rabbits, seem to negative the notion of an unusual destructive power. The animals excreted melanin, or rather its chromogen melanogen, in their urine. Kobert mentions that some of the animals injected were albinos, but does not say that they behaved differently in this respect from the pigmented rabbits. The injection brought about no pigmentation of the hair or eyes of albino rabbits,

2 Ueber Melanine, Wiener Klinik, 1901, Band xxvii, p. 99. 
nor is it to be expected that it would do so, whichever of the above hypotheses be correct. It is very unlikely that the melanin is conveyed to the pigmented cells and there deposited, for all the evidence available indicates that the pigment is formed in situ, probably by the action of intracellular enzymes. If the melanin were formed in albinos and merely not utilized we should expect it to be excreted by them in the urine, which is not the case. Only certain specialized cells appear to have the power of forming melanin; in cases of melanotic sarcoma these are enormously multiplied, and there is a correspondingly increased production of pigment which may find its way into the blood and be excreted in the urine. Such an increase is only to be explained on the supposition that the pigment is actually formed in the tumour cells. In favour of this view also is the fact that melanotic tumours apparently originate only in structures in which melanins are normally present, such as the eye and skin, and possibly in the pineal gland, which as a vestigial remnant of the pineal eye of certainly lowly animal forms may retain some pigment-forming power.

The hypothesis of local formation also supplies the easiest explanation of the phenomena of partial or local albinism, such as is seen in the Himalayan rabbit, which has the pink eyes of an albino but the hair of which is always pigmented at certain points. It may be that, in such cases, some of the pigment-forming cells retain their power of producing melanins. The partial albinism seen 
in man, in which the hair retains a certain amount of colour, and especially the rare form in which red hair is associated with pink eyes, a variety which has been met with in one albino of scveral in a family, the others conforming to the ordinary type, ${ }^{3}$ is a phenomenon calling for careful investigation. It must be emphasized that the presence of pigment in any structure does not negative the view here put forward as to the nature of albinism, unless it can be shown that the pigment present belongs to the melanin group.

The ordinary physiological causes of pigmentation are not operative in albinos. In them exposure to the sun does not cause the usual tanning of the skin which is seen in normal individuals; a mere hyperæmia results. It has also been observed that in female subjects the pigmentation of the areolæ of the nipples and of other parts, which usually accompanies pregnancy, is not developed. ${ }^{4} \mathrm{I}$ know of no observations on the occurrence in albinos of tumours originating in the eye and running the course of melanotic sarcomata. One would expect that such growths, if they occur, would fail to be pigmented. Nor does there appear to be any record of Addison's disease occurring in such subjects, which might throw important light upon the question whether the Addisonian pigment is a true melanin.

3 Folker : The Lancet, 1879, vol i, p. 795. Nettleship : Transactions of the Ophthalmological Society, 1908, vol. xxvi, p. 244.

- B. W. Richardson: Dublin Hospital Gazette, 1856, vol. iii, p. 73 . 
Taking all the known facts into consideration, the theory that what the albino lacks is the power of forming melanin, which is normally possessed by certain specialized cells, is that which has most in its favour and is probably the true one. If so, an intracellular enzyme is probably wanting in the subjects of this anomaly, an explanation which, as we shall see later, brings albinism into line with some other inborn metabolic errors, of which a similar explanation is at least a possible one.

I must not omit to mention that there are indications that the differences between albinos and normal individuals are not confined to the absence or presence of melanins in the tissues. In animals differences have been observed in the matter of liability to certain infections, and clinical observations of the incidence of infective diseases upon human albinos would be of considerable interest. Halliburton, Brodie, and Pickering ${ }^{5}$ found that intra-vascular injections of nucleo-proteins failed to produce in albino animals such clotting as they cause in pigmented ones. G. R. Mudge, ${ }^{6}$ who has carried out a number of such experiments; found that all albinos do not behave alike in this respect. Differences were also observed between the results of the injection of nucleo-proteins derived from albino and pigmented animals respectively. $\mathrm{He}$ arrived at the conclusion that an albino animal requires a larger dose of nucleo-protein per kilo-

5 Journal of Physiology, 1894, vol. xvii, p. 148.

- Proceedings of the Royal Society, 1907, Series B, vol. lxxix, p. 103. 
gramme of body weight to cause death by intravascular clotting. Pickering's 7 remarkable observation that the Norway hare when in its winter coat behaves as an albino when injected with nucleoprotein, but in its summer coat as a pigmented animal, opens up the most interesting question of the relation, if any, of the change of coat in Arctic animals to albinism.

It will be clear from the above fragmentary sketch that even the lines along which the systematic study of albinism may profitably be directed aro only beginning to indicate themselves. The carrying out of such a research remains as a task for future workers.

7 Journal of Physiology, 1896, vol. xx, p. 310. 


\section{CHAPTER III}

\section{Alkaptonuria}

OF inborn errors of metabolism, alkaptonuria is that of which we know most, and from the study of which most has been learnt. In itself it is a trifling matter, inconvenient rather than harmful, which only attracts attention because an infant stains its clothing, or because an adult fails to effect an insurance of his life. The medical man merely needs to be aware of its existence, and to be acquainted with the methods for its recognition, in order that he may not mistake it for troubles of graver kinds; but for the chemical physiologist and pathologist it is one of the most interesting of metabolic abnormalities. Not only has the study of alkaptonuria thrown much light upon the fate of the aromatic fractions of the proteins of the food and tissues but has also helped materially to reveal a fact of far wider significance-namely, that for each protein fraction, or group of allied fractions, a special catabolic path has been evolved.

When freshly passed the urine of an alkaptonuric seldom exhibits any abnormality of tint, but it quickly begins to darken in contact with the air. The darkening, which is associated with absorption 
of oxygen, commences at the free surface of the liquid, and passes through various shades of brown to actual blackness. Alkalinity of reaction greatly hastens the change. Linen and woollen fabrics moistened with the urine become stained as by a photographic developer. On heating the urine with Fehling's solution a deep brown colour develops and copious reduction occurs, but the browning of the liquid in which the orange precipitate is suspended gives to the test a quite peculiar appearance, which should be recognized by any one who has once seen it. An ammoniacal solution of silver nitrate is rapidly reduced, even in the cold. On heating the urine with Nylander's solution a darkening is produced by the alkaline reagent, but no reduction of bismuth is brought about. With Millon's reagent a yellow precipitate is formed. The most striking reaction is observed when a dilute solution of ferric chloride is allowed to fall into the urine drop by drop. The fall of each drop is followed by the appearance of a deep blue colour, which lasts but for a moment, and the phenomenon is repeated until oxidation is complete. With yeast no fermentation occurs, and the polarized ray is not rotated either to the right or left.

Our knowledge of alkaptonuria is dated from the year 1858, in which year Bödeker ${ }^{1}$ detected, in the urine of a patient with glycosuria, a second reducing substance, not a sugar, to which, on aecount of its behaviour towards alkalies, he assigned the

1 Zeitschrift für rationelle Medicin, 1859, vol. vii, p. 130. Annalen der Chemie und Pharmacie, 1861, vol. cxvii, p. 98. 
name of alkapton, a bilingual word derived from alkali and $\kappa a ́ \pi \tau \epsilon \iota$. However, indications of the anomaly may be detected in much earlier medical writings. Thus there can be no doubt that the case of an infant who passed black urine, described by Alexander Marcet ${ }^{2}$ in 1823, was of this nature. It is true that Marcet knew nothing of the reducing properties of the urine, but he describes accurately its darkening in colour on standing, the staining of napkins, and the effect of the addition of an alkali; and mentions that the condition was present from the earliest days of the child's life. Until the early years of the nineteenth century no distinction was drawn in medical writings between urines which were black when passed and such as darkened on exposure to air, but it is difficult to suggest any other diagnosis than that of alkaptonuria for some cases referred to in works of the sixteenth and seventeenth centuries, such as that mentioned by G. A. Scribonius ${ }^{3}$ (in 1584) of a schoolboy who, although he enjoyed good health, continuously excreted black urine, and that cited by Schenck 4 (in 1609) of a monk who exhibited a similar peculiarity and stated that he had done so all his life. The most interesting record of this kind is to be found in the work of Zacutus Lusitanus, ${ }^{5}$ published in 1649. The patient was a boy who passed black urine and who, at the age of fourteen years, was

2 Transactions of the Royal Medical and Chirurgical Society, 1823, vol. xii, p. 37 .

${ }^{3}$ De Inspectione Urinarum, 1584, p. 50.

- Observationes Medica, 1609, Lib. iii, p. 558.

- Praxis Mcdica Admiranda, 1649, Lib. iii, cap. cxxxiv. 


\section{INBORN ERRORS OF METABOLISM}

submitted to a drastic course of treatment which had for its aim the subduing of the fiery heat of his viscera, which was supposed to bring about the condition in question by charring and blackening his bile. Among the measures prescribed were bleedings, purgation, baths, a cold and watery diet, and drugs galore. None of these had any obvious effect, and eventually the patient, who tired of the futile and superfluous therapy, resolved to let things take their natural course. None of the predicted evils ensued, he married, begat a large family, and lived a long and healthy life, always passing urine black as ink.

That alkaptonuria is a very rare anomaly admits of no question, and many medical men of large experience have never met with it. Of its occurrence in several members of a family, and of its mode of incidence, I have already spoken at sufficient length. In the great majority of instances it is present from birth and persists throughout life, but has been said to have been developed as a temporary morbid sign in a very few exceptional cases. It gives rise to no symptoms save occasional dysuria with undue frequency of micturition, but some few alkaptonurics have developed, in later life, that peculiar tissue staining which Virchow ${ }^{6}$ first described and to which he gave the name of ochronosis.

The essential feature of ochronosis is the staining of the cartilaginous structures of an inky blackness, but surface or sub-surface pigmentation is sometimes present, and has rendered possible the recog-

- Virchow's Archiv, 1866, vol. xxxvii, p. 212. 
nition of the condition in living subjects. The tint of the blackened aural cartilages may show through the skin and give a slaty-blue colour to the hollows of the ears, black flecks may appear upon the conjunctivæ or even upon the skin of the face, and the knuckles may have a bluish tint. Less than 20 cases of ochronosis are on record, but it is becoming evident that, rare as the condition is, it yet has several distinct causes. Albrecht ${ }^{7}$ first suggested that alkaptonuria was one of these, and Osler ${ }^{8}$ described the development of surface pigmentation, of the characteristic distribution and character, in three elderly men who were wellauthenticated alkaptonurics. Clemens, ${ }^{9}$ A. Wagner ${ }^{10}$ Gross, and Allard and Landois ${ }^{11}$ have recently supplied the conclusive demonstration of the presence of ochronotic pigmentation of the cartilages in the bodies of men who were subjects of the urinary anomaly under discussion. In four of the recorded cases of ochronosis the pigmentation was apparently due to the application of carbolic acid to ulcers of the legs during long series of years. ${ }^{12}$ In some of

- Zeitschrift für Heilkunde, 1902, vol. xxiii, p. 366.

\& The Lancet, 1904, vol. i, p. 10.

- Verhandlungen des Congresses für innere Medicin, 1907, vol. xxiv, p. 249.

${ }_{10}$ Zeitschrift für innere Medicin, 1908, vol. lxv, p. 119.

11 Gross and Allard: Mittheilungen aus d. Grenzgebieten d. Med. u. Chirurg. 1908, xix, 24. Archiv. f. exper. Path. u. Pharm. 1908, vol. lix. p. 384. Landois: Virchow's Archiv., 1908, exciii, 275.

12 Pope: The Lancet, 1906, vol. i. p. 24. Pick: Berliner klinische Wochenschrift, 1906, vol. xliii, v, 478. Graeffner : Ibid. 1907, vol. xliv, p. 1,051. Reid: Quarterly Journal of Medicine, 1908, vol. i, p. 199. 


\section{INBORN ERRORS OF METABOLISM}

the remaining cases the urine has shown no peculiarity of tint, or if present it is not mentioned in the records, and in others dark urine was passed which does not seem to have bcen either of the alkaptonuric or carboluric variety. ${ }^{13}$ In the case described by Gross, Allard and Landois there were changes in the joints which these authors associate with the alkaptonuria and ochronosis, and some other patients also have exhibitcd signs of progressive articular disease. Such changes were observed in Osler's cases, and are also present in the patient at Basle, although he shows no outward signs of ochronosis.

The evidence available leaves no doubt in the mind that alkaptonuria is one of the causes of ochronosis and that prolonged absorption of carbolic acid is another, but it would appear that not all alkaptonurics develop ochronosis in later life, and in the records of post-mortem examinations of alkaptonurics by Fürbringer ${ }^{14}$ and Moraczewski ${ }^{15}$ no mention is made of staining of the cartilages which, if present, could hardly have been overlooked. It is not yet possible to explain why in some cases oxidation and blackening should occur within the tissues during life, but Gross and Allard have succeeded in producing blackening of cartilages by soaking them in a colourless solution of homo-

13 Hansemann: Berliner klinische Wochenschrift, 1892, vol. xxix, p. 660. Hecker und Wolf: F'estschrift des Stadtkrankenhauses zu Dresden-Friedrichstadt, 1899, p. 325.

14 Berliner klinische Wochenschrift, 1875, vol. xii, pp. $313,390$.

15 Centralblatt für innere Medicin, 1896, vol. xvii, p. 177. 
gentisic acid nearly neutralized with sodium hydrate. Pieces of fibrous tissue which were attached to the cartilages remained unstained, which points to a selective pigmentation of cartilaginous structures.

The substance which Bödeker isolated from the urine of his patient, and which he called alkapton, contained nitrogen and was obviously an impure material. In some cases afterwards recorded the abnormal constituent was thought to be pyrocatechin ${ }^{16}$ and in others protocatechuic acid. ${ }^{17}$ Marshall 18 obtained from the urine of his patient a substance which he named glycosuric acid, and $\mathrm{R}$. Kirk, ${ }^{19}$ investigating a group of cases in a single family, isolated an acid which he called uroleucic acid, which yielded on analysis percentages of carbon and hydrogen conforming closely to the requirements of the formula $\mathrm{C}_{9} \mathrm{H}_{10} \mathrm{O}_{5}$. These two investigators, Marshall and Kirk, approached very nearly to the recognition of the actual nature and composition of the abnormal constituent. There are no sufficient grounds for supposing that the reducing substances present in these earlier cases were different from that found in all the more recent ones, and where re-examination of the urine, or of material

16 Ebstein und Müller: Virchow's Archiv, 1875, vol. lxii, p. 554.

${ }_{17}$ Fleischer: Berliner klinische Wochenschrift, 1875, vol. xii, pp. 529, 547. W. Smith : Dublin Journal of the Medical Sciences, 1882, vol. lxxiii, p. 465.

${ }_{18}$ Medical News, Philadelphia, 1887, vol. 1, p. 35.

10 Journal of Anatomy and Physiology, 1889, vol. xxiii, p. 69. Brit. Med. Jour., 1888, vol. ii,' p. 232. 


\section{INBORN ERRORS OF METABOLISM}

extracted therefrom, has been possible the presence of homogentisic acid has since been demonstrated.

Homogentisic acid, the excretion of which is the essential feature of the alkaptonuria, was isolated, analysed, and fully investigated by Wolkow and Baumann, ${ }^{20}$ as is set forth in thcir classical paper, published in 1891, some years later than the investigations of Marshall and Kirk. It was shown to have the empirical formula $\mathrm{C}_{8} \mathrm{H}_{8} \mathrm{O}_{4}$; and the work of its discoverers, which has been confirmed by Huppert ${ }^{21}$ and by syntheses effected in three different manners, by Baumann and Fränkel, ${ }^{22}$ and Osborne, ${ }^{23}$ and Otto Neubauer and Flatow ${ }^{24}$ respectively, has definitely proved that its constitution is that of para-di-oxy-benzene acetic acid (hydroquinone-acetic acid).

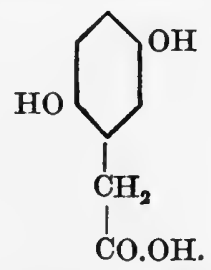

The acid was originally isolated from the urine as

${ }^{20}$ Zeitschrift für physiologische Chemie, 1891, vol. xv, p. 228.

${ }_{21}$ Deutsches Archiv für klinische Medicin (Festschrift), 1899 , vol. lxiv, p. 129.

${ }_{22}$ Zeitschrift für physiologische Chemie, 1895, vol. xx, p. 219.

${ }_{23}$ Journal of Physiology, 1903, xxix; Proc. Physiol. Soc., xiii.

${ }^{24}$ Zeitschrift für physiologische Chemie, 1907, vol. lii, p. 375 . 
a lead salt, which may be obtained by an even far simpler method ${ }^{25}$ than that employed by Wolkow and Baumann. The urine having been heated nearly to boiling, five grammes of solid neutral lead acetate are added for each 100 cubic centimetres of urine taken. A dense precipitate forms which is filtered off whilst the liquid is still hot, and the clear yellow filtrate is allowed to stand in a cool place. After a time lead homogentisate begins to separate out in crystalline form, and after twentyfour hours the crystals are filtered off, washed, and dried. The free acid may be obtained by passing sulphuretted hydrogen through ether in which the powdered lead salt is suspended. When the solvent, freed from lead sulphide by filtration, is allowed to evaporate colourless crystals of homogentisic acid are left, and these melt at $146^{\circ}$ and $147^{\circ} \mathrm{C}$.

As alternative methods of extraction that of Wolkow and Baumann, in which the concentrated urine, acidified with sulphuric acid, is repeatedly extracted with ether, and the lead salt is thrown down from an aqueous solution of the residue from the ethereal extracts, or that of Erich Meyer, ${ }^{26}$ which yields ethyl homogentisate, may be employed.

For the purpose of quantitative estimation of homogentisic acid in urine the volumetric method of Baumann ${ }^{27}$ is made use of. This somewhat p. 512 .

26 Garrod: Journal of Physiology, 1899, vol. xxiii,

${ }_{28}$ Deutsches Archiv für klinische Medicin, 1901, vol. 1xx, p. 443.

${ }^{27}$ Zeitschrift für physiologische Chemie, 1892, vol. xvi, p. 268. 
tedious method is based upon the reduction of a decinormal solution of silver nitrate in the presence of ammonia, but it is necessary to employ a stronger solution ( 8 per cent.) of ammonia than that prescribed by Baumann ( 3 per cent.) in order to obtain complete reduction in the allotted period of five minutes. ${ }^{28}$

Solutions of homogentisic acid yield all the characteristic reactions of alkapton urines, darken on exposure to air and more quickly when an alkali is added, reduce Fehling's solution on boiling and ammoniacal silver nitrate in the cold, and yield a transient blue colour with ferric chloride. Abderhalden and Falta ${ }^{29}$ were able to detect the presence of the acid in the blood of an alkaptonuric man, and to obtain the lead salt from the serum. From the fæces it is certainly absent, and I have failed to find it in the sweat. Ewald Stier ${ }^{30}$ and Bandel ${ }^{31}$ described an unusual blackness of the aural wax of their patients, and from it the former obtained a substance which yielded the alkapton reactions.

In all the accounts of alkaptonuria written in recent years the statement will be found that in some cases there has been present in the urine, in addition to homogentisic acid, a second acid possessed of similar properties-viz., uroleucic acid,

28 Garrod and Hurtley: Journal of Physiology, 1905, vol. xxxiii, p. 206.

29 Zeitschrift für physiologische Chemie, 1903, vol. xxxix, p. 143.

so Berliner klinische Wochenschrift, 1898, vol. xxxv, p. 185.

${ }^{31}$ Deutsche med. Wochenschr, 1906, vol. xxxii, p. 287. 
and that this substance is probably hydroquinone $\boldsymbol{a}$-lactic acid.

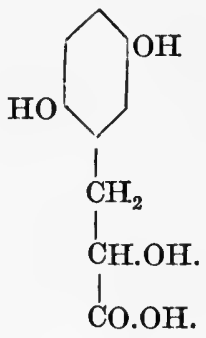

This statement I believe to be grounded upon a misapprehension and to be incorrect, and the grounds for this belief have been fully set out in a recent paper written in conjunction with Dr. Hurtley. ${ }^{32}$

It will be remembered that the name of uroleucic acid was assigned by Kirk to the material which he isolated from the urine of his patients at a time before homogentisic acid was known. The late $\mathrm{Dr}$. Kirk never claimed that this was a second distinct alkapton acid, and, indeed, in a letter to me he expressed his opinion that his uroleucic acid was merely impure homogentisic acid. Kirk's substance, to which as the result of his analyses he assigned the formula $\mathrm{C}_{9} \mathrm{H}_{10} \mathrm{O}_{5}$, melted at about $133.3 \mathrm{C}$., whereas, as has already been mentioned, the melting point of homogentisic acid is $146^{\circ}$ to $147^{\circ} \mathrm{C}$. The analytical figures agreed very closely with the requirements of the above formula, and titration of a solution with alkali, under a layer of petroleum ether, gave a result which indicated a molecuır weight

${ }^{32}$ Journal of Physiology, 1907, vol. xxxvi, p. 136. 
corresponding to that of a monobasic acid of the above constitution. However, there is no room for doubt that Kirk's later surmise was correct, and that in spite of these coincidences the substance which he analysed was impure homogentisic acid. Thus we found that when Kirk's method of extraction was applied to an alkapton urine, in which a second acid had been sought for without success, the product obtained agreed with his description of the lead salt which he obtained, and the free acid isolated from the lead salt melted at $134^{\circ}$ to $136^{\circ} \mathrm{C}$., but examination showed that it consisted mainly of homogentisic acid. It is known that the urines which Kirk examined contained this acid. Huppert obtained it from some of Kirk's original material, and we also found it in a further specimen of that material,- blackened with age, but labelled " uroleucic acid." Morever, when, in 1902, I was enabled by the kindness of Dr. Kirk to examine fresh specimens of the urine of his patients much homogentisic acid was obtained from them, but there was no indication of the presence of a second alkapton acid.

The view that the uroleucic acid of Kirk was a distinct substance had its origin in some investigations of the late Professor Huppert, ${ }^{33}$ carried out upon some of the original material sent to him in 1897. After separation of as much as possible of the homogentisic acid which it contained a residue remained which melted at $130.5^{\circ} \mathrm{C}$., and this residue

"Zeitschrift für physiologische Chemie, 1897, vol. xxiii, p. 412. 
Huppert regarded as uroleucic acid. Further investigations led him to the conclusion that it was a derivative of hydroquinone and was probably hydroquinone a-lactic acid, which acid has the formula $\mathrm{C}_{9} \mathrm{H}_{10} \mathrm{O}_{5}$ assigned by Kirk to uroleucic acid.

The accuracy of Professor Huppert's results does not admit of question, but it is evident that the scanty material at his disposal did not allow of a fresh analysis of the fraction of lower melting point, and if, as I believe, after careful comparison of Kirk's account of his investigations with Huppert's description of the material sent to him, and after personal examination of a further portion of the material, the substance examined was not a crude one, as Huppert supposed, but the actual uroleucic acid analysed by Kirk, it is obvious that the results of analyses of the material as a whole could not be applied to the fraction of lower melting point. Otto Neubauer and Flatow, ${ }^{34}$ who have succeeded in effecting the synthesis of hydroquinone $a$-lactic acid, have shown that it differs from the supposed uroleucic acid in melting point and in other respects ; and it is a significant fact that with the exception of a minute residue, which melted at $133^{\circ} \mathrm{C}$, , but which only sufficed for the determination of the melting point, obtained by Langstein and $\mathrm{E}$. Meyer ${ }^{35}$ from the urine of their patient, no indicacation of the presence of uroleucic acid has been found

${ }^{34}$ Loc. cit., sub. 24.

${ }_{35}$ Deutsches Archiv für klinische Medicin, 1903, vol. Ixxviii, p. 161. 


\section{INBORN ERRORS OF METABOLISM}

in any of the alkapton urines since described. Therefore the conclusion appears to be justified that no sufficient evidence is forthcoming of the occurrence in some alkapton urines of a second abnormal acid (uroleucic acid), a conclusion which has the advantage of making for simplicity. Beyond the presence in it of homogentisic acid the urine of alkaptonurics shows no obvious deviation from the normal. Some earlier investigators described a conspicuous diminution of the uric acid output, but more recent work has failed to confirm this. In a number of cases the excretion of uric acid has been found not to be below the average, and crystals of uric acid stained by the brown pigment are not infrequently deposited from such urines. We may therefore confine our attention to the consideration of the parent substances and mode of origin of homogentisic acid in the human organism.

Seeing that there is no evidence that synthesis of the benzene ring ever occurs in the animal economy, Wolkow and Baumann looked to the proteins of the food and tissues as the most likely sources of the alkapton acid, and to the aromatic fractions which proteins contain-viz., tyrosin and phenylalanin-as its special precursors. This conjecture was shown to be correct by the result of the administration of tyrosin by the mouth to their alkaptonuric subject. Such administration caused a very conspicuous increase of the output of homogentisic acid. Since then this observation has frequently been repeated by other investigators, and the result has been shown to hold good for alkaptonurics in 
general. A corresponding increase follows an augmented intake of protein food, and especially of such proteins as are unusually rich in the aromatic fractions.

Wolkow and Baumann were not able to test the effect of the administration of the phenyl-alanin, but at a later period Langstein and Meyer ${ }^{36}$ arrived at the conclusion that the tyrosin of the proteins broken down in the metabolism of their alkaptonuric did not suffice to account for the quantity of alkapton acid which he excreted. This conclusion was based upon a comparison of the estimated daily output of homogentisic acid with that of nitrogen, which latter affords a measure of the protein destruction going on in the body. Hence, it appeared probable that phenyl-alanin also serves as a parent substance, and that it does so was afterwards demonstrated by Falta and Langstein, ${ }^{37}$ who found that phenyl-alanin given by the mouth increases the homogentisic output just as tyrosin does.

Falta ${ }^{38}$ afterwards showed, by a long series of feeding experiments with different proteins added to a constant diet, that the excretion of alkapton acid varies directly with the richness in phenylalanin and tyrosin of the proteins taken, and arrived at the conclusion that, on any given diet, the output

36 Deutsches Archiv für Klinische Medicin, 1903, vol. lxxviii, p. 161.

37 Zeitschrift für physiologische Chemie, 1903, vol. xxxvii, p. 513; see also Falta: Deutsches Archiv für klinische Medicin, 1904, vol. lxxxi, p. 250.

${ }^{36}$ Deutsches Archiv für klinische Medicin, 1904, vol. lxxxi, p. 231. 
corresponds closely with that to be expected if the aromatic fractions of the catabolized proteins are wholly converted into homogentisic acid and excreted as such.

The yield of alkapton acid after feeding with tyrosin or phenyl-alanin varies with the mode of administration, and when small doses are given at short intervals, instead of a single large dose, the output is practically quantitative. This observation we owe to Mittelbach. ${ }^{39}$

Yet one other of the known protein fractions has a benzene ring in its molecule, but in tryptophane the ring forms part of the more complex, heterocyclic, indol grouping. It appears unlikely $a$ priori that in catabolism tryptophane will follow the same path as tyrosin, and that it will become converted into homogentisic acid, but in order to test the point I recently administered one gramme of tryptophane, for which I was indebted to the kindness of Dr. F. G. Hopkins, to an alkaptonuric boy.

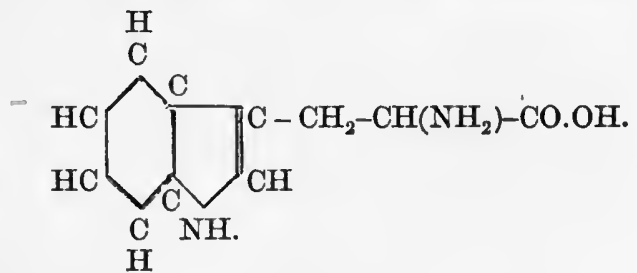

Tryptophane.

The dose was a very small one, and any effect might be expected to be slight. Therefore an equivalent

39 Deutches Archiv für klinische Medicin, 1901, vol. lxxi, p. 50 . 
dose of tyrosin ( 0.9 gramme) was given on two occasions as a control, the patient being kept upon a constant diet. The effect of each dose of tyrosin upon the $\frac{\text { homogentisic acid }}{\text { nitrogen }}$ ratio was clearly marked, but no disturbance of the ratio was observed on the day on which the tryptophane was given. Hence I felt justified in concluding that tryptophane administered by the mouth does not increase the output of homogentisic acid, although further confirmation with a larger dose was necessary before the point could be regarded as definitely established. I may add that Dr. Hopkins, who was good enough to examine the urine of the tryptophane day, failed to find in it any abnormal constituent the presence of which could be ascribed to an error of tryptophane catabolism. The fact that tryptophane does not yield homogentisic acid in metabolism has now been conclusively proved by Otto Neubauer, ${ }^{\Delta 0}$ who administered five grammes of tryptophane to an adult alkaptonuric. This dose produced neither an increased output of homogentisic acid, nor any disturbance of the $\mathrm{H}: \mathrm{N}$ ratio. - To sum up, it would appear that the tyrosin and phenyl-alanin of proteins are the only parent substances of the alkapton acid.

A glance at the respective formulæ of tyrosin and homogentisic acid suffices to show that the change from the one to the other is a complex one, for it involves the removal of the hydroxyl group from the para-position and substitution of two others

${ }^{\circ}$ Deutsches Archiv f. klin Med. 1909, vol. xcv, p. 211. 
in the $2: 5$ position in relation to the side chain, or possibly a shifting of the side chain itself.

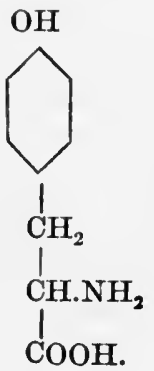

Tyrosin.

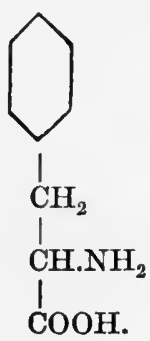

Phenyl alanin.

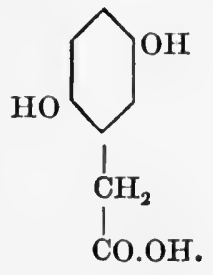

Homogentisic acid

Such a change presented greater chemical difficulties when Baumann wrote than it does now and could not be paralleled in animal metabolism. As, however, such successive reduction and oxidation were known to be brought about by bacterial action Wolkow and Baumann suggested that it might have its seat in the intestine of alkaptonurics, being there brought about under the influence of a rare specific micro-organism. Nowadays this infective theory, which was at one time widely accepted, has bcen completely abandoned, for it has been abundantly disproved.

Intestinal disinfection has no influence upon the excretion of homogentisic acid by alkaptonurics, nor can any organism be grown from their fæces which is able to effect such a conversion of tyrosin. Moreover, it has been shown by Mittelbach, ${ }^{41}$ and 
afterwards by Langstein and Meyer and by Falta, ${ }^{\mathbf{4 2}}$ that abstinence from protein food, and indeed from all food, does not arrest the excretion of the acid, although it naturally greatly reduces its amount. Hence we must conclude that not the food proteins alone, but also those of the tissues, contribute their quota to the total output of homogentisic acid, which would not be the case if the conversion were effected in the alimentary canal, and the fact, which we owe to Abderhalden, Bloch, and Rona, ${ }^{43}$ that the soluble dipeptide glycyl-l-tyrosin when injected subcutaneously into an alkaptonuric produces the same effect as tyrosin introduced into the alimentary canal, affords equally conclusive evidence that the change is not merely due to the action of intestinal bacteria.

Lastly, if the aromatic fractions of the proteins were thus changed in the intestine before undergoing absorption therefrom, seeing that they are not synthesized in the animal organism, the tissue proteins of alkaptonurics should exhibit a shortage of tyrosin and phenyl-alanin, if, indeed, such a deviation from normality be compatible with the maintenance of life. Abderhalden and Falta, ${ }^{44}$ who have investigated the blood proteins of such subjects as well as their hair and nails, have found no evidence of deficiency of the fractions in question.

42 Loc. cit. sub. 36 and 38.

43 Zeitschrift für physiologische Chemie, 1907, vol. lii, 435.

4 Ibid., 1903, vol. xxxix, p. 143, and 1907, vol. lii, p. 445. 
It will be obvious, from all that has gone before, that the error of metabolism which is at the back of alkaptonuria is a failure to deal with the aromatic fractions of proteins in the ordinary way, and that both the proteins of the food and those of the tissues, are implicated in the error. Before proceeding further it is, therefore, necessary to consider what is known as to the ordinary way of dealing with these fractions.

It is an unquestionable fact that the great majority of aromatic compounds when introduced into the human organism, escape with their benzene ring intact and are excreted in the urine in combination with sulphuric acid, as aromatic sulphates, or with glycocoll, as the acids of the hippuric group. Not so tyrosin and phenyl-alanin, which are in no sense foreign substances but important constituents of proteins, for these suffer disintegration of the aromatic nucleus and are completely destroyed. It is true that they do not stand quite alone in this respect, nor is it to be expected that they should do so, for any aromatic substance which is an intermediate product of their catabolism will obviously be in like manner broken up, as also will compounds so closely allied to them in their molecular structure that when exposed to the same destructive influences they share their fate. Some recent investigations have supplied a clue to the seat of the destruction of such substances and the nature of the changes which they undergo. Thus, G. Embden, Saloman, and F. Schmidt ${ }^{45}$ found that when certain protein

${ }_{45}$ Hofmeister's Beiträge, 1906, vol. viii, pp. 121, 129. 
substances are perfused through the liver acetone is formed. Glycocoll, alanin, glutaminic acid, and asparagin led to no such formation of acetone, but with leucin, tyrosin, and phenyl-alanin, as well as with phenyl- $a$-lactic and homogentisic acids, a conspicuous yield of acetone was obtained. The aromatic acids on this list are all broken up in the normal organism, whereas phenyl- $\beta$-lactic, phenylpropionic, and phenyl-acetic acids, which are not so broken up, do not yield acetone in the perfused liver. Furthermore, J. Baer and L. Blum ${ }^{46}$ have found that substances which figure in the above list of acetone-yielding compounds cause an increased excretion of $\beta$-oxybutyric acid when administered to diabetics. Hence they regard it as probable that the formation of acetone from them is a secondary event, and that $\beta$-oxybutyric acid is first formed.

The question which next calls for consideration is whether in alkaptonuria the failure to deal with tyrosin and phenyl-alanin is or is not complete. In diabetes we are confronted with a failure to burn glucose, which may be of any degree, from such as leads to a small excretion of glucose only after a meal rich in carbohydrates, to a failure so nearly complete that the proteins are called upon to contribute to the urinary output of glucose. In congenital cases of alkaptonuria, at any rate, and concerning temporary cases no information on this

46 Archiv für Experimentelle Pathologie und Pharmakologie, 1906, vol. lv, p. 89. 
point is forthcoming, the excretion of homogentisic acid, although it varies considerably, as it obviously must do, according to the nature of the diet taken, is fairly uniform in different cases, provided always that the food of the subjects is similar in kind and in proportions. ${ }^{47}$ There is no evidence that the alkapton acid ever occurs in traces in the urine; an output of several grammes in the day is observed or no homogentisic acid is found. Four or five grammes a day is the average on an ordinary mixed diet. The evidence afforded by the ratio of homogentisic acid to nitrogen is of far greater value in this connexion than that derived from the measure of the daily output of homogentisic acid alone. A mere increased supply of a given protein in the food does not disturb this ratio, for with the increased destruction nitrogen and alkapton acid in the urine increase pari passu. But though unaffected by quantitative changes in the diet the ratio is profoundly disturbed by changes in the quality of the proteins taken, as must needs be the case, seeing that some proteins are far richer in tyrosin and phenyl-alanin than others, whereas their yield of nitrogen is comparatively constant. Thus the substitution of casein, which is rich in the aromatic fractions, for egg albumin, in which they are much more scantily

47 Unusually high figures may for the most part be ascribed to the diet taken; but it should be mentioned that Zimper records figures for his case whieh are out of all proportion to those obtained in any other. The homogentisic acid output amounted to as much as 18 grammes per diem. The tyrosin and phenyl-alanin of proteins brokon down could not account for such an excretion. 
present, will greatly increase the output of homogentisic acid relatively to that of nitrogen, as Langstein and Meyer and Falta have demonstrated.

If in alkaptonuria the error be complete and maximal, all subjects of that anomaly when fed upon a given standard diet should excrete equal quantities of homogentisic acid, and changes in the quantities consumed, although they will conspicuously affect the total output of the acid, should leave the Homogentisic acid : Nitrogen ratio undisturbed. In order to obtain conclusive evidence upon this point it would be necessary to place a number of alkaptonurics upon a standard diet, in which not only are the proteins the same but in which also the several proteins are represented in uniform proportions. These conditions would be best fulfilled by a diet of milk alone. Unfortunately, observations so carried out are not available, but such observations as are forthcoming strongly suggest that the error is in all cases of one degree, and that the failure to deal with tyrosin and phenylalanin is complete. The best available standard, although far from a uniform one, is a mixed diet, and the figures quoted ${ }^{48}$ are drawn from the observations of Langstein and Meyer and Falta upon one alkaptonuric, of Schumm upon another, and of Hele and myself upon yet three others. All the patients were, at the times to which the figures refer, upon a mixed diet, and the results serve to show that under roughly uniform conditions of 


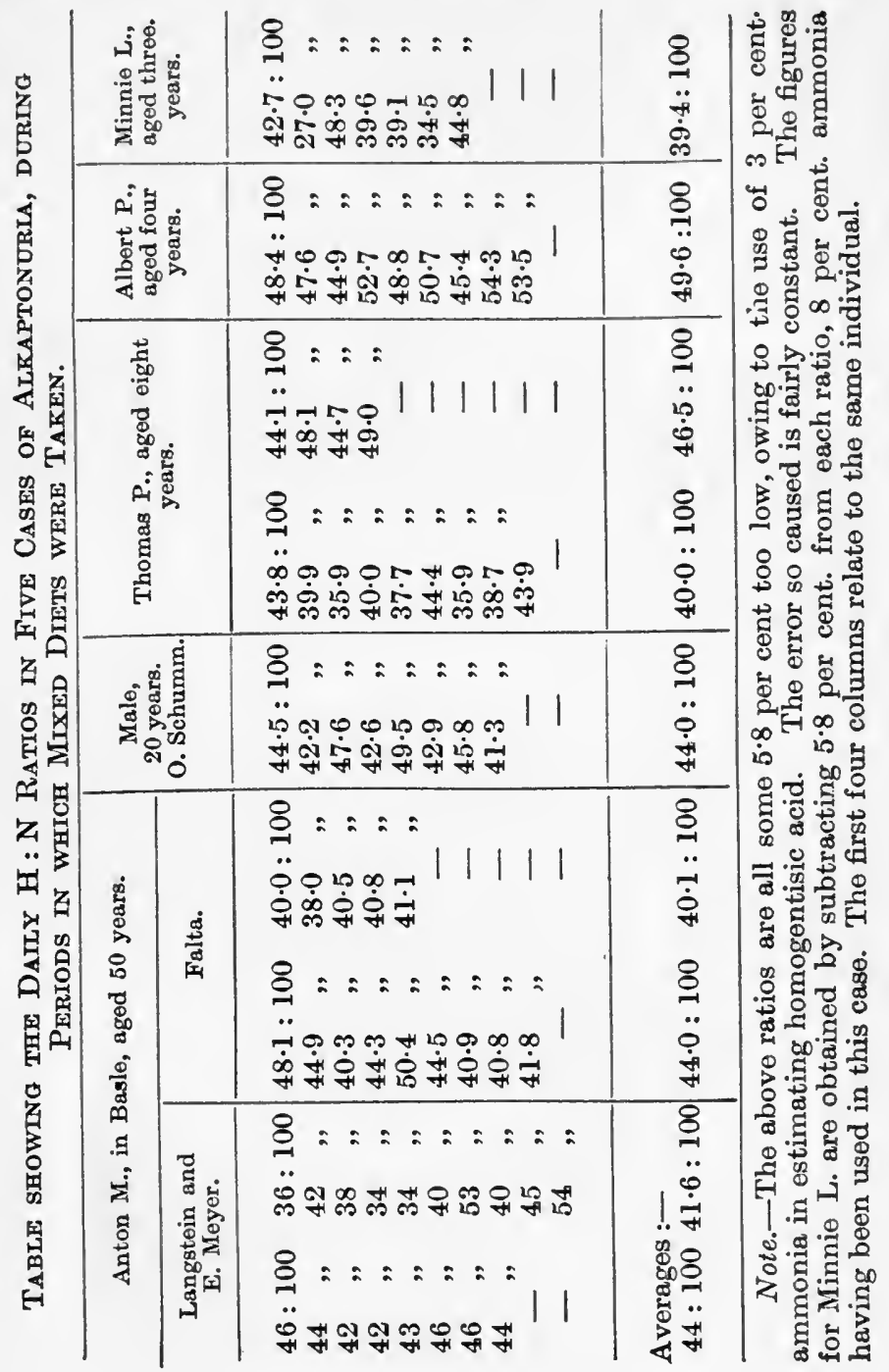


diet the ratios show at least a striking similarity. ${ }^{49}$ Some other observations bearing upon this point have been published in the last year or two. Cronvall ${ }^{50}$ obtained ratios varying between $45: 100$ and $61: 100$ in his case, the mean being $55: 100$. As he used 8 per cent. ammonia in estimating the homogentisic acid the percentages of that acid must be reduced by 5.8 per cent. to render them comparable with those given in the table, and he himself suggested that the ratios were rendered higher by a considerable amount of milk in his patient's diet. Fromherz ${ }^{51}$ obtained ratios which accord well with those tabulated above.

Gross and Allard 52 in a recent investigation obtained very high $\mathrm{H}: \mathrm{N}$ ratios, $60-70: 100$, which they regarded as showing a want of uniformity in different cases, but their patient was taking large quantities of milk, on one day as much as three litres, and changes in the protein content of the diet appear to have been chiefly brought about by the addition or withdrawal of milk. Their ratios are comparable with those worked out by Langstein and E. Meyer during a period of milk and plasmon diet (average $62 \cdot 6: 100$ ), and that the above explanation is correct is shown by the fact that even the addition of plasmon (sodium casein) to the diet

a Journal of Physiology, 1905, vol. xxxiii, p. 198, and 1906, vol. xxxv (Proceedings of the Physiological Society, p. xv).

so Upsala Läkareförenings Förhandlingar, 1907, vol. xii, p. 402.

${ }_{61}$ Dissert. Freiburg i. Br., 1908.

12. Zeitschrift für klinische Medicin, 1907, vol. lxiv, p. 359. 
scarcely affected the ratio, whereas when superposed upon an ordinary mixed diet it greatly increases the homogentisic output relatively to that of nitrogen. Abderhalden, Bloch, and Rona ${ }^{53}$ also give some figures relating to yet another case, that of a boy, and the ratios obtained from these figures are somewhat low, the average for five days being $35 \cdot 7: 100$. The nature of the diet is not mentioned.

So far as the available evidence goes it tends to show that there is only one degree of alkaptonuria, and that from a given quantity of a given protein all subjects of the anomaly tend to form and to excrete the same amount of homogentisic acid, and it is probable that that quantity is a maximal one, seeing that Falta has shown that the output of homogentisic acid corresponds roughly to the estimated amounts of the aromatic fractions in the proteins broken down.

Two explanations are possible of the fact that alkaptonurics excrete homogentisic acid whereas normal persons do not. Either the alkapton acid is a strictly abnormal product formed by a perverted metabolism of tyrosin and phenyl-alanin, in virtue of which these protein fractions experience a wholly different fate from that which overtakes them in the normal organism, or it is an intermediate product of normal metabolism which is usually completely destroyed and does not come to excretion, but which in alkaptonuria escapes destruction.

It may be premised that the behaviour of homo-

ss Zeitschrift für physiologische Chemie, 1907, vol. lii, p. 444 . 
gentisic acid in the organism is rather that of a normal product than that of an interloper. None of the chemical protective mechanisms are called into play to cope with it in alkaptonuria, save that which is called out by any acid which is not destroyed in metabolism. It is excreted in simple combination with bases and not as an aromatic sulphate or in combination with glycocoll. Its next homologue, gentisic acid, on the other hand, although it is for the most part destroyed in passage through the body, is in part excreted as aromatic sulphate, as Likhatscheff ${ }^{54}$ showed and as Neubauer and Falta ${ }^{55}$ also found.

As an acid, homogentisic acid is in part combined with ammonia, for the protection against acids is in no wise selective. Erich Meyer ${ }^{56}$ obtained evidence of an increased excretion of ammonia by an alkaptonuric child and Schumm ${ }^{57}$ made a like observation in the case of an adult. In neither instance was the increase of urinary ammonia comparable with that observed in some pathological conditions, such as grave diabetes, for, as we have seen, the output of the acid itself is never large as compared with that of the acids of the acetone group in some morbid states.

It stands to reason that an intermediate product

"Zeitschrift für physiologische Chemie, 1895, vol. xxi, p. 422.

"s Ibid., 1904, vol. xlii, p. 92.

" Deutsches Archiv für klinische Medicin, 1901, vol. lxx, p. 463.

"Münchener med. Wochenschrift, 1904, vol. li, p. 1599. 
of catabolism which is normally absent from the excreta must needs be completely destroyed under ordinary conditions, and that homogentisic acid conforms to this requirement there is abundant evidence to show. Thus, although H. Embden ${ }^{58}$ succeeded in producing a transitory alkaptonuria in himself by swallowing eight grammes of the acid, he found that smaller doses had no such effect. Falta, ${ }^{59}$ too, failed to induce an excretion of the acid in himself and two others by taking quantities of from four to six grammes in repeated half-gramme doses at short intervals. Hence it is evident that homogentisic acid is a member of that small group of aromatic compounds of which the benzene ring is broken down in their passage through the body, and, as has been mentioned, further evidence of this is afforded by the fact that it yields acetone when perfused through the liver. In these respects it behaves as a normal intermediate product might be expected to do. That this destructive power may be overtaxed is shown by Embden's experiment upon himself, and by those of Wolkow and Baumann upon dogs. ${ }^{60}$ In normal persons such overtaxing can never occur, since the maximum daily output taken at a single dose will hardly give rise to experimental alkaptonuria; but in disease the power of destroying homogentisic acid is sometimes conspicuously lowered-for example, in grave cases

ss Zeitschrift für physiologische Chemie, 1893, vol. xvii, p. 182, and vol. xvii., p. 304.

"Loc. cit., sub. 38, p. 264.

os Loc. cit., sub. 20 , p. 282. 
of diabetes, as Langstein, ${ }^{61}$ Falta, ${ }^{62}$ and others have demonstrated.

Garnier and Voirin, ${ }^{63}$ who were the first to suggest that homogentisic acid is a product of normal metabolism, were inclined to ascribe its presence in the urine to excessive production, the power of destroying it being overtaxed. Whether the power of destroying it were merely overtaxed or wholly lost it might be expected that homogentisic acid given by the mouth to an alkaptonuric will be excreted nearly quantitatively, being added to the ordinary output, and H. Embden showed that this is the case. If, however, it were merely a question of overtaxing, the output of the acid should be considerably less than the amount which corresponds to the whole of the aromatic fraction of the proteins broken down, but, as we have seen, there is reason to believe that the failure to deal with tyrosin and phenylalanin in the usual way is complete. On such grounds the more recent adherents of the intermediate product theory have held that the alkaptonuric differs from the normal individual in that he does not possess the power of destroying homogentisic acid.

This theory has lately been challenged by Grutterink and Hijmans van der Bergh, ${ }^{64}$ and upon the following grounds. To patients who were found to have much impaired powers of destroying homo-

${ }^{61}$ Deutsche medicinische Wochenschrift, 1905, vol. xxxi, p. 457 .

2 Loc. cit., sub. 38, p. 265.

'3 Archives de Physiologie, 1892, 5e s., vol. iv, p. 225.

- Nederlandsh Tijdschrift voor Geneeskunde, 1907, vol. ii, p. 1117 
gentisic acid taken by the mouth, being sufferers from diabetes or hepatic disease, and in one of whom as small a dose as two grammes caused a temporary alkaptonuria, these observers administered tyrosin in doses of 10 to 15 grammes. They argue that after such large doses of tyrosin sufficient homogentisic acid should have been formed to overtax the limited destructive power, supposing that it were a normal intermediate product, and that some should have been excreted in the patient's urine, whereas in no instance did such a result follow. This evidence cannot, certainly, be lightly set aside. However, we cannot be sure that at any moment sufficient alkapton acid would be in existence to overtax the destructive power, which although diminished was undoubtedly not abolished. Nor is it certain that when such impairment results from disease the formation of homogentisic acid, as well as its destruction, is not interfered with. Grutterink and van der Bergh satisfied themselves that the tyrosin given was well absorbed, but they do not state whether tyrosin itself, or derivatives thereof, other than homogentisic acid, were sought for in the urine. Knoop ${ }^{65}$ had previously raised a similar objection. He fed dogs with phenyl-a-lactic acid, a compound which, like tyrosin, increases the homogentisic output of alkaptonurics. $\mathrm{He}$, too, argued that, as the power of dogs to destroy homogentisic acid is known to be limited, if it were a normal product it should have appeared in the urine. However, the fact that some of the phenyl-a-lactic acid was re's Hofmeister's Beiträge, 1905, vol. vi, 150. 
covered as such from the urine suggests that a block occurred at an earlier stage in the catabolic series.

It appears to me that at present the evidence in favour of the theory of an intermediate product far outweighs that which can be brought against it. Perhaps the most serious objection which can be raised to the view that homogentisic acid is an abnormal product, peculiar to alkaptonurics, is that such a view involves the assumption that the alkaptonuric, who alone has the power of forming homogentisic acid, is also exceptional in having no power of destroying it when formed.

The impaired destruction of the alkapton acid which results from certain morbid conditions has also interesting bearings upon the question of temporary or intermittent alkaptonuria. The records of such cases are very few, only four or five in all, and further work upon such cases is much to be desired. In some of them the evidence that the condition was temporary is not conclusive, and in others the evidence of the nature of the abnormal excretory product is not sufficiently complete for the establishment of so important a point. In none of them save in that of Zimnicki, ${ }^{66}$ whose paper appeared in a Russian journal which $I$ have not been able to obtain, have quantitative estimations been carried out. His patient, whose alkaptonuria was intermittent, suffered from hypertrophic cirrhosis of the liver. In Geyger's ${ }^{67}$ case, also inter-

68 Jeshenedelnik, 1899, No. 4; abstract Centralblatt für Stoff wechsel und Verdauungskrankheiten, 1900, vol. i, p. 348.

${ }_{67}$ Pharmakeutische Zeitung, 1892, p. 488. 


\section{INBORN ERRORS OF METABOLISM}

mittent, the patient was a diabetic. Of strictly temporary cases that described by Carl Hirsch ${ }^{68}$ is the most remarkable. A girl, aged 17 years, with a febrile gastro-enteric catarrh, passed for three days only a urine which darkened on standing, contained indican, and also yielded the alkapton reactions. From it Professor Siegfried extracted an acid which formed a sparingly soluble lead salt, but neither the melting point of the acid nor any analytical figures are given.

A temporary or intermittent excretion of homogentisic acid seems more compatible with the theory that it is a normal metabolic product than with the opposite theory. It is noteworthy that the diseases from which Geyger and Zimnicki's patients suffered were such as have been found to be sometimes attended by impaired power of destroying of the acid in question, and is conceivable that in rare instances the impairment may proceed further and become practically complete. I realise, however, that what has been suggested above, as to diminution of power of forming as well as of destroying the alkapton acid in such diseases, may be equally urged against such an interpretation of the intermittent cases.

In support of the intermediate product theory certain observations of Gonnermann, Bartels, ${ }^{69}$ and others have been adduced, as pointing it to the forma-

${ }^{68}$ Berliner klinische Wochenschrijt, 1897, vol. xxxiv, p. 866 .

69 Archiv für gesammte Physiologie, (Pfluger), 1900, vol. lxxxii,p. 289. Berichte der deutschen botanischen Gesellschaft, 1902, vol. xx, p. 454. 
tion of homogentisic acid in plants by the action of a tyrosinase upon tyrosin. The evidence brought forward has never appeared to me to be at all conclusive, and the investigations of Schultze, ${ }^{70}$ who has failed to obtain any evidence of the formation of homogentisic acid under such conditions, have deprived this argument of all cogency.

Assuming it to be a fact that homogentisic acid is a product of normal metabolism, the result of the administration of various aromatic acids to alkaptonurics may reasonably be expected to throw light upon the higher intermediate steps between the parent protein fractions and that substance. Any compound, which represents a link in the chain should, on the one hand, be destroyed, as tyrosin and homogentisic acid are, in the normal organism, and, on the other hand, should increase the output of the latter by alkaptonurics. Any substance which does not behave in the manner indicated cannot form such an intermediate link.

Many aromatic acids have been administered to alkaptonurics at various times, but very few have been found to fulfil the above conditions. The most complete set of observations of the kind have been carried out by Otto Neubauer and Falta, ${ }^{71}$ and their findings have recently been fully confirmed by Grutterink and van der Bergh. ${ }^{72}$ It was found

${ }^{20}$ Zeitschrift für physiologische Chemie, 1906, vol. xlviii, p. $396 ; 1907$, vol. 1., p. 508.

${ }^{21}$ Zeitschrift für physiologische Chemie, 1904, vol. xlii, p. 81 .

${ }_{2}$ Loc. cit., sub. 63. 


\section{INBORN ERRORS OF METABOLISM}

that compounds, such as phenyl-acetic and phenylpropionic acids, which have simple side chains, have no effect upon the output. Those which increase homogentisic excretion resemble tyrosin and phenylalanin in having an easily attacked grouping in the $a$ position upon the side chain, whereas when the substituted group occupies the $\beta$ position no such result follows. Thus phenyl-a-lactic and phenylpyruvic acids are excreted as homogentisic acid, whereas phenyl- $\beta$-lactic acid is not. Even the presence of a second substituted group in $\beta$ position as in phenyl-glyceric acid, suffices to prevent the transformation.

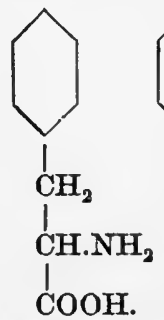

Phenyl-elanin.

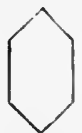

$\mathrm{CH}_{2}$

CH.OH<smiles>CC(=O)O</smiles>

Phenyl. $a$-lactic acid

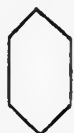

$\stackrel{1}{\mathrm{CH}_{2}}$<smiles>C=CCC</smiles><smiles>CCC(=O)O</smiles>

Phenyl. pyruvic acid.

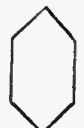

1

$\mathrm{CH} . \mathrm{OH}$<smiles>CC</smiles><smiles>C1CC1</smiles>

$\mathrm{CO} . \mathrm{OH}$.

Phenyl-

B-lactic acid.

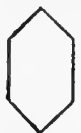

CH.OH

'́⿴囗ОН

CO.OH.

Phenyl-

glycerio acid.

Again, when the substituted grouping in the $a$ position is rendered more stable by benzoylation the formation of homogentisic acid is prevented, for as L. Blum ${ }^{73}$ has found, benzoyl-phenyl-alanin does not increase the alkapton output.

There is good reason to believe that desamination - that is to say, the removal of the amino groupis a very early stage in the catabolism of the amino- 
acids of which the molecules of proteins are built up, and of the aromatic fractions amongst others. After a meal rich in proteins the resulting excretion of homogentisic acid was found by Falta ${ }^{74}$ to commence more promptly and to come to an end sooner than the corresponding increase of the output of nitrogen, and this has been confirmed by Langstein and Meyer. Mittelbach ${ }^{75}$ placed the maximum excretion of homogentisic acid within the two or three hours following the protein meal, but in some observations which I made ${ }^{76}$ upon specimens of urine passed at short intervals throughout the day, although an obvious increase occurred shortly after a meal rich in protein, the excretion was still larger during the second period of four hours than during the four hours immediately following the meal. It is easy to imagine that desamination is effected by substitution of hydroxyl for the amino-group, and that the formation of phenyl-a-lactic acid is the first step in the breaking down of phenyl-alanin. Not only does phenyl-a-lactic acid fulfil the conditions laid down above, but it is one of the compounds which have been found to yield acetone when perfused through the liver; but a recent observation of Otto Neubauer ${ }^{77}$ apparently negatives this supposition. This observer found to his surprise that paroxy-phenyl-a-lactic acid, which stands to tyrosin in the same relationship as does phenyl-a-lac-

24 Verhandlungen der Naturforschenden Gesellschaft in Basel, 1903, vol. xv Heft, 2. ${ }_{73}$ Loc. cit., sub. 39 .

"Transactions of the Royal Medical and Chirurgical Society, 1903, vol. lxxxv. p. 69 .

77 Dẹtsches Archiv f. klin. Med. 1909, vol, xev. p. 211. 
tic acid to phenyl-alanin, fails entirely to increase the output of homogentisic acid by an alkaptonuric. Hence he concludes that the intermediate product is probably the ketonic acid, and the probability is greatly increased by his further observation that paroxy-phenyl-pyruvic acid does increase the alkapton output-

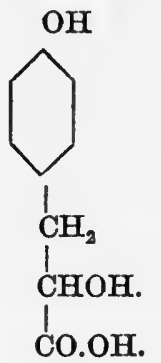

Paroxy-phenyl-a-lactio acid.

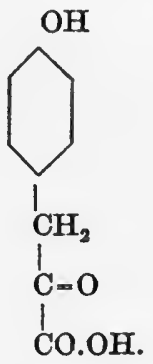

Paroxy·phenyl-pyruvic acid.

Between paroxy-phenyl-pyruvic acid and homogentisic acid other stages must intervene, and the appearance of two hydroxyl groups in the $2: 5$ positions upon the ring must precede or coincide with the final oxidation of the side chain. Were this not the case paroxy-phenyl-acetic acid would be formed, and this acid has not the properties requisite for an intermediate product, and is not converted into homogentisic acid by an alkaptonuric.

The structure of the benzine ring itself is of no less importance than that of the side chain. Falta found that di-brom-tyrosin and halogen proteins do not increase the homogentisic excretion in alkaptonuria, and we owe to L. Blum ${ }^{78}$ the important observation

is Archiv f. exper. Path. u. Pharmakol. 1908, lix, p. 283. 
that ortho-tyrosin and meta-tyrosin are equally inert in this respect, although each of these compounds has a hydroxyl group in the position of one of the hydroxyls of homogentisic acid. Otto Neubauer has shown that the same holds good for the allied compounds, ortho- and meta- oxyphenylpyruvic acids.

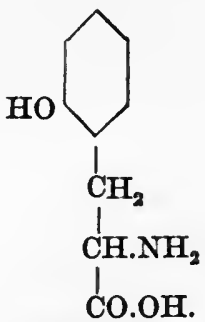

Ortho-tyrosin.

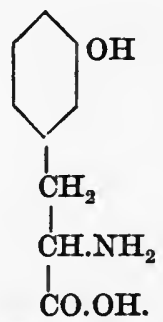

Meta-tyrosin. Homogentisio acid.

Hence it would appear that the presence of a hydroxyl-group in the para-position is not only no hindrance to the change but is rather essential to it, and that the change in the ring is not brought about, as was originally supposed, by removal of the hydroxyl in the para-position, but rather by shifting of the side chain. Such a shifting was first suggested by Erich Meyer, ${ }^{79}$ on the analogy of Bamberger's ${ }^{80}$ observations on the conversion of toluyl-hydroxylamine into tolu-hydroquinone, and is presumably brought about by the formation of a compound with the quinone grouping. ${ }^{81}$

"Deutsches Archiv f. klin. Med., 1901, 1xx, p. 446.

30 Berichte d. deutschen chemischen Gesellsch., xxviii, 245.

31 See Friedländer. Hofmeister's Beiträge, 1908, xi, 304. 
Otto Neubauer represents the probable series of changes as follows.

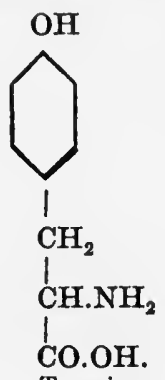

Tyrosin.

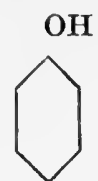

${ }^{\prime} \mathrm{CH}_{2}$ ${ }_{\mathrm{C}-\mathrm{O}}^{\mathrm{O}}$ '

Paroxy-phenylpyruvic acid.

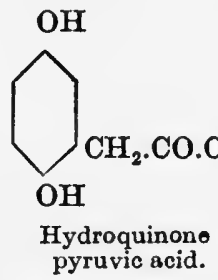

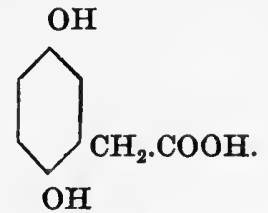

Homogentisic acid.

He has administered hydroquinone-pyruvic acid, the third intermediate product in this series, to an alkaptonuric and has found that it has the requisite power of increasing the homogentisic output although the increase was less than might be expected.

If such a path, through a compound having the quinone linkage, be actually followed, it is necessary to assume that phenyl-alanin acquires a hydroxyl group in the para-position and is converted into tyrosin as to a preliminary to the further changes which it undergoes.

It is interesting to note that Blum found that 
when ortho- or meta-tyrosin is given to a normal man it is in part excreted as the corresponding oxy-phenyl-acetic acid, which shows that the shortening of the side chain, such as occurs when homogentisic acid is formed, is within the powers of the normal metabolic processes.

So far we have been discussing changes which, if homogentisic acid be a product of normal metabolism, are carried out in the normal and alkaptonuric organisms alike. Where the alkaptonuric differs from the normal individual is in having no power of destroying homogentisic acid when formed -in other words of breaking up the benzene ring of that compound.

Apparently the factor which determines the disruption of the ring is the presence of the two hydroxyl groups in the $2: 5$ position upon it.

Thus, Neubauer and Falta ${ }^{82}$ found that of the three isomeric dioxybenzoic acids gentisic acid alone was to a large extent burnt in the human organism, although some 15 per cent. of the dose given appeared in the urine as aromatic sulphate. In gentisic acid, as in its homologue the alkapton acid, the hydroxyl groups occupy the 2 and 5 positions.

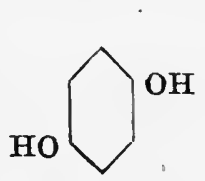

$\mathrm{COOH}$.

Gentisic acid.

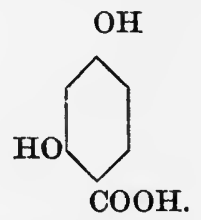

2 : 4 dioxybenzoic acid.

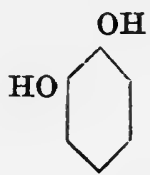

$\mathrm{COOH}$.

Protocatechuic acid.

82 Loc. cit., sub. 71. 
When the alkaptonuric took gentisic acid by the mouth Neubauer and Falta found that the reducing power of his urine was conspicuously increased, not owing to a greater output of homogentisic acid, which could hardly have resulted, but to the excretion of gentisic acid as such.

This indicates that in alkaptonuria the failure to break up the benzene ring extends to acids with hydroxyl groups in the $2: 5$ position other than homogentisic acid, and that the essential error resolves itself into an inability to destroy the ring of acids so constituted. Homogentisic acid is apparently the only compound formed in normal metabolism which offers itself for such disruption, and accordingly the alkaptonuric excretes it.

This conception of the anomaly locates the error in the penultimate stage of the catabolism of the aromatic protein fractions, which is in accord with the fact that all the tyrosin and phenyl-alanin, both exogenous and endogenous, is swept into the net and goes to contribute to the excreted homogentisic acid in alkaptonuria.

We may further conceive that the splitting of the benzene ring in normal metabolism is the work of a special enzyme, that in congenital alkaptonuria this enzyme is wanting, whilst in disease its working may be partially or even completely inhibited.

The experiments of G. Embden and others upon perfusion of the liver suggest that organ as the most probable seat of the change. If, however, the acetoneforming enzyme is that which is at fault, it is worthy of note that not only the aromatic fractions of pro- 
teins but leucin also contributes to the formation of acetone, and might be expected to be likewise involved. Dr. Hurtley was good enough to examine a large quantity of alkapton urine for me, by extraction with ether after acidification, and distillation in steam of the residue of the ethereal extracts, but was unable to detect the presence of any abnormal acid of the fatty series, and there is at present no evidence forthcoming of any disturbance of the path of leucin catabolism in alkaptonuria. 


\section{CHAPTER IV}

\section{Cystinuria}

OUR knowledge of cystin and of cystinuria alike dates from the year 1810, in which year Wollaston ${ }^{1}$ described a previously unknown variety of urinary calculus, of which two specimens had come into his hands. The first of these had been removed from the bladder of a young child. Seeing that both stones had been found in the urinary bladder Wollaston assigned to the new compound of which they were composed the name of cystic oxide.

It was Berzelius ${ }^{2}$ who suggested the change of name from cystic oxide to cystin, and of this new name, which has since been universally adopted, Civiale wrote ${ }^{3}$ in 1838 , that although it corrected an error of chemistry it perpetuated an error of physiology, for cystin is excreted by the kidneys and does not have its origin in the bladder.

The sediments of hexagonal orystals found in urine, upon which the diagnosis of cystinuria is so

1 Philosophical Transactions of the Royal Society, 1810, vol. c, p. 223.

2 Traité de Chemie, 1833, vol. vii, p. 424.

3 Comptes Rendus de l'Académie des Sciences, Paris, 1838 , vol. vi, p. 897. 
often based, were first observed by Stromeyer ${ }^{4}$ in 1824 and by Prout ${ }^{5}$ in 1825.

Prout made the earliest analysis of cystin, but, being unaware of the presence of sulphur in it, he reckoned the contained sulphur as oxygen. Baudrimont and Malaguti ${ }^{6}$ announced that cystin contains sulphur in 1837, no less than twentyseven years after Wollaston's discovery; and in the year following Thaulow ${ }^{7}$ published a complete analysis which was in accord with that of Prout, save that half the oxygen of his reckoning was replaced by sulphur. ${ }^{8}$

To Goldmann and Baumann ${ }^{8}$ we owe the recognition of the fact that cystin is an amino-derivative of thio-lactic acid, in which two molecules are linked together by their sulphur atoms, whereas cystein, which is easily obtained by reduction of cystin, contains an SH group in its single molecule. In Baumann's formula the sulphur atom and the amino-group were represented as being both attached to the $a$ carbon atom, but Friedmann ${ }^{10}$

- Annals of Philosophy, 1824, vol. viii, p. 146.

- On Stomach and Urinary Diseases, second edition, 1825, p. 166.

- Comptes Rendus de l'Académie des Sciences, Paris, 837 , vol. v, p. 394 .

- Annalen der Chemie (Liebig's), 1838, vol. xxvii, p. 197.

- Baudrimont and Malaguti state (Journal de Pharmacie, 1838, vol. xxiv, p. 633) that they presented a complete analysis to the Académie des Sciences in 1837, but I can find no published account of this. The Comptes Rendus for that year contain only a brief note of their paper, in which the presence of sulphur in cystin is mentioned.

- Zeitschrift für physiologische Chemie, 1888, vol. xii, p.254.

10 Hofmeister's Beiträge zür chemischen Physiologie und Pathologie, 1903, vol. iii, p. 1. 
has more recently shown that this is not the case, but that the amino-group occupies the $a$ and the sulphur atom the $\beta$ position. Cystin must therefore be regarded as di-a-amino- $\beta$-thio-lactic acid.

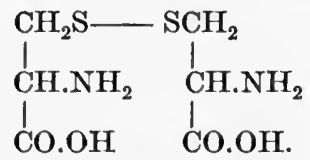

Cystin.
$\mathrm{CH}_{2} \cdot \mathrm{SH}$

CH. $\mathrm{NH}_{2}$

$\mathrm{CO} . \mathrm{OH}$.

Cystcin.

Since then the synthesis of this compound, which had repeatedly been attcmpted without success, has been accomplished by Erlenmeyer, jun., ${ }^{11}$ and its formula may be regarded as finally established.

The revised formula renders possible the existence of an isomeric cystin, with the composition of di- $\beta$-amino- $\alpha$-thio-lactic acid :-

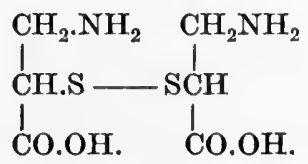

And this substance also has been synthetically prepared by Gabriel. ${ }^{12}$

Carl Neuberg and P. Meyer ${ }^{13}$ have put forward the view that some cystin calculi consist wholly or in part of this isomeric cystin, although they found that the cystin of sediments and that which is present in solution in the urines which they ex-

1 Berichte der deutschen chemischen Gesellschaft, 1903, vol. xxxvi, p. 2720.

12 Ibid., 1905, vol. xxxviii, p. 637.

13 Zeitschrift für physiologische Chemie, 1905, vol. xliv, p. 472. 
amined was of the ordinary kind. This would imply that some cystinurics excrete one and some the other cystin, for it cannot be supposed that urinary calculi are formed of a material which is not present in the urine of the patients who produce them. Some calculi which Neuberg examined, when dissolved in ammonia, yielded on evaporation of the ammonia acicular crystals which he believed to consist of iso-cystin. This view has not met with acceptance from other investigators. The great majority of the calculi are undoubtedly composed of ordinary cystin, which is deposited in hexagonal plates from ammoniacal solutions. That the materials obtained from proteins and from such calculi are identical in their chemical and physical properties, including their effect upon the polarised ray, has been proved by Rothera, ${ }^{\mathbf{1 4}} \mathrm{Abder}$ halden, ${ }^{15}$ and J. Gaskell. ${ }^{16}$ Moreover, Emil Fischer and Zuzuki, ${ }^{17}$ who examined some of the same calculus material which Neuberg used, found that it gave a pronounced red colour with Millon's reagent, and they suggest that the acicular crystals described consisted of tyrosin. I have never obtained the acicular crystals from any cystin calculus which I have examined, although slender hexagonal prisms were not infrequently obtained. It is obvious that the occurrence of iso-cystin as

14 Journal of Physiology, 1905, vol. xxxii, p. 175.

15 Zeitschrift für physiologische Chemie, 1907, vol. li, p. 391 .

${ }_{18}$ Journal of Physiology, 1907, vol. xxxvi, p. 142.

17 Zeitschrift für physiologische Chemie, 1905, vol. xlv, p. 405 . 
a metabolic product is as yet very far from proven. Thero are a few scattered records, of tho last century, of the detection of cystin in animal tissues. Cloetta ${ }^{18}$ found it in the kidneys of an ox but failed to obtain it from other ox kidneys. Scherer 19 isolated eystin from the liver of a man who had died from typhoid fever, and $K u l z{ }^{20}$ obtained it on one occasion among the products of panereatic digestion in vitro. Such observations lent support to the view, which had been held all along, that the sulphur of proteins was the parent of the sulphur of cystin, which was regarded as an intermediate product of sulphur metabolism.

The year 1899 was marked by a great advance in our knowledge of the origin of cystin, for in that year K. A. H.' Mörner ${ }^{21}$ showed that cystin could be obtained in abundance by the hydrolysis of hair. Soon afterwards G. Embden ${ }^{22}$ obtained it, in like manner, by the hydrolysis of serum- and egg-albumins. Not only was there thus provided a ready source of supply of this compound, which had previously only been obtaincble from the rare cystin calculi and from the no less rare urinary sediments, but also it was shown that cystin has a place among the numerous $a$-amino-acids of which the complex molecules of proteins are built up. Like other primary protein fractions it is contained in widely

18 Leibig's Annalen, 1856, vol. xcix, p. 299.

19 Jahresbericht für Chemie, 1857, p. 561.

20 Zeitschrift für Biologie, 1884, vol. xx, p. 1.

21 Zeitschrift für physiologische Chemie, 1899, vol. xxviii, p. 595 .

22 Ibid., 1901, vol. xxxii, p. 94. 
different proportions in different members of the protein group.

Whether or no cystin is the sole protein fraction which contains sulphur, and is responsible for the entire sulphur contents of proteins save the small quantity of sulphate which they hold, apparently in some sort of combination, cannot be regarded as finally decided. Mörner's work shows that all the sulphur of some proteins is in this form, but it is not yet proved that other sulphur compounds obtained from certain substances of the group are derivatives of cystin. Thus the $a$-thio-lactic acid, which has frequently been obtained, offers obvious difficulties in this respect, for in it the sulphur atom occupies the $a$ position, whereas in cystin it is attached to the $\beta$ carbon atom.

Some account of what is known concerning sulphur metabolism forms a necessary preliminary to any discussion of the disturbance which it undergoes in cystinuria. However, our knowledge concerning it is far less advanced than that of the metabolism of nitrogenous compounds; the processes at work are evidently of considerable complexity and it appears certain that the cystin of the proteins broken down in the body does not all follow the same catabolic path. Almost the whole of the sulphur of the proteins of food and of tissues ultimately appears in the urine, for little of it is excreted by way of the alimentary canal. A small portion is present in the saliva and gastric contents as sulphocyanide, but as the sulphocyanide grouping is not represented in protein molecules 
it must be supposed that it is formed by synthesis within the organism. This fraction is ultimately reabsorbed from the alimentary canal and is excreted, at least in part, unchanged in the urine. A more considerable sulphur fraction goes to form the taurin of the bile and this portion too appears in the urine, probably as a part of the ncutral sulphur. The bulk of the sulphur takes a more direct route and is excreted as sulphates. Of the urinary sulphur, by far the greater part is in such fully oxidized form, and only some 14-20 per cent. is contained in a number of unoxidized or incompletely oxidized constituents which go to make up what is known as the neutral sulphur. Of the sulphates, the output of which may be swelled by sulphates absorbed as such from the alimentary canal, some portion is in combination as aromatic or ethereal sulphates; the greater part, some 90 per cent. of the total, is in the form of simple salts. The formation of the aromatic sulphates is usually ascribed to the working of a protective mechanism, by means of which aromatic substances of harmful nature, such as are apt to be absorbed from the alimentary canal, are rendered harmless and inert. The ratio of aromatic to simple sulphates is therefore regarded as affording a valuable index of the amount of protein decomposition brought about by the bacteria which inhabit the alimentary canal. Folin has recently thrown doubt upon this prevalent view, and seeing that the output of aromatic sulphate is little affected by a change from a diet rich in proteins to one poor in such constituents, 
he classes these compounds among the products of tissue metabolism as distinguished from that of the proteins of the food. However, the large amount of evidence available upon the other side-the increased output of aromatic sulphates in cases in which intestinal decomposition is abnormally active, the conversion of the whole of the sulphate into aromatic sulphate in some cases of carboluria, and the effects of intestinal disinfection in limiting the output-appear to me to call for the production of stronger evidence than has yet been brought forward before the accepted view need be given up. As F. G. Hopkins ${ }^{23}$ has suggested, the comparative uniformity of the excretion of these compounds upon widely different diets may well be due to the want of conspicuous variations in the bacterial activity in the intestine, a factor which is not known to be dependent upon the amount of protein contained in the food.

That variations in the amount of protein in the diet, although they influence very conspicuously the output of sulphates in the urine, have little effect upon that of neutral sulphur is a well-established fact, from which Folin concludes that the latter is made up of products of tissue metabolism as distinguished from that of protein foods. $\mathrm{He}$ compares the neutral sulphur with the endogenous uric acid and kreatinin among nitrogenous waste products, whereas the sulphates may be compared to urea. Abstention from food causes relative increase of neutral sulphur and, it is said, an abso-

23 Guy's Hospital Gazette, 1907, vol. xxi, p. 424. 
lute increase also, and so does the increascd breakdown of tissue proteins which is brought about by certain toxic substances, such as chloral and chloroform.

Of the materials which go to make up the so-called neutral sulphur our knowledge is as yet very incomplete. Some is probably derived from taurin; the cystin-like compound found by Baumann and Goldmann may contribute a fraction; minute quantities of sulphocyanide have already been mentioned, and among the sulphur-containing substances must be reckoned certain little-known acids of high molecular weight, but which do not yield the reactions of proteins, to which the names of uroproteic and uroferric acids have been assigned. In the urine of animals there have been met with, also, products of the decomposition of cystin in the alimentary canal, such as thio-sulphates, methyl mercaptan, and ethyl sulphide.

Some interesting experiments carried out by Baumann and Preusse ${ }^{24}$ and Jaffe, ${ }^{25}$ at a time when it was not yet known that cystin is one of the primary fractions of proteins, were of much importance as showing that it is present in the animal organism as an intermediate product of protein metabolism. These investigators found that when monochlorbenzene or monobrombenzene was administered by the mouth to a dog there appeared

24 Zeitschrift für physiologische Chemie, 1879, vol. iii, p. 159. See also Marriott and Wolf: Biochemische Zeitschr., 1907, vii, p. 213.

${ }_{25}$ Berichte der deutschen chemischen Gesellschaft, 1879, vol. xii, 1093. 
in the urine of the animal a compound known as a mercapturic acid, which is excreted in combination with glycuronic acid. The process which leads to the formation of the mercapturic acid may be classed among the chemical protective processes, cystein being taken into combination with the halogen-benzene, just as glycocoll combines with benzoic acid to form hippuric acid. Mester ${ }^{26}$ afterwards found that when a halogen benzene was taken by a man hardly any excretion of mercapturic acid resulted. When it was shown that the rational formula of cystin required revision the force of this evidence was apparently destroyed, supposing that the formula of the mercapturic acid as given by Baumann were correct; but Friedmann ${ }^{27}$ followed up his work on cystin itself by a reinvestigation of the mercapturic acids, and showed that their formulæ also required correction in a similar sense. Consequently the excretion of mercapturic acid by dogs after the administration of halogen-benzene was reinstated as a true experimental cystinuria, such as Baumann and Jaffe originally believed it to be.

Of the cystin formed in the breaking down of proteins within the body, a portion, which has been estimated at some 30 per cent. of the total amount, is set apart for the formation of taurin, which is found in the bile in combination with cholalic acid,

28 Zeitschrift für physiologische Chemie, 1890, vol. xiv, p. 109.

27 Hofmeister's Beiträge zur chemischen Physiologie und Pathologie, 1903, vol. iv, p. 486. 
as taurocholic acid. Taurin stands in a simple chemical relationship to cystin as the following formulæ show :-

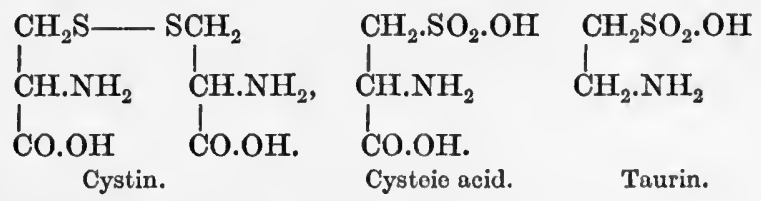

and it has actually been obtained from it, in vitro, by Friedmann. ${ }^{28}$ It is obvious that the cystin destined to follow this metabolic path must be set apart at a very early stage of catabolism, before either the sulphur atom or the amino-group has been removed, and there is evidence that the removal of both of these is early effected.

The question whether the taurin, as such, combines directly with cholalic acid to form taurocholic acid, or whether the combination first occurs with cystin itself or with some other precursor of taurin, taurocholic acid being afterwards produced by oxidation, is still an open one. In favour of the latter view may be quoted an observation made by L. Blum ${ }^{29}$ that when cystin is injected into the portal circulation of an animal with a biliary fistula the sulphur of the bile is thereby increased, but that the additional sulphur is neither in the form of cystin nor in that of taurin.

It seems probable that the formation of taurocholic acid is not limited merely by the quantities

${ }^{28}$ Hofmeister's Beiträge zur chemischen Physiologie und Pathologie, 1903, vol. iii, p. 1.

29 Ibid., 1904, vol. v, p. 1. 
of cystin and cholalic acid available, although these factors appear to play a part. Thus von Bergmann ${ }^{30}$ found that when cystin is given by the mouth to a dog with a biliary fistula the taurocholic acid of its bile is not appreciably increased, whereas if cholalic acid be administered at the same time a conspicuous increase is obtained. On the other hand, sodium cholate when given alone caused an obvious but transitory increase of taurocholic acid. This suggests that no excess of cholalic acid is available in the canine organism, but that an excess of cystin is available which is, however, quickly exhausted. Only when an excess of both cystin and cholalic acid were swallowed was taurocholic acid continuously formed in abnormal quantities. In rabbits, on the other hand, as Wohlgemuth ${ }^{31}$ found, the administration of cystin alone suffices to cause an increased formation of taurocholic acid. Rothera has shown that in man the administration of cholalic acid alone, or of this acid and of cystin together, does not bring about any decrease of the sulphates of the urine such as might be expected to result if an excess of taurin were formed, always supposing that the taurin fraction finally appears in the urine as neutral sulphur. When cystin was swallowed with cholalic acid it was burnt completely to sulphate, just as was the case when no cholalic acid was given with

so Hofmeister's Beiträge zur chemischen Physiologie und Pathologie, 1903, vol. iv, p. 192.

${ }^{31}$ Zeitschrift für physiologische Chemie, 1903, vol. xl, p. 81 . 


\section{INBORN ERRORS OF METABOLISM}

it. Goldmann's 32 investigations leave no doubt that the excretion of mercapturic acid, which follows the administration of halogen-benzenes to dogs, is at the expense of the sulphates of the urine and not at that of the neutral sulphur. In other words, the cystin which is in combination in the mercapturic acid is some of that which in ordinary circumstances would have been fully burnt to sulphuric acid. However, Blum ${ }^{33}$ states that when an experimental cystinuria is induced in dogs with biliary fistulæ, presumably by the halogen-benzene method, although this is not stated, the taurin disappears almost completely from their bile, and this would suggest that the mercapturic cystin is that which ordinarily goes to form taurin. If this be so the inference is not to be avoided that under normal conditions the sulphur of taurin is mainly excreted as sulphate. However, there is not a little evidence which points in a contrary direction and which tends to show that the taurin sulphur is excreted as neutral sulphur. Thus Salkowski ${ }^{34}$ found that in dogs, and in man also, taurin introduced into the stomach does not increase the output of sulphates, but is largely excreted as taurin-carbamic acid. In rabbits, on the other hand, and probably in the vegetivora in general, the administration of taurin by the mouth leads to an increase of the urinary sulphates. Kunkel's ${ }^{35}$

${ }^{32}$ Zeitschrift für physiologische Chemie,1885, vol. ix, p. 260.

${ }^{33}$ La Semaine Médicale, 1906, vol. xxvi, p. 554.

34 Virchow's Archiv, 1877, vol. lviii, p. 460.

${ }^{35}$ Archiv für die gesammte Physiologie (Pflüger's), 1877, vol. xiv, p. 344. 
observation, that the establishment of a biliary fistula in a dog, and the withdrawal of bile from the alimentary canal, conspicuously diminished the neutral sulphur in the animal's urine, points in the same direction, but Kunkel himself declines to base any generalization upon an experiment upon a single dog. The question of the ultimate fate of the sulphur which goes to form taurin is clearly one which calls for further investigation.

It is found that when cystin itself is introduced into the stomach of animals, even in very large doses, no unchanged cystin is excreted in their urine. In addition to an increase of the sulphates an increase of neutral sulphur has been observed in animals so treated, and this has been largely in the form of thio-sulphates, which are probably formed by the decomposition of cystin in the intestine, and thence absorbed. When doses of a few grammes of cystin are swallowed by a normal man the cystin is wholly burnt to sulphate and no increase of the neutral sulphur has been observed. ${ }^{36}$ Polypeptides containing cystin, such as di-alanyl-cystin and di-leucyl-cystin, were found by Abderhalden and Samuely 37 to be dealt with by normal man in the same way as free cystin is. By injecting cystin into the systemic veins of animals L. Blum ${ }^{38}$ caused cystin to appear in their urine,

36 Rothera : loc. cit., sub. 14.

${ }^{37}$ Zeitschrift für physiologische Chemie, 1905, vol. xlvi, p. 187.

${ }^{38}$ Hofmeister's Beiträge zür chemischen Physiologie und Pathologie, 1904, vol. v, p. 1. 
but when the injection was made into the branches of the portal vein it was apparently destroyed in the liver and no cystinuria resulted. However neither Blum, nor Rothera, ${ }^{39}$ who also tried the experiment, was able to bring about the destruction of cystin by adding it to crushed hepatic tissue. Obviously the whole of the cystin ingested in protein foods, as distinguished from that derived from the tissues, is not burnt straightway to sulphates and excreted as such. Some, as we have seen, is probably utilized in the formation of taurin, and some must eseape direct destruction and be built up into the tissue proteins, the cystin content of which must necessarily be maintained.

We may now turn to the consideration of the derangement of sulphur metabolism in cystinuria, in virtue of which the subjects of that anomaly excrete some part of their cystin as such in their urine, often to their serious disadvantage. That cystinuria is less rare than alkaptonuria I am convinced, although I cannot bring forward any statistical evidence in support of this statement, which is based upon personal experience acquired during a search for examples of both anomalies during the past ten years. That a far larger number of cases of cystinuria than of alkaptonuria are on record counts for little, for the former has been known for well-nigh a century, whereas our knowledge of the latter does not extend back more than sixty years. Moreover, the surgical consequences of cystinuria are such as compel

30 Loc. cit., sub. 14. 
attention. To the greater frequency of the condition in males than in females, a characteristic which it shares with other inborn chemical errors; to the evidence of its congenital occurrence and its persistence, and to its so frequent transmission from generation to generation in a family, I referred at some length in Chapter I.

The liability to the formation of calculi composed of cystin, and to other urinary disorders such as cystitis, gives to cystinuria a practical as well as a theoretical importance, as its study may possibly lead to the discovery of some means of averting its evil consequences. It may even happen that cystin is deposited in crystalline form in the organs and tissues of a cystinuric, as sodium biurate is in those of a victim of gout. Only one case of the kind is as yet on record. An infant, described by Abderhalden, ${ }^{40}$ died at the age of twenty-one months with symptoms of inanition. The child was one of a family which included a number of cystinurics. At the necropsy the internal organs showed innumerable white specks, visible to the naked eye, which were found to be deposits of cystin. From the spleen cystin was readily extracted by ammonia, and was deposited from the solution in hexagonal plates, the nature of which was fully confirmed by chemical methods. In the few other available records of post-mortem examinations of cystinurics no mention is made of such deposits in the tissues.

The urine of cystinurics has been described by

${ }^{40}$ Zeitschrift für physiologische Chemie, 1903, vol. xxxviii, p. 557. 
Golding Bird and others ${ }^{41}$ as possessing an odour not unlike that of sweetbriar and as assuming a greenish tint on standing; and acquiring an odour like that of putrid cabbage when decomposition sets in. Golding Bird cven described one specimen which assumed a bright apple-green tint. I cannot say that $I$ have ever noticed a smell rccalling that of sweetbriar from such urines nor any distinctly green tint, but the odour of sulphuretted hydrogen which is given off in decomposition is sufficiently obvious. The deposits of crystalline cystin which are thrown down from such urines are not very abundant, but may often be seen with the naked eye to consist of glancing crystals. Under the microscope these appear as hexagonal plates, the edges of which usually show paired inequalities of length. Hexagons of different sizes are often superposed upon each other, and with the plates longer or shorter hexagonal prisms are occasionally intermixed. In some specimens the crystals show a radiating striation and jagged edges, but they still retain roughly hexagonal forms. Fresh crystals are deposited after the urine has been passed, especially on addition of acetic acid, and Delépine ${ }^{42}$ came to the conclusion that, in a case which he investigated, their deposition was favoured by the presence of an organism, probably one of the blastomycetes, which could be separated by filtration. No confirmation of this has yet come from other observers.

${ }^{11}$ Urinary Deposits, London, 1851, p. 181.

42 Proceedings of the Royal Society, 1890, vol. xlvii, p. 198. 
The solubility of cystin in ammonia affords a ready means of identifying the crystals, which are insoluble in acetic acid. In case of doubt the following test may be applied, which was described by Wollaston in his original paper on Cystic Oxide. Some crystals are dried upon a glass slide and covered with a cover-slip. A drop of strong hydrochloric acid is then allowed to flow over the deposit, and as each crystal is bathed in the acid there springs from it a stellate cluster of delicate prisms, which grow rapidly under the eye and which are composed of cystin hydrochlorate. If now a drop of water be allowed to dilute the acid the prisms melt away as rapidly as they were formed. The urinary crystals which are most likely to be mistaken for the hexagons of cystin are the almost colourless plates of uric acid which are sometimes deposited from feebly pigmented urines, and which may assume roughly hexagonal forms.

The cessation of deposits must not be taken as evidence that a patient has ceased to excrete cystin, for when no crystals are found in the untreated urine, and especially in such as is alkaline in reaction, the addition of acetic acid may cause their deposition. Even in acid urine cystin is by no means insoluble. However, there is reason to believe that the excretion of cystin may be actually suspended, at least for a time. Thus Loewy and Neuberg ${ }^{43}$ failed to detect any, either as sediment or in solution, in the urine of a medical man who had undoubtedly been cystinuric at a former period,

* Biochemische Zeitschrift, 1907, vol. ii, p. 438. 


\section{INBORN ERRORS OF METABOLISM}

and Lewis and Simon ${ }^{44}$ have described a case in which eystin could no longer be found although cadaverin was isolated from the urine. It is noteworthy that in both cases the urine yielded hydrogen sulphide very readily, and this was attributed by Loewy and Neuberg to an excessive output of neutral sulphur. This suggests that possibly the error of sulphur metabolism persists, although the form of its manifestation is changed, and that in such cases some other intermediate product than cystin itself may come to excretion. It may be hoped that further investigations will throw fresh light upon such intermittent or temporary cystinuria. In some of the records of temporary cystinuria the evidence adduced does not suffice to establish a fact of so much importance.

In the fæces of cystinurics no cystin can be found. Dewar and Gamgee ${ }^{45}$ state positively that cystin is present in the sweat in some cases, and that silver coins carried in the pockets of the patients are apt to become blackened. In a single case, in which I examined some collected sweat,'I failed to find any evidence of the presence of cystin therein.

The error of metabolism of which cystinuria is a manifestation is clearly a far more complcx one than that which underlies alkaptonuria, and far less uniform in character. Although the excretion of cystin in the urine is apparently a constant fea-

44 American Journal of the Medical Sciences, 1902, vol. cxxiii, p. 838.

45 Journal of Anatomy and Physiology, 1871, vol. v, p. 142 . 
ture, and is that by which it has hitherto always been recognized, cystin is by no means the only protein fraction which is implicated and in some cases other amino-acids or their derivatives are to be found in the urine. The commonest of these are the diamines cadaverin and putrescin, which stand in intimate chemical relationship to the diamino-acids lysin and ornithin respectively, of which the former is a primary constituent of the protein molecule, whilst the latter enters into the composition of another such fraction, arginin. More rarely leucin and tyrosin are excreted unchanged, and it is probable that other amino-acids, less easily detected, will be found to be excreted in some cases. Thus it comes about that cases of cystinuria differ widely among themselves, not only in the number of protein fractions which are implicated but also in their behaviour as regards the individual fractions, so that what is true of one cystinuric may be quite untrue of another.

The cases hitherto investigated admit of classification upon the following lines: 1. In some no diamines and no primary protein fractions other than cystin have been found in the urine. 2. In some the urine has contained cadaverin or putrescin or both, in addition to cystin, but the excretion of diamines is apt to occur in an intermittent manner. 3. In a very few cases leucin or tyrosin or both have been excreted with or without diamines. 4. In a single case, that of Loewy and Neuberg, ${ }^{46}$ $₫ 6$ Zeitschrift für physiologische Chemie, 1904, vol. xliii, p. 338. 


\section{INBORN ERRORS OF METABOLISM}

cystin was present in the urine, but no diamine, leucin, or tyrosin. When diamino-acids were given by the mouth the patient excreted the corresponding diamines, and when tyrosin and aspartic acid were given these were excreted unchanged. In other cases, in which similar feeding experiments have been tried, no such results have followed the swallowing of diamino- or monamino-acids, and this patient was also exceptional in his method of dealing with cystin introduced by the mouth.

The investigation of the pathogeny of cystinuria has been greatly impeded by the lack of a simple and reliable method for the estimation of cystin in urine, and the methods employed by different observers have been of very different values. The naphthalene-sulphon-chloride method employed by Abderhalden 47 is not easy of application. Concentration of the urine under reduced pressure, with the addition of acetic acid, gives results which are presumably reliable, and J. Gaskell's ${ }^{48}$ method, recently described, in which the deposition of cystin is aided by the addition of acetone to the urine acidified with acetic acid, is easily carried out and is satisfactory, save for the detection of very small quantitative variations, in connexion with which the degree of dilution of the urine has a disturbing effect upon the results. The mere addition of acetic acid, without concentration, does not suffice, for, as with Heintz's old method of estimating uric acid, the results obtained are capricious and quite unre-

47 Loc. cit., sub. 40.

48 Loc. cit., sub. 16. 
liable. The method of Mester, ${ }^{49}$ which has been extensively employed, is based upon the assumption that an increase of the ratio of neutral sulphur to total sulphur, beyond the average ratio for normal urines, is due to cystin excreted as such. The objections to this indirect method are obvious, in view of the conspicuous effect of diet upon the excretion of sulphates, although, as has been already pointed out, the output of neutral sulphur is little affected by the amount of protein in the food. Alsberg and Folin ${ }^{50}$ adopt a different plan of reckoning, by which any increase of neutral sulphur above the average normal output, which they estimate at a lower figure than most other observers, is reckoned as cystin sulphur. This plan avoids the error due to fluctuations of the sulphate excretion, but involves the assumptions that the cystin is excreted wholly at the expense of the sulphates, the normal neutral sulphur remaining intact, and also that the increase of neutral sulphur is wholly in the form of cystin.

As regards the disturbance of sulphur metabolism in cystinuria it is at least certain that only a portion of the total cystin of the proteins broken down is excreted as such, and that the error is in no sense complete. Cystinurics always excrete sulphates, and neutral sulphur other than that contained in the cystin. In no single recorded instance has any approach been made to a maximal excretion, which

49 Loc. cit., sub. 26.

so American Journal of Physiology, 1905, vol. xiv., p. 54. 


\section{INBORN ERRORS OF METABOLISM}

would attain to some five grammes per diem. The figures for the average daily output given by different observers have been obtained by methods of very different degrees of reliability, but if the various records are compared, and especially if one has had opportunities of personal study of a series of cases, it is borne in upon one as highly probable that the excretion of cystin in different cases makes some approach to uniformity, and that it averages some 0.3 to 0.5 gramme in the twenty-four hours.

The figures included in the following table are collected from the published records and from the notes of several cases which have recently been investigated by $\mathrm{T}$. $\mathrm{S}$. Hele ${ }^{51}$ in the laboratory under my charge at St. Bartholomew's Hospital. In most instances averages have been calculated from the published figures, and in Caracciolo's case the amount of cystin has been worked out by Mester's method from the figures given in his paper.

It would be unwise to lay too much stress upon the uniformity of many of the figures in view of the differences in the methods employed and their unequal values, but the figures are certainly suggestive, and with the more satisfactory methods of estimation there is more uniformity of results. As regards the large excretion estimated by Mester in his case it may be mentioned that in one of Hele's cases Mester's method of estimation gives an out-

51 I am much indebted to Mr. Helo for allowing me to make use of these and other unpublished figures from his work. See epitome, Brit. Med. Jour.. 1908, vol. i (supplement), p. 440 . 


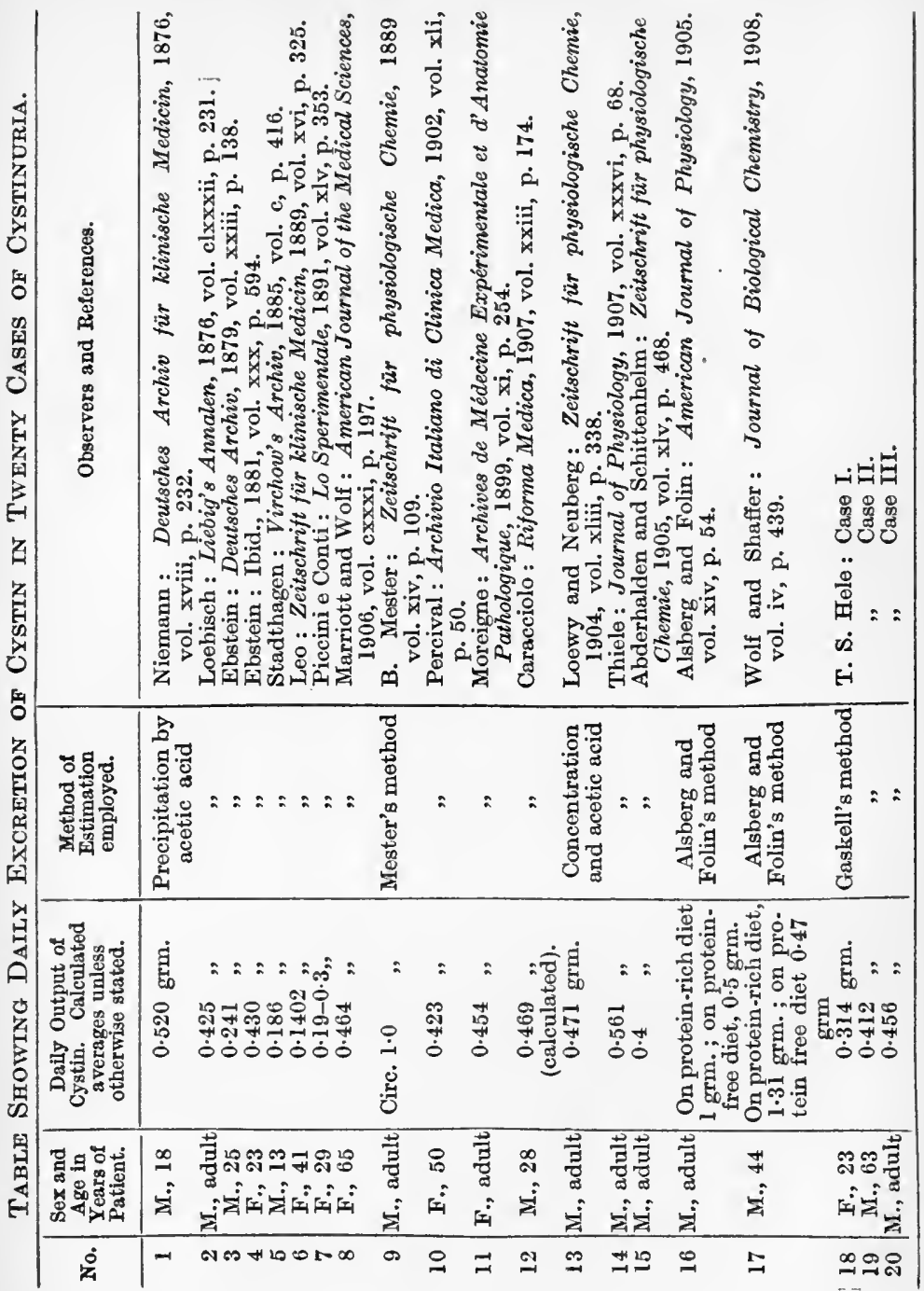




\section{INBORN ERRORS OF METABOLISM}

put of about one gramme. If further work with reliable methods should show that the uniformity here foreshadowed is an actual fact, and that the quantity of cystin excreted in different cases of cystinuria does not exceed a certain limit, one would be driven to suppose that some definite fraction of the cystin of the proteins broken down escapes its usual fate-such a fraction, for example, as is normally diverted to the formation of taurin.

There is a consensus of opinion among those who have worked at the subject that the unchanged cystin is excreted at the expense of the sulphates rather than at that of the neutral sulphur. The high ratios of neutral sulphur to total sulphur in the urine of cystinurics, which far exceed the normal ratios, bear witness to this, and it is upon the assumption that the neutral sulphur is not implicated that the indirect methods of estimating cystin suggested by Mester and by Alsberg and Folin are based. That the output of sulphates is diminished is a fact which is established beyond question, but the immunity of the normal neutral sulphur does not appear to me to be so well established. Loewy and Neuberg obtained in their case normal values for the neutral sulphur after removal of cystin by concentration of the urine acidified with acetic acid, but Thiele ${ }^{52}$ who employed the same method for the removal of cystin, obtained unduly high values of neutral sulphur after its removal. In a few cases in which cystin excretion has ceased, or nearly

62 Journal of Physiology, 1907, vol. xxxvi, p. 68. 
ceased, for a time, the excretion of neutral sulphur has remained much above the normal. This was so in Loewy and Neuberg's second case and the ready formation of hydrogen sulphide in the case recorded by Lewis and Simon suggests that the same was true for it. Bödtker ${ }^{53}$ also obtained ratios of neutral to total sulphur as high as in any investigated case of cystinuria, when the urine of his patient no longer deposited cystin, even with acetic acid, and when the presence thereof could only be detected by benzoylation after concentration of the urine. Unless we are prepared to admit that precipitation methods may wholly fail, even when cystin is abundantly present in urine, the inference cannot be avoided that under certain condition cystinurics excrete a sulphur compound which is not free cystin but a compound or unoxidized derivative thereof. If this be so, estimations of cystin cannot be safely based upon variations, either relative or absolute, of the neutral sulphur.

The next question which calls for discussionnamely, whether or no the excretion of cystin is influenced by the amount of protein in the dietis one of much interest but which cannot yet be regarded as definitely settled. That the output is in part endogenous and derived from the tissue proteins cannot be doubted, for Alsberg and Folin found cystin in the urine of their patient after he had been for thirteen days upon a diet which was practically protein-free. They found, however,

53 Zeitschrift für physiologische Chemie, 1905, vol. xlv, p. 393. 


\section{INBORN ERRORS OF METABOLISM}

that, although the ratio of neutral to total sulphur was naturally far higher on a protein-free diet, the actual quantity of neutral sulphur excreted was considerably greater on a diet rich in protein. As the excretion of neutral sulphur remains almost constant in normal individuals, even on such extremes of dietary, they infer that the increase was in the form of cystin and that the output of that substance, which averaged 0.5 gramme on a nitrogen-free diet, rose to 1 gramme on one rich in protein. In support of this view they adduee the fact that whereas upon the latter diet there was an abundant deposit of crystals, these almost ceased to be deposited when protein was withheld. Wolf and Schaffer ${ }^{54}$ have obtained results which are in complete accord with those of Alsberg and Folin. With a high protein diet, and an exeretion of 14.63 grammes of nitrogen in the urine, the cystin as estimated by the increase of neutral sulphur amounted to 1.31 grammes on an average. With an output of 3.53 grammes of nitrogen the eystin fell to 0.47 gramme. They also observed a greatly increased deposition of crystalline eystin when a diet rieh in protein was taken. Thiele, 55 whose observations were unavoidably restrieted to isolated days, and are therefore open to the objection that an unequal rate of excretion of nitrogen and sulphur such as indicated by the results of other observers, may come into play, concluded that the output of cystin

\$ Journal of Biological Chemistry, 1908, iv, 444.

85 Loc. cit., sub. 52. 
by his patient was not affected by the nature of the food taken. The cystin extracted by concentration and addition of acetic acid hardly varied in amount on a day of complete abstinence from food, on account of an operation, with a nitrogen excretion of 5 grammes, on a day of diet poor in protein on which 9 grammes of nitrogen were excreted, and on one of protein-rich diet on which the nitrogen amounted to 17.29 grammes. Moreover, the residual neutral sulphur, excluding that of the separated cystin, showed very slight variations, amounting to 0.359 gramme $\mathrm{SO}_{3}$ on the fasting day and to 0.428 on that of protein-rich diet. Abderhalden and Schittenhelm ${ }^{56}$ give two estimations of cystin by the same method in a case described by them. With an excretion of $16 \cdot 6$ grammes of nitrogen the extracted cystin amounted to 0.31 gramme, with 12 grammes of nitrogen to 0.42 gramme. Of earlier observers Leo and Mester expressed the belief that the excretion of cystin in cystinuria is not influenced by diet. In a case under my care, which was investigated by Hele, it was not possible to give any extremes of diet and the capricious appetite of the patient even prevented the maintenance of a constant scale of feeding, but the results obtained in observations extending over series of days, pointed to a scanty augmentation of cystin, as extracted by Gaskell's method, and also of neutral sulphur, when the protein of the food was increased.

" Zeitschrift für physiologische Chemie, 1905, vol. xlv, p. 468 . 


\section{INBORN ERRORS OF METABOLISM}

In another case which Hele investigated the neutral sulphur of the urine rose slightly when protein food was increased. However the rise was small and not proportional to the large rise of oxidized sulphur.

If the excretion of cystin were directly dependent upon the breaking down of food and tissue protcins

alike the ratio $\frac{\text { cystin }}{\text { nitrogen }}$, the $\mathrm{C}: \mathrm{N}$ ratio, should not vary with the quantities of the same proteins taken, but only with the quality of the food proteins -i.e. their richness or poorness in the cystin fraction. In other words, it should behave as does the $\mathrm{H}: \mathrm{N}$ ratio in alkaptonuria. If, on the other hand, the output of cystin be independent of, or only slightly influenced by, the amount of protein in the food the $\mathrm{C}: \mathrm{N}$ ratio should fall conspicuously as the protein food is increased, seeing that the nitrogen will be increased thereby but not the cystin.

The following table, calculated from the figures recorded for a number of cases of cystinuria, shows that such a variation of the ratio is constantly observed, but it is not possible to say how far this is due to differences in the quality rather than in the quantity of the proteins taken. The very unequal variations in different cases suggest that qualitative differences may have had an important share in bringing about the results. 
Table Showing Variations of the C : N Ratio in CYSTINURIA.

\begin{tabular}{|c|c|c|c|}
\hline $\begin{array}{l}\text { Names of } \\
\text { Observers. }\end{array}$ & $\begin{array}{l}\text { Total } N \text { in } 24 \\
\text { Hours. }\end{array}$ & $\begin{array}{l}\mathrm{C}: \mathrm{N} \\
\text { Ratio. }\end{array}$ & $\begin{array}{l}\text { Method of Esti- } \\
\text { mating Cystin. }\end{array}$ \\
\hline Moreigne . & $\begin{array}{l}\text { grm. } \\
\left\{\begin{array}{c}4 \cdot 13 \\
16 \cdot 8\end{array}\right.\end{array}$ & $\left.\begin{array}{ll}7 \cdot 4 & : 100 \\
4 \cdot 8 & : 100\end{array}\right\}$ & Mester's method. \\
\hline Percival. . & $\left\{\begin{array}{c}3 \cdot 98 \\
15 \cdot 1\end{array}\right.$ & $\left.\begin{array}{ll}5 \cdot 9 & : 100 \\
3 \cdot 1 & : 100\end{array}\right\}$ & ", $\quad "$ \\
\hline $\begin{array}{l}\text { Alsberg and } \\
\text { Folin . }\end{array}$ & $\left\{\begin{array}{l}\text { Mean } 5 \cdot 19 \\
\text { Mean 14.84 }\end{array}\right.$ & $\left.\begin{array}{l}9 \cdot 6: 100 \\
6 \cdot 7: 100\end{array}\right\}$ & $\begin{array}{l}\text { Absolute increaso } \\
\text { of noutral sul- } \\
\text { phur above } \\
\text { normal average }\end{array}$ \\
\hline $\begin{array}{l}\text { Wolf and } \\
\text { Shaffer }\end{array}$ & $\left\{\begin{array}{r}\text { Mean } 3 \cdot 53 \\
14 \cdot 63\end{array}\right.$ & $\left.\begin{array}{rl}13 \cdot 3 & : 100 \\
8 \cdot 9 & : 100\end{array}\right\}$ & 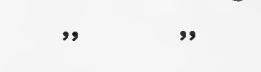 \\
\hline $\begin{array}{l}\text { Abderhalden } \\
\text { and Schit- } \\
\text { tenhelm }\end{array}$ & $\left\{\begin{array}{l}12 \cdot 0 \\
16 \cdot 6\end{array}\right.$ & $\left.\begin{array}{l}3 \cdot 3: 100 \\
1 \cdot 08: 100\end{array}\right\}$ & $\begin{array}{l}\text { Concentration } \\
\text { and acetic acid. }\end{array}$ \\
\hline Thiele . & $\left\{\begin{array}{c}5 \cdot 15 \\
9 \cdot 1 \\
17 \cdot 29\end{array}\right.$ & $\left.\begin{array}{c}9 \cdot 4: 100 \\
6 \cdot 2: 100 \\
2 \cdot 9: 100\end{array}\right\}$ & $\begin{array}{l}\text { Concentration } \\
\text { and acetic acid. }\end{array}$ \\
\hline Hele : Case I & $\left\{\begin{array}{r}4 \cdot 30 \\
11 \cdot 16\end{array}\right.$ & $\left.\begin{array}{l}5 \cdot 2: 100 \\
4 \cdot 2: 100\end{array}\right\}$ & Gaskell's method. \\
\hline " Case II & $\left\{\begin{array}{r}6 \cdot 52 \\
16 \cdot 90\end{array}\right.$ & $\left.\begin{array}{l}5 \cdot 52: 100 \\
3 \cdot 37: 100\end{array}\right\}$ & $"$ \\
\hline
\end{tabular}

Even in Alsberg and Folin's and Wolf and Shaffer's cases the $\mathrm{C}: \mathrm{N}$ ratio was higher on a nitrogen-free diet, which shows that even if the increase of neutral sulphur was all due to increase of cystin this increase was not proportional to the amount of protein added to the diet. Although it is evident that, in some cases at least, the excretion of neutral sulphur by cystinurics is largely influenced by the amount of protein in the diet, the final proof is still wanting of a conspicuously increased output of cystin, as such, upon a diet rich in protein. 


\section{INBORN ERRORS OF METABOLISM}

Some observers ${ }^{57}$ have noted differences in the quantities of cystin in the day and night urines respectively, but their results have been contradictory, and Hele was unable to find any constant difference in the cases which he investigated. In one of Hele's cases the rate of excretion of neutral sulphur was very constant during the day and night, whereas that of nitrogen and oxidized sulphur underwent great variations.

Much interest attaches to the effects of the administration of cystin, as such, to cystinurics. As we have seen, a normal man burns cystin so given to sulphate, and Alsberg and Folin found that their patient behaved in this respect as does a normal man. Two doses of cystin, obtained by hydrolysis of hair, amounting to 1.2 and 6 grammes respectively, were given by the mouth at different times. The neutral sulphur output was unchanged and the increased excretion of sulphur was wholly as sulphates. In one of our cases Hele obtained a similar result from the administration of 5 grammes of cystin from hair. Thiele gave $4 \cdot 6$ grammes of the patient's own cystin thoroughly purified. The cystin excreted was estimated by concentration of the urine and addition of acetic acid, and showed no increase worthy of mention. The quantities for the day before the cystin day, for the cystin day

37 Beale: Kidney Diseases, Urinary Deposits, and Calculous Disorders, third edition, 1869, p. 385. Ebstein : Deutsches Archiv, 1881, vol. xxx, p. 504. Piccini o Conti : Io Sperimentale, 1891, vol. xlv, p. 353. Bartels : Virchow's Archiv, 1863, vol. xxvi, p. 419. 
itself, and for the day following were $0.577,0.604$, and 0.561 gramme respectively. However, on the cystin day there was a very conspicuous increase of neutral sulphur as well as of sulphate, and the total increase of sulphur of both kinds corresponded to 3.526 grammes of cystin, of which increase 35 per cent. was in the form of neutral sulphur. It will be remembered that in this case the output of neutral sulphur, above the normal, was always higher than was accounted for by the cystin extracted from the urine. On Alsberg and Folin's reckoning this patient would have been taken as having excreted some of the cystin given as such. In Loewy and Neuberg's case, which stands wholly apart from all others hitherto investigated, the administration of cystin by the mouth produced far more remarkable results. When 5 grammes of cystin from hair were so taken the excreted cystin, estimated, as in Thiele's case, by concentration with acetic acid, rose from 0.388 gramme per diem to 7.04 grammes in the collected urine of the three days following the administration, an increase which corresponds to the whole of the cystin swallowed. In other words, this cystinuric was quite unable to burn protein cystin given by the mouth, and simply added it to his ordinary daily output. Whether increase of protein food influenced the excretion in this case we are not told. Still more extraordinary was the result when cystin obtained from a calculus was given. The taking of 3.52 grammes of this material caused no increase of cystin in the urine, but there resulted a conspicu- 


\section{INBORN ERRORS OF METABOLISM}

ous increase of the neutral sulphur, mainly in the form of thio-sulphate. Why cystin obtained from hair and from a calculus respectively should have been dealt with in such wholly different ways by this patient remains a mystery, no solution of which can be suggested unless these authors are right in regarding them as different substances. The excretion of thio-sulphate suggests the possibility that some of the cystin taken by the mouth may sometimes undergo decomposition in the intestine, and that this may account for the increase of neutral sulphur other than cystin in the urine, which has sometimes followed its administration.

The fact that in ordinary cases of cystinuria swallowed cystin is burned to sulphate, as by normal persons, certainly lends support to the view that the cystin which the patients excrete unchanged has its origin in the breaking down of the tissue proteins and not of those of the food. As Thiele showed, even the cystin which the patient himself has excreted can be dealt with, when it enters the organism by way of the alimentary canal. It is evident that, as the limitation of the error to a part only of the catabolized cystin also indicates, only a certain path of sulphur metabolism is interfered with in cystinuria. If this be so Loewy and Nouberg's patient must be the victim of a distinct anomaly from that manifested in ordinary cases, and as we shall see, there is much other evidence to support this view.

If it be established that the cystin of protein foods increases the urinary output of cystinurics, whereas 
cystin taken as such is fully burnt, it must be inferred that cystin is not absorbed as such from protein foods, but in some higher combination. This is in accord with Loewy and Neuberg's converse observation that their patient disposed of amino-acids given in proteins, whereas he excreted unchanged amino-acids given as such.

Wolf and Shaffer ${ }^{58}$ found that cystin and cystein subcutaneously injected into their patient caused a marked increase of neutral sulphur in the urine, and a smaller increase of sulphate sulphur. If the increase of neutral sulphur was, as they believe, in the form of cystin, this would indicate that the cystin or cystein injected was in part excreted as cystin and in part destroyed. It was at least shown that the patient had the power of oxidizing part of injected substance.

Before leaving the subject of the disturbance of sulphur metabolism in cystinuria certain observations upon the effects of administration of cholalic acid must be referred to.

Von Bergmann's observations upon the effects of such administration to dogs with biliary fistula suggested to Simon and Campbell, ${ }^{59}$ and independently to Alsberg, ${ }^{60}$ that the excretion of cystin in the urine might possibly be due to deficient formation of cholalic acid, and that the cystin set apart for the formation of taurocholic acid might on this account fail to be utilized and be excreted

"Loc cit., sub. 54, p. 452.

"Johns Hopkins Hospital Bulletin, 1904, vol. xv. p. 164.

- Journal of Medical Research, 1904, vol. xiii, p. 105. 


\section{INBORN ERRORS OF METABOLISM}

unchanged. If this were so the administration of cholalic acid should have the effect of restricting or of abolishing the output of urinary cystin. If it be the case that much of the neutral sulphur of urine is derived from taurin, the fact that cystinurics apparently excrete normal quantities of neutral sulphur in addition to cystin suggests that the formation of taurocholic acid is not interfered with.

Alsberg showed that when cholalic acid is administered to cats protein catabolism is increased, as is evidenced by an increased excretion of nitrogen, as well as of total sulphur, both in the form of neutral sulphur and of sulphate. Rothera ${ }^{61}$ found the same to be true for man, and the taking of cholalic acid by the mouth caused no diminution of the urinary sulphate, such as might be expected if the taurin fraction is excreted as neutral sulphur and the cholalic acid causes an increased formation of taurin.

There are obviously great difficulties in arriving at any definite conclusions as to the influence of cholalic acid upon taurocholic formation in the absence of a biliary fistula, and for this reason the observations of Simon and Campbell are not conclusive. They could obtain no evidence that in their cystinuric the taking of cholalic acid had any influence upon the output of cystin, but this was not estimated by any direct method and the fluctuations of the excretion of neutral sulphur during the period over which the observations extended were very wide, so that it is not easy to gauge the ${ }^{01}$ Loc. cit., sub. 54, p. 462. 
effect of the cholalic acid upon the ratio of neutral sulphur to sulphate.

All that we know of the pathology of cystinuria renders it highly improbable that the formation of cholalic acid is primarily at fault, but these observations are of special interest as embodying a rational attempt to influence by treatment a condition which may give rise to grave morbid events.

Wolf and Shaffer had the exceptional opportunity of investigating a case of cystinuria in which a biliary fistula existed after an operation for gall-stone. Unfortunately special difficulties were encountered in connexion with this case, and the results obtained were incomplete. However, they were able to show that the ratio of sulphur to nitrogen in the bile which came from the fistula lay within the normal limits, as indicated by comparison with the results obtained by Shaffer in another case of biliary fistula. The actual amounts of sulphur and nitrogen in the bile were greater than in that of the control subject. The administration of cystin by the mouth to the cystinuric patient appeared to increase the sulphur of the bile, and disturbed the $\mathrm{S}: \mathrm{N}$ ratio. No such observations on a non-cystinuric patient with a biliary fistula are available.

It was a remarkable feature of the case in question that shortly after the operation cystin disappeared from the urine, and the ratio of neutral to total sulphur, which had been very high, fell at the same time to within the normal limits. It is difficult to suppose that this event can have bcen connected 


\section{INBORN ERRORS OF METABOLISM}

with the drainage of the bile, but the coincidence was, at least, a remarkable one. Even when the cystin had disappeared from the urine the output of undetermined nitrogen therein remained very high.

As I have already pointed out, the excretion of cystin in the urine is, after all, only one of the manifestations of the metabolic anomaly which we know as cystinuria. Other protein fractions than cystin may also be implicated in the error, with the result that cadaverin and putrescin, leucin and tyrosin may be excreted side by side with cystin, but the consideration of these further aspects of the subjects must be deferred to a separate chapter. 


\section{CHAPTER V}

\section{Cystinuria (continued)}

THE foundation of the wider conception of cystinuria as an error of protein metabolism of which the excretion of cystin in the urine, although the most constant, is only one of the manifestations, was laid by Udranszky and Baumann ${ }^{1}$ in 1888 . These investigators found diamines, cadaverin and putrescin, both in the urine and fæces of a cystinuric patient under their observation; and the significance of this find was greatly enhanced when, shortly afterwards, Stadthagen and Brieger ${ }^{2}$ detected cadaverin in the urine of two other cystinurics. In Baumann's case the diamines were readily isolated from the urine of twenty-four hours by benzoylation in the presence of sodium hydrate, ${ }^{3}$

1 Zeitschrift für physiologische Chemie, 1889, vol. xiii, p. 562 .

2 Berliner klinische Wochenschrift, 1889, vol. xxvi, p. 344.

31,500 cubic centimetres of urine are shaken with 200 cubic centimetres of 10 per cent. sodium hydrate solution and from 20 to 25 cubic centimetres of benzoyl-chloride, till the smell of the last disappears. The precipitate is filtered off, washed, and treated with hot alcohol. The filtered alcoholic extract is thrown into excess of water. If diamines be present their benzoyl compounds will in a short time separate in minute crystals. The meltingpoint of benzoyl-cadaverin is $129^{\circ} \mathrm{C}$., that of benzoyl- 


\section{INBORN ERRORS OF METABOLISM}

and the daily yield varied between 0.2 and 0.4 gramme of benzoyl-diamines. The major part of the urinary diamine was cadaverin, whereas in the fæces putrescin was the more abundantly present. In 1893, when Garcia had the same patient under investigation, putrescin was alone found in the urine, but in 1897, nine years after their original discovery, both diamines were once more excreted as at first.

In no condition other than cystinuria have these diamines been found in urine in quantities which could be detected by the ordinary methods in the excretion of twenty-four hours. By evaporating down as much as 100 litres of normal urine Dombrowski ${ }^{5}$ was able to demonstrate the presence of traces of cadaverin therein, and after evaporation of large volumes of the urine of patients with pernicious anæmia William Hunter ${ }^{6}$ obtained small yields of benzoyl-diamines. Roos ${ }^{7}$ also found cadaverin in the fæces of a patient with dysentery and putrescin in those of a sufferer from cholera nostras, but the urine was not examined for dia-

putrescin $176^{\circ} \mathrm{C}$. Two other methods have been employed for the detection of diamines in urine-viz., the picric acid method of Stadthagen and Brieger (loc. cit., sub. 2) and the phenyl-isocyanate method of Loewy and Neuberg (Zeitschrift für physiologische Chemie, 1904, vol. xliii., p. 355.

- Zeitschrift für physiologische Chemie, 1893, vol. xvii, p. 577.

5 Archives Polonaises des Sciences biologiques et médicales, 1903 , vol. ii.

- Transactions of the Medical Society of London, 1890, vol. xiii, p. 386 .

7 Zeitschrift für physiologische Chemie, 1892, vol. xvi, p. 192. 
mines. During the past ten years I have myself benzoylated the urine of twenty-four hours of large numbers of patients suffering from various maladies, but such searches for diamines have invariably proved fruitless, save in cases of cystinuria.

Even in cystinuric cases the search for diamines in the urine and fæces is far from being uniformly successful. In a nümber of cases they have been found by Bödtker, ${ }^{8}$ C. E. Simon, Riegler, Marriott and Wolf, Thiele, Cammidge, Schölberg, and myself, but in others Cohn, ${ }^{9}$ Baumann, ${ }^{10}$ Alsberg and Folin, Loewy and Neuberg, Hurtley, Hele, and I have been unable to detect their presence, although in some instances the examinations were persisted with over considerable periods.

My own experience relates to nine cases of cystinuria. In four of these diamines were found in the urine at one time or another and in one in the fæces also ; in several cases no opportunity of examining the fæces presented itself. My impression is that the likelihood that diamines will be detected in any given specimen of cystin urine is comparatively small, but that if in any case the examination be continued over sufficiently long periods they are likely to be found eventually.

Of the two diamines cadaverin has been much

${ }^{8}$ Norsk Magazin for Lagevidenskaben, 1892, vol. liii, p. 1220; Zeitschrift für physiologische Chemie, 1905, vol. xlv, p. 393.

- Berliner klinische Wochenschrift, 1899, vol. xxxvi, p. 503.

10 Pfeiffer : Centralblatt für Krankheiten der Harn- und Sexual-Organe, 1897, vol. viii, p. 173. 


\section{INBORN ERRORS OF METABOLISM}

the more frequently found in the urine, whereas there is evidence that putrescin is more often present in the fæces. In no other case have cadaverin and putrescin, or either of them, been shown to be present so continuously, in quantities easy of detection, both in urine and fæces, as in the original one of Udranszky and Baumann; but even in that case the quantities and relative proportions of the diamines present varied considerably, and at one time they were almost absent from the urine for several days. In the case investigated by Cammidge and myself ${ }^{11}$ cadaverin was found in the urine of two days only out of 41 , and putrescin in the fæces at one of six examinations. In another case, in which specimens of urine were sent up to us in gallon jars, one such specimen was rich in cadaverin which was readily extracted by benzoylation from each separate fraction treated, but in no other sample from this patient was any diamine found. From the urine of yet a third patient Schölberg and I 12 got putrescin and cadaverin on several occasions, but five years later, when the same patient was under continuous observation for several weeks, Hurtley and $\mathrm{I}^{13}$ were uniformly unsuccessful in our search for diamines in his urine and fæces.

These results, taken in conjunction with those of other observers, indicate that in some cases of cystinuria the presence of diamines, in quantities which

11 Journal of Pathology and Bacteriology, 1900, vol. vi, p. 327.

12 The Lancet, 1901 , vol ii, p. 526.

13 Journal of Physiology, 1906, vol. xxxiv, p. 217. 
can be detected in the urine of twenty-four hours, is a very intermittent phenomenon which may only be manifested at long intervals. It is evident that it cannot safely be asserted that a given cystinuric never excretes them, even when they cannot be found in the urine for days or even weeks together. It is possible that the apparent intermittence is merely due to varying amounts, for a number of experiments, in which cadaverin was added to normal urine in different proportions, have convinced me that failure to detect diamines by the methods in use cannot be held to exclude their presence in quantities, small indeed, but much greater than the normal traces found by Dombrowski.

The substance known as cadaverin is pentamethylene-diamine, and putrescin is tetra-methylenediamine. They are two members of a series of such compounds, of which other members are known.
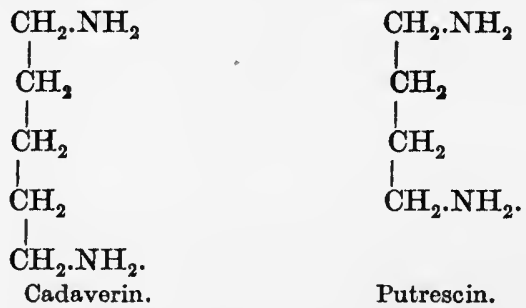

Cadaverin.

Putrescin.

An obvious explanation of the occurrence of these two particular members of the diamine series, both in the excreta of cystinurics and when proteins undergo decomposition under the influence of bacteria, is afforded by the fact that they are intimately related to two of the protein fractions, the diamine-acids lysin and ornithin. 


\section{INBORN ERRORS OF METABOLISM}

Lysin is converted into cadaverin by the elimination of carbon dioxide, and in like manner ornithin, which enters into the composition of the important protein fraction arginin, yields putrescin by a similar change.
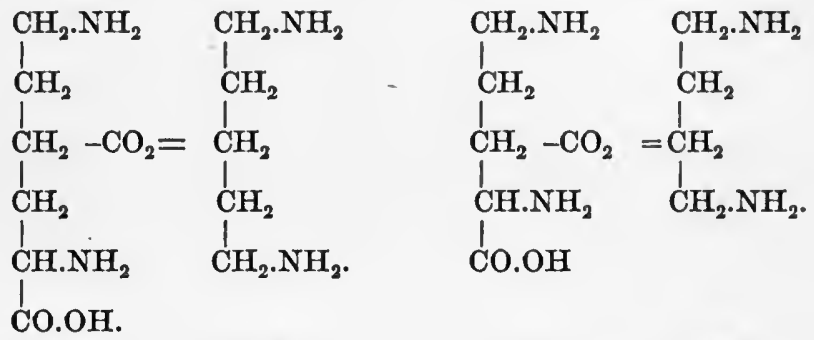

Lysin.

Cadaverin.

Ornithin.

Putrescin.

When Udranszky and Baumann wrote our knowledge of the structure of protein molecules was far more imperfect than it now is, and, as the known source of the diamines in question was the bacterial decomposition of proteins, they naturally suggested that their presence in the urine and fæces of cystinurics might result from a similar decomposition carried out in the alimentary canal, and that cystinuria itself was probably indirectly due to an intestinal infection. The absence of cystin from the fæces weighed strongly against its being itself a product of intestinal decomposition, but it was thought that the diamines thence absorbed might $i_{n}$ some way preserve the cystin from its usual fate. However, the administration of diamines to dogs was found not to produce cystinuria in them, intestinal disinfection was found to have no influence upon the excretion of cystin or diamines, and cul- 
tures from the fæces of cystinurics have failed to reveal the presence of abnormal bacteria having the power of forming diamines from proteins. In the absence of any positive evidence in its favour the infective theory of cystinuria, which at one time met with wide acceptance, has now been abandoned, and opinion has veered round to the view that the diamines which cystinurics excrete are themselves products of metabolism, derived from the lysin and arginin of proteins broken down in the organism, a view which was independently advanced by Moreigne $^{14}$ in France and by C. E. Simon ${ }^{15}$ in America.

This hypothesis receives very strong support from the observations of Loewy and Neuberg ${ }^{16}$ upon their exceptional patient already frequently referred to. Although no diamines could at ordinary times be detected in his urine, when lysin was administered to him by the mouth he excreted cadaverin in large quantities, and when arginin was so administered he excreted putrescin. In two other cases of cystinuria Hurtley and Hele and I ${ }^{17}$ could find no putrescin in the urine after the administration of 5-gramme doses of arginin carbonate, although one of the : patients had spontaneously excreted putrescin five years previously, sometimes

14 Archives de Médecine Expérimentale et d'Anatomie Pathologique, 1899, vol. xi, p. 254.

16 American Journal of the Medical Sciences, 1900, vol. cxix, p. 39.

10 Zeitschrift für physiologische Chemie, 1904, vol. xliii, p. 355 .

${ }_{11}$ Loo cit., sub. 13, p. 220. 


\section{INBORN ERRORS OF METABOLISM}

alone and sometimes in association with cadaverin. As we shall see, these results are fully in keeping with those obtained with other protein fractions in Loewy and Neuberg's case and other cases of cystinuria respectively.

It would be very interesting to know whether in Loewy and Neuberg's case the taking of diaminoacids by the mouth was followed by the appearance of diamines in the fæces as well as in the urine, for, although the diamines have comparatively seldom been found in the fæces of cystinurics their occurrence therein is beyond question, and if in cystinuria they are products of metabolism we must assume that they are in part excreted by way of the alimentary canal.

It does not necessarily follow that the diamines present in the fæces in cases of grave intestinal infection, such as Roos examined, have the same origin as those excreted in cystinuria, for it is quite possible that they are formed in the intestine by bacterial action, and even that the normal traces in urine have such an origin; but in.Udranszky and Baumann's case the abundant diamine yield from the fæces was undoubtedly connected with the urinary output, and with the underlying cystinuria, for diamines are not to be detected in normal fæces, and their patient had no intestinal disorder. It is worthy of note that, in the case at which Cammidge and I worked, the urine of the only day on which putrescin was found in the fæces yielded no diamine.

It is conceivable that the change from diaminoacids to diamines might occur after excretion, both 
in urine and fæces, but some observations which we have made on specimens of urine kept for considerable times lend no support to such a view. Specimens which yielded no diamine when fresh equally failed to yield any when kept, or even when decomposing. T. S. Hele allows me to quote the interesting fact, from his as yet unpublished results, that when he recently examined large specimens of urine from a cystinuric already referred to, who at one time excreted cadaverin, he failed to obtain, by the method employed by Wohlgemuth for their detection in cases of phosphorus poisoning, any evidence of the presence therein of lysin or arginin. There is therefore no evidence yet forthcoming to support the tempting hypothesis that diamino-acids are excreted as such by cystinurics.

Garcia ${ }^{18}$ thought that the excretion of diamines varied with the amount of protein in his patient's diet, and Thiele ${ }^{19}$ has recently expressed the same opinion. The latter observer obtained a far larger yield of benzoyl-cadaverin from the urine of a day of excessive meat diet than in that of a day of abstinence or of a diet rich in carbohydrates. However, his observations are too few to allow any definite conclusion to be drawn from them, seeing how widely the diamine excretion varies, apart from changes of diet. In the case which Cammidge and I investigated the diet of the days in which diamines were excreted did not differ from that of other days.

To sum up, the excretion of cadaverin and pu-

18 Loc. cit., sub. 4.

19 Journal of Physiology, 1907, vol. xxxvi, p. 68. 


\section{INBORN ERRORS OF METABOLISM}

trescin in some cases of cystinuria, both in the urine and fæces, in quantities such as have not been found in any other condition, is an established fact. The easier explanation which ascribes their presence to an intestinal infection offers no adequate explanation of their association with the excretion of cystin, and receives no support save from its inherent plausibility. The alternative theory, which regards the diaminuria as an outcome of the same error of metabolism as cystinuria, has much more in its favour, although it presents certain obvious difficulties, for other primary protein fractions besides cystin are undoubtedly present in the urine of some of the subjects of this anomaly.

Leucin and tyrosin have been found in several cystin urines. Thus in 1891 Piccini and Conti ${ }^{20}$ detected crystals of tyrosin, together with those of cystin and of uric acid, in the urinary sediment in their case. Percival ${ }^{21}$ speaks confidently of the presence of both leucin and tyrosin in small amounts in the urine of his cystinuric patient. Moreigne ${ }^{22}$ also described the presence of tyrosin, but the method which he recommends for its detection suggests that he mistook for crystals of that substance the prismatic crystals of cystin hydrochlorate. The presence of these amino-acids in the urine of one cystinuric at least has been established, beyond all possibility of doubt, by Abderhalden and Schitten-

20 Lo Sperimentale, 1891, vol. xlv, p. 353.

21 Archivio Italiano di Clinica Medica, 1902, vol. xli, p. 50 .

22 Loc. cit., sub. 14. 
helm, ${ }^{23}$ who extracted from the urine of their patient both tyrosin and leucin in considerable quantities, and fully proved their nature by the ultimate analysis of the tyrosin which separated after evaporation of the urine, and of the naphthalene-sulphonderivate of leucin obtained therefrom. Emil Fischer and Zuzuki ${ }^{24}$ also detected tyrosin in a cystin calculus. Leucin and tyrosin would appear to be far rarer constituents of such urines than are the diamines. In no case which I have had under observation have they been detected, although sought for. Millon's reagent lends valuable aid in the detection of tyrosin, for although all urines yield some pink colour with this reagent, even in the cold, the presence of tyrosin in any considerable quantity conspicuously intensifies the colour on heating. It may safely be concluded, indeed, that any urine which does not yield more than the normal reaction on heating with Millon's reagent does not contain tyrosin in appreciable amount. The urine of Loewy and Neuberg's patient contained no tyrosin, but when tyrosin was given to him by the mouth he excreted it unchanged and almost quantitatively. After a dose of 6.2 grammes of tyrosin no less than 4.82 grammes were recovered from the urine, and its nature was confirmed by ultimate analysis. On the other hand, C. E. Simon, ${ }^{25}$ Alsberg and Folin, ${ }^{26}$

${ }^{23}$ Zeitschrift für physiologische Chemie, 1905, vol. xlv, p. 468 .

${ }^{24}$ Ibid., 1905, vol. xlv, p. 405.

25 Zeitschrift für physiologische Chemie, 1905, vol. xlv, p. 357.

${ }^{26}$ American Journal of Physiology, 1905, vol. xiv, p. 54. 


\section{INBORN ERRORS OF METABOLISM}

Thiele, ${ }^{27}$ Hele, Hurtley, and I ${ }^{28}$ have failed to find any tyrosin in the urine of other cystinurics after the administration of similar doses. Hurtley and I obtained from the urine of our patient, on the days on which tyrosin was given, a benzoyl compound which melted at $253^{\circ} \mathrm{C}$. The yield was small and its nature has not been determined. Thiele obtained no such product by benzoylation of the urine of the tyrosin day in his case. Loewy and Neuberg also found that aspartic acid, another protein fraction, was excreted by their patient when administered by the mouth, but in Alsberg and Folin's case aspartic acid so given did not reappear in the urine. Hurtley and I obtained, on many occasions, on benzoylating the urine of our patient, small quantities of a benzoyl compound which, after repeated recrystallization from alcohol, melted at $205^{\circ} \mathrm{C}$. The collected yields amounted only to 0.22 gramme of substance, and a single analysis, which was alone possible, gave figures which suggested that it was probably the benzoyl compound of a derivative of tryptophane. However, we are not prepared to make any definite suggestion as to the nature of this substance, which we have not obtained from any other cystin urine.

The question arises whether the implication of the several protein fractions follows any definite sequence, according to the extent of the error, or whether, in different cases, now one and now another fraction is implicated. To this question no certain reply can yet be given. It may be that the excretion ${ }^{37}$ Loc. cit., sub. 19, ${ }^{28}$ Loc. cit., sub. 13, 
of cystin in all cases hitherto examined is due to the fact that it is by the presence of cystin in the urine that the anomaly has always been recognized hitherto; but the cystin fraction alone appears to escape destruction in so many of the cases that it is highly probable that it is the first to be involved in the error.

Not a few cystinurics have excreted cystin and diamines, but no leucin or tyrosin, but Percival, who found leucin and tyrosin in the urine of his patient, failed to detect any diamine, and Abderhalden and Schittenhelm make no mention of the presence of diamines in their case in which leucin and tyrosin were undoubtedly excreted. The evidence available suggests that the incidence of the error upon the several protein fractions is capricious, rather than that the amino- and diamino-acids are involved in any definite order.

The nitrogenous metabolism of cystinurics deviates from the normal in certain ways not fully explained. When diamines and amino-acids are present an excess of undetermined nitrogen in the urine-i.e., of nitrogen not contained in urea, uric acid, kreatinin, and ammonia-is to be expected, but Alsberg and Folin, and Wolf and Shaffer, whose observations upon this aspect of the subject are the most complete yet carried out, found an abnormally high nitrogenous residue, although the urine of their patients contained no diamine nor recognizable quantities of amino-acids other than cystin. This excess could not be ascribed to the small quantity of cystin excreted. Marriott and Wolf 


\section{INBORN ERRORS OF METABOLISM}

also found an excess of undetermined nitrogen, but their patient excreted diamine. Alsberg and Folin suggest that the excess of undetermined nitrogen in the urine in their case, which was conspicuously increased when cystin was given by the mouth, may have been due to an incomplete destruction of cystin, the sulphur of which was excreted as sulphate, whereas the nitrogen was apparently not eliminated in urea. Wolf and Shaffer are inclined to ascribe it to amino-acids, in quantities too small to be detected by the available methods, In their case with biliary fistula the proportion of undetermined nitrogen remained unduly high, even when cystin was no longer being excreted in the urine.

It will be clear, from all which has gone before, that we are still far from being in a position to formulate a satisfactory theory of cystinuria. Before this can be done it will be necessary to accumulate many more data by patient investigation of individual cases, and, above all, quantitative data. Obviously the anomaly is a very complex one, of different range in different cases and even of distinct natures. No theory which will explain the ordinary cases of cystinuria can apply to such a case as that studied by Loewy and Neuberg, in which any protein fraction given by the mouth appeared in the urine, the monamino-acids as such and the diamino-acids as diamines, whereas these same fractions, when given in combination as polypeptides or in the more complex form of proteins, were dealt with in the ordinary way. This raises im- 
portant side issues relating to the degree of disintegration which proteins normally undergo in the alimentary canal, and suggests that, if they were broken down into their component amino- and diamino-acids before absorption, this patient should have excreted the fractions unchanged, as, indeed, he did excrete cystin and the mixed products of advanced tryptic digestion. When the patient took glycocoll by the mouth some 20 per cent. of the quantity administered was apparently burned, whereas when glycyl-glycin was given, a dipeptide which is not split up by the pancreatic ferment but is split by the intestinal juice, only 10 per cent. escaped destruction. Polypeptides were completely burnt. ${ }^{29}$

The varying extent of the error, as regards the number of protein fractions involved in cases of cystinuria, suggests that it is manifested at an early stage of the catabolic series, and concerns a mechanism which deals with a number of aminoand diamino-acids in common. In this respect cystinuria stands in conspicuous contrast to alkaptonuria, which involves a late stage in the catabolism of two closely allied protein fractions, a stage so late, indeed, that the tyrosin and phenyl-alanin derived from the breaking down of food and tissues are alike implicated. The fact that the abnormal substances excreted retain their amino-groups intact points in the same direction, for there is strong evidence that desamination occurs at an early stage of the breaking down of proteins. It

29 Biochemische Zeitschrift, 1907, vol. ii, p. 438. 


\section{INBORN ERRORS OF METABOLISM}

is a process to which all the protein fractions are normally subjected and, as Lang ${ }^{30}$ has shown, desaminating enzymes are widely distributed in the tissues. Moreover, it would appear that the several amino-acids are desaminated with various degrees of ease, and that different members of the group are specially attacked in different organs and tissues. Lang found that phenyl-alanin was the most difficult of desamination of the protein fractions and under some conditions cystin and tyrosin were refractory. The maximum yield of ammonia, by which the change was estimated, was obtained when glycocoll or leucin was exposed to the action of the liver or the pancreas.

This complex process of desamination, carried out in a variety of tissues, by the action of enzymes which appear to differ somewhat in their modes of action, may possibly afford a clue to the differences observed in individual cases of cystinuria. Thus the observation of Lang that the power of removing the amino-group is specially conspicuous in the intestinal mucous membrane on the one hand, and in the liver on the other, gives a hint of a possible explanation of such different types of cystinuria as are exemplified in the ordinary cases and in Loewy and Neuberg's respectively ; an explanation based upon absence or inhibition of the enzyme which effects the change in the one situation or in the other. It would seem, also, that when, for any reason, the amino-acids escape this early change no alternative mechanism is available for dealing

30 Hofmeister's Beiträge, 1904, v, p. 321. 
with them, and they are excreted unchanged or in the case of lysin and arginin as diamines. Thus cystinuria, like alkaptonuria, may be classed as an arrest rather than as a perversion of metabolism. 


\section{CHAPTER VI}

\section{Pentosuria}

Our knowledge of the sugars of the pentose group is of recent acquisition, and dates back only a few years further than the discovery of pentosuria, the last of the inborn errors of metabolism to be considered in these lectures. It was in the year 1887 that Kiliani ${ }^{1}$ showed that arabinose, the sugar of gum arabic, which had previously been classed as a hexose, was a member of a different class of sugars from any which had up till then been thoroughly investigated, and that its molecule contained only five carbon atoms, its formula being $\mathrm{C}_{5} \mathrm{H}_{10} \mathrm{O}_{5}$. Not long afterwards Wheeler and Tollens ${ }^{2}$ found that the wood sugar, xylose', was a second member of the group, and since then other pentoses have been recognized or obtained, including a series of methyl-pentoses, of which rhamnose is the best known. However, the original pair, arabinose and xylose, remain the important members of the class from the point of view of physiology.

1 Berichte der deutschen chemischen Gesellschaft, 1887, vol. $\mathrm{xx}, \mathrm{p} .339$.

2 Annalen der Chemie und Pharmacie (Liebig's), No. 254, 1889, pp. 304, 320 . 
Like other sugars the pentoses exist in dextroand lævo-rotatory forms, and also in optically inactive, racemic, combinations. The structures of the isomeric arabinoses and xyloses are represented by the following formulæ:-

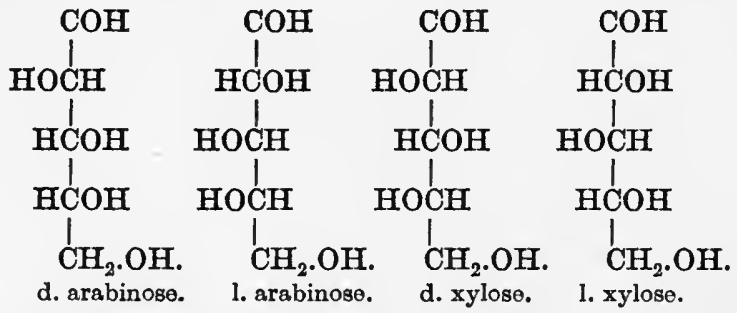

The names 1 . and $d$. arabinose and xylose express their affinities to the 1 . and d. series of hexose sugars respectively, and not their own optical properties. As a matter of fact, both 1 . arabinose and 1. xylose, the forms usually met with in nature, are dextrorotatory. The pentoses are abundantly represented in vegetable structures, not as such, but in the form of complex anhyhrides known as pentosanes.

In 1892 Salkowski and Jastrowitz ${ }^{3}$ described the case of a young man, neurasthenic and a victim of the morphia habit, whose urine gave the reduction tests for sugar, did not ferment with yeast, was optically inactive, but yielded an osazone the melting point of which was $159^{\circ} \mathrm{C}$. The melting point of the osazone suggested that the sugar present was a pentose, although no compound of that class

${ }_{3}^{3}$ Centralblatt für die medicinischen Wissenschaften, 1892, vol. $\mathrm{xxx}, \mathrm{p} .337$. 


\section{INBORN ERRORS OF METABOLISM}

had previously been recognized as a product of animal metabolism, nor as a constituent of animal tissues. Further investigation confirmed this conjecture, and thus was laid the foundation of our knowledge of pentosuria. Soon afterwards Hammarsten demonstrated the presence of a pentose in the pancreas, and since then the presence of such a substance in the nucleo-proteins of various tissues and organs has been practically proven, althoügh the demonstration is not so complete as in the case of the pancreas. Neuberg has identified the pancreatic pentose as 1 .xylose.

The power of the normal human organism to destroy pentoses is very limited, and quite small doses, such as one gramme of arabinose or even less, lead to the appearance of some of the sugar in the urine. Different observers have found that the fractions excreted varied widely, and the destruction may be in part effected in the alimentary canal before absorption.

Seeing that many vegetable foods are rich in pentosanes it is not surprising that some degree of alimentary pentosuria is occasionally induced by their free consumption, but the quantities excreted after the eating of such fruits as plums and cherries, even in abundance, are very small, and delicate tests are required for their detection. Such an alimentary pentosuria, which is wholly distinct from the socalled essential pentosuria, is little likely to lead to diagnostic errors, but von Jaksch ${ }^{4}$ has found

4entralblatt für innere Medicin, 1906, vol. xxvii, p. 145 
that when the unfermented fruit juices, which are popular beverages on the Continent, are taken, in such quantities as a litre or more, the next passed urine yields Trommer's and Nylander's tests and also the special tests for pentoses. Under such conditions the sugar excreted is the 1. arabinose contained in fruits and the urine rotates the polarized ray to the right. Hence it is evident that the presence of a pentose in urine, in quantities easy of detection, is not necessarily due to an error of metabolism, but may be of accidental alimentary origin.

Again, Kulz and Vogel ${ }^{5}$ found that from some diabetic urines there may be obtained by means of phenyl-hydrazine, in addition to glucosazone, an osazone soluble in hot water, which has the melting point and nitrogen content of a pentosazone. Only small yields of this product were obtained when quantities of urine amounting to several litres were so treated, and other observers have failed to detect pentose in diabetic urines, and among them Bendix, ${ }^{\circ}$ who employed the same method as was used by Kulz and Vogel. It would appear, indeed, that the presence of pentose in diabetic urines is an unusual phenomenon and that it has no direct bearing upon the pathology of essential pentosuria. On the other hand, it should be mentioned that Kulz and Vogel found a pentose in the urine of dogs rendered diabetic by removal of the pancreas, but the actual nature of the five-carbon suga

- Zeitschrift für Biologie, 1895, vol. xxxii, p. 185.

- Die Pentosurie, Stuttgart, 1903, p. 55. 


\section{INBORN ERRORS OF METABOLISM}

excreted in such circumstances, and in human diabetes, has not been determined.

The case studied by Salkowski and Jastrowitz ${ }^{7}$ has not remained an isolated one, and of quite recent years such observations have been multiplied, so that some thirty cases of essential pentosuria are now on record. The great majority of the recorded cases have been met with in Germany, especially at watering-places to which patients with the milder forms of diabetes are wont to resort, and the three cases recorded in America have been in patients of German or Russian birth. ${ }^{8}$ In this country no case has yet been described. There can be little doubt that pentosuria is a very rare anomaly. An assiduous search carried out over several years by myself, and by others at my instigation, has failed to reveal a case ; and eloquent testimony to its rarity is afforded by the fact, to which Dr. Pavy kindly allows me to refer, that he has never met with an authentic example of the condition, and that those of his cases in which there have been grounds to suspect its presence have all been found on further investigation to be of other natures.

However, the rarity of pentosuria among us cannot be ascribed to any immunity of the AngloSaxon race, for there is evidence of a special frequency of the anomaly in Jews, and among the large Jewish population in our midst, both alien and

? Loc. cit., sub. 3.

8 T. Janeway : American Journal of the Mcdical Sciences, 1906, vol. cxxxii, p. 423. Kaplan: New York Medical Journal, 1906, vol. Ixxxiv, p. 233. 
native, it cannot fail to occur. Of twenty-six recorded examples no less than five are definitely stated to have been in members of the Hebrew race, and it is probable that other patients whose race is not mentioned would swell the proportion. Erben ${ }^{9}$ quotes von Jaksch as saying that in his experience the majority of pentosurics are of Jewish origin. The tendency of pentosuria to occur in several collaterals of a family, and the great preponderance of males among its subjects, have already been referred to, and also the fact that the youngest recorded patient was a boy aged fifteen years. ${ }^{10}$ At least two patients have been over sixty years of age.

Pentosuria is not necessarily associated with any morbid symptoms. In some instances the detection of sugar at an examination for life assurance has been the first indication of anything amiss, but this is also true of not a few cases of mild diabetes. There is a growing opinion, among those whose experience enables them to speak with authority on the subject, that this anomaly is in itself harmless and calls for no treatment. The mos $t$ recent writers suggest that it should be included in the class of which cystinuria and alkaptonuria are members. In a considerable proportion of cases there have been symptoms of neurasthenia, and if any morbid condition can be

- Prager medicinische Wochenschrift, 1906, vol. xxxi, p. 301.

10 Chobola : Centralblatt für innere Medicin, Abstract, 1907, vol. xxviii, p. 864. 


\section{INBORN ERRORS OF METABOLISM}

looked upon as specially associated with the urinary peculiarity it is this. However, race and racial temperament may here play no unimportant part, and, the diagnosis of diabetes, usually made, may contribute to the result. Most pentosurics have been supposed to have diabetes and have been for a time treated accordingly.

The question of the existence of any relationship of essential pentosuria to diabetes is of considerable interest. There can be no doubt that from the metabolic standpoint the two are absolutely distinct, despite the fact already referred to that some diabetics excrete small quantities of pentose. It has been demonstrated that the pentosuric is as capable of dealing with ingested glucose as an ordinary individual ; only when it is given in doses which suffice to overtax the power of destroying glucose which is possessed by a normal man does that sugar appear in his urine.

However, when we turn to the clinical evidence their independence of each other is less obvious. A certain number of the observed pentosurics have excreted glucose as well as pentose at times. The original patient of Salkowski and Jastrowitz did so, but in him the morphia habit may have been the exciting cause of the temporary glycosuria. One of Blumenthal's ${ }^{11}$ patients was glycosuric, and so also was one of af Klerker's. ${ }^{12}$ Some pentosurics have been members of diabetic families. $\mathrm{Kj}$. $\mathrm{O}$. af

11 Berliner klinische Wochenschrift, 1895, vol. xxxii, p. 567.

12 Nordiskt medicinskt Arkiv, 1905, Afd. ii, Heft i, pp. 1 and 53. 
Klerker's patients were two brothers, Jews, whose father and another brother had diabetes. Schüler's ${ }^{13}$ patient had a brother and two sisters who were diabetic, and in one of the cases described by Rosenfeld, ${ }^{14}$ who lays special stress upon these points, the patient, whose father and brother had diabetes, developed pentosuria after being in a railway accident. The evidence of its recent development was afforded by the fact that an examination of his urine a year and three-quarters previously had revealed nothing abnormal. The pentosuria diminished as time went on. In this connexion also race may come into play, seeing that members of the Jewish race show a special liability to diabetes, but of those mentioned above af Klerker's patients alone are stated to have been Jews.

Clearly the correct diagnosis of cases of pentosuria is a matter of real practical importance. If it be not made the patient is not only subjected to the distress which the diagnosis of diabetes entails, but is subjected to irksome dietary restrictions which in his case are wholly uncalled for, are quite useless, and when not necessary are certainly undesirable. On the other hand, it is better that a few persons who exhibit an anomaly so rare as pentosuria should be erroneously classed as diabetic, than that a diagnosis of pentosuria, on inadequate grounds, should lead to the omission of treatment in a number of cases of true diabetes.

13 Münchener medicinische Wochenschrift, 1905, vol. lii, p. 1657.

14 Medizinische Klinik, 1906, vol. ii, p. 1041. 


\section{INBORN ERRORS OF METABOLISM}

In pentosuria the urine is not excessive in quantity, nor are the symptoms so often prominent in diabetic cases, such as thirst and undue appetite, met with in connexion therewith. The specific gravity of the urine usually varies from 1.025 to 1.035 and when it is boiled with Fehling's solution it reduces as does a diabetic urine containing some 0.5 per cent. of glucose. Many observers have described the reduction as delayed, and as occurring suddenly after the test-tube has been removed from the flame. Urine containing small percentages of glucose may behave in this way, and Bial, ${ }^{15}$ who had an exceptionally large experience in this matter, stated that, when fresh, pentose urines may show no such peculiarity of behaviour and that the reduction may occur before the boiling point is reached. He suggested that the delayed, but sudden, reduction, so often observed, is due to the urine having been kept for some time with the addition of preservative substances, such as toluene or chloroform. The only specimen of pentose urine which I have had the opportunity of examining, and for which I was indebted to the kindness of Professor von Jaksch, behaved in this manner, but it had been preserved for some long time under toluene. Pentose urines also yield Moore's test for sugar and that of Nylander, although not very strikingly since the amount of the sugar present is never large. They also yield the saffranin test.

With the yeast test no fermentation occurs, and after standing with yeast in a warm place for twenty-

18 Berliner Klinik, 1907, Heft 226. 
four hours the reducing power of the urine is not impaired. Kj. O. af Klerker lays special stress on this as affording a ready means of detecting pentose when present in association with glucose. In every case hitherto observed, with the exception of one of Luzzato's, ${ }^{16}$ the urine has been optically inactive, unless glucose were also present. In Luzzato's case, in which it was clearly established that the sugar present was arabinose, the urine was dextrorotatory.

With the phenyl-hydrazine test a crystalline osazone is obtained, but as it is to some extent soluble in hot water it is only thrown out in crystalline form after the liquid has cooled. In appearance the crystals closely resemble those of phenyl-glucosazone, but whereas the latter after recrystallization melts at $205^{\circ} \mathrm{C}$., the melting point of pentosazone is much lower, between $156^{\circ}$ and $160^{\circ} \mathrm{C}$. This melting point supplies one of the most important means of diagnosis of pentosuria, but to ensure complete certainty as to its nature the nitrogen content of the osazone must be estimated. The theoretical amount for a pentosazone is 17.07 per cent. N.

The special tests which are available for the detection of pentoses are based upon the property which such sugars possess of yielding furfurol when heated with mineral acids. The phloroglucin test is performed as follows: a small quantity of phloroglucin is dissolved in 5 or 6 cubic centimetres of fuming hydrochloric acid, a slight excess remaining

${ }^{16}$ Hofmeister's Beiträge, 1905, vol. vi, p. 87. 


\section{INBORN ERRORS OF METABOLISM}

undissolved. To one portion of the solution half a cubic centimetre of the urinc to be tested is added in a test-tube, and to the other portion an equal quantity of normal urine as control. Both tubes are then placed in a beaker of boiling water. If pentose be present the test containing it quickly assumes a deep red colour from the surface downwards, whereas the normal specimen shows little change. The colour can be readily extracted by shaking with amylic alcohol, and the amylic extract, suitably diluted, shows a spectroscopic absorption band between the Fraunhofer lines D and E-about $\lambda 5425$ to $\lambda 5750$. More satisfactory for diagnostic purposes is the orcin test. A specimen of urine is warmed with an equal volume of concentrated hydrochloric acid in which sufficient orcin to cover a knife point has been dissolved. A green colour quickly develops if pentose be present and the liquid becomes turbid by the formation of a bluish-green flocculent precipitate. After cooling the precipitate may be taken up with amyl alcohol, which acquires a rich green colour and shows a characteristic absorption band between the solar $\mathrm{C}$ and $\mathrm{D}$ lines and overlapping the D line-about $\lambda 5850$ to $\lambda 6150$. A second band nearer to the red end of the spectrum and a fainter band in green, which are often seen, are not of diagnostic importance.

Bial's ${ }^{17}$ modification of the orcin test is very useful for clinical purposes. It is based upon the effect of the addition of ferric chloride in quickening

17 Deutsche medicinische Wochenschrift, 1902, vol. xxviii, p. 253 , 
the reaction. The reagent is prepared as follows: 1 gramme of orcin is dissolved in 500 cubic centimetres of hydrochloric acid of specific gravity $1 \cdot 151$, and to the solution 25 drops of a 10 per cent. solution of ferric chloride are added. The liquid when kept in an amber-coloured bottle will preserve its activity for a long period. Five cubic centimetres of the reagent are boiled in a test-tube and, after the tube has been removed from the flame, five drops of the urine to be tested are allowed to run on to the surface of the liquid from a pipette. If pentose be present a green ring appears at the junction of the liquids, and if the tube be gently shaken the green colour spreads through the liquid. With the spectroscope the characteristic absorption band is seen. Care is required that the correct proportions be employed in mixing the reagent, and the hydrochloric acid must be of the prescribed strength. If a pentose urine be not available the efficiency of the reagent may be tested with a dilute solution of gum arabic. I can testify, from my own experience, that the reaction so obtained is a very striking and characteristic one. By its means it is easy to exclude pentosuria in doubtful cases, and it is easily applied in ordinary clinical work. Bial and also Kraft maintain that, if performed in the manner described, the test is diagnostic and is yielded by none but pentose urines. However, for the diagnosis of pentosuria one should not rely upon any single reaction and 'confirmatory tests should be applied.

The discrimination between pentosuria and gly- 


\section{INBORN ERRORS OF METABOLISM}

cosuria should present no real difficulty, as glucose does not yield the above colour tests. It is in connexion with glycuronic acid that the risk of error comes in. Glycuronic acid has obvious chemical relationships to the pentoses as their respective formulæ show. By splitting off carbon dioxide

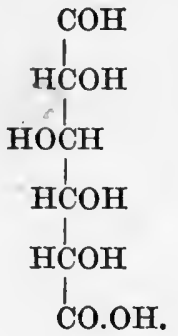

d. glycuronio acid.

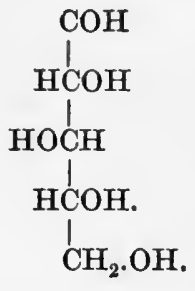

1. xylose.

from it a pentose results, and the acid itself vields the furfurol reactions. Urine containing glycuronic acid may yield the phloroglucin test, but as the acid is almost always in combination in urine, as compound glycuronates, the reactions are not obtained until the combination is loosened. However, some compound glycuronates, such as the menthol compound, break up spontaneously in urine.

It is not easy to make sure from the writings of those who have had most experience of these reactions whether in clinical work the risk of mistaking a urine containing glycuronic acid for a pentose urine is really great. It is stated that the orcin test is not yielded by compound glycuronates unless heating be unduly prolonged, and although Bial's reagent, if boiled with a urine containing a compound glycuronate, gives the green colour and the 
absorption band, it is claimed that no risk cf confusion exists if the urine be added after the test tube has been removed from the flame. With tree glycuronic acid Paul Mayer ${ }^{18}$ obtained crystalline phenyl-hydrazine compounds, one of which had a melting point like that of a pentosazone, but this is not yielded by compound glycuronates, and in case of doubt an estimation of the nitrogen in the crystalline product will settle the point.

Again, the polarimeter may help in the diagnosis, for all known compound glycuronates are lævorotatory, although the free acid is dextrorotatory, whereas pentose urine is almost always optically inactive. Lastly, patients who excrete glycuronic acid in appreciable quantities are almost always taking some drug which is known to be excreted as a compound glycuronate. Nevertheless there is some doubt whether in certain cases ${ }^{19}$ which have been described as examples of pentosuria the reducing property of the urine was not really due to glycuronic acid.

The most remarkable fact of all in regard to pentosuria is the optical inactivity of the excreted sugar. In one case Neubery ${ }^{20}$ succeeded in isolating the pentose from the osazone obtained from a large volume of urine treated with di-phenyl-

${ }^{18}$ Zeitschrift für physiologische Chemie, 1900, vol. xxix, p. 59 .

19 Caporelli : Riforma Clinica e Terapeutica, 1896, i ; Colombini : Monatshefte der praktischen Dermatologie, 1897, vol. xxiv, p. 129.

${ }_{20}$ Berichte der deutschen chemischen Gesellschaft, 1900, vol. xxxiii, p. 2243. 


\section{INBORN ERRORS OF METABOLISM}

hydrazine, and was able to identify it as racemic arabinose. Thus the pentose of urine stands out as the sole example of a racemic sugar occurring as such in the animal organism, and forms an exception to the rule that such organisms are built up of optically inactive materials. When racemic arabinose is administered by the mouth to a normal man it does not appear in the urine unchanged. Neuberg and Wohlgemuth ${ }^{21}$ found that when 15 grammes of this sugar were so taken, the urine, which had previously contained no reducing substance, had been optically inactive and had failed to yield the orcin test, acquired after the lapse of four hours strongly reducing properties, was optically active, and gave the pentose reactions. Of the excreted arabinose, to which these properties were due, no less than two-thirds was the lævorotatory d. arabinose, and it was evident that the individual in question had a much greater power of destroying the ordinary 1. arabinose than the other form. This observation only makes it the more remarkable that in pentosuria the racemic arabinose is excreted as such and alone.

It is certain that essential pentosuria is not alimentary. This is fully proved by its persistence when all pentosane is excluded from the diet, and moreover the arabinose present in vegetable food stuffs is always the dextrorotatory 1. arabinose and not the racemic sugar. Nor can it be derived from the pentose contained in the nucleo-proteins

${ }_{21}$ Zeitschrift für physiologische Chemie, 1902, vol. xxxv, p. 41. 
of the food and body tissues. This is an entirely different sugar 1. xylose, which cannot be supposed to become converted into racemic arabinose. Moreover, the quantity present in the body is too small to serve as a source of supply. Grund ${ }^{22}$ estimated the total quantity in the human body at 10 grammes and Bendix ${ }^{23}$ makes it only slightly more Lastly, Bial and Blumenthal ${ }^{24}$ found no increase of pentose in the urine after feeding with 500 grammes of calf's thymus, and the uric acid and phosphate excretion of pentosurics affords no evidence of an abnormal breaking down of nucleo-proteins.

Our knowledge of the quantities of pentose excreted by pentosurics is very imperfect. The ordinary Fehling's method of estimation is not applicable to such urines, because the cuprous-hydrate precipitate does not separate satisfactorily, and other methods have to be resorted to, such as Allihn's, Knapp's, or weighing the phloroglucin precipitate. The estimated amounts in individual cases have differed widely-from 1 to 7 grammes in the twenty-four hours-and Neuberg ${ }^{25}$ states that all such estimates are too low, sometimes by 100 per cent., because much of the pentose is in combination with urea as a ureide, and the portion so combined does not reduce until the ureide is broken

22 Zeitschrift für physiologische Chemie, 1902, vol. xxxv, p. 111 .

${ }_{23}$ Die Pentosurie, Stuttgart, 1903, p. 20.

24 Deutsche medicinische Wochenschrift, 1901, vol. xxvii, p. 349 .

25 Pathologie des Stoffwechsels (von Noorden), second edition, 1907, vol. ii, p. 220. 


\section{INBORN ERRORS OF METABOLISM}

up by heating with an acid. In view of the uncertainty which surrounds this matter it is obviously impossible as yet to draw any conclusions from the published figures, obtained by various methods in different cases, as to the constancy or otherwise of the output. The quantity estimated-viz., the uncombined arabinose-may represent no constant fraction of the total amount. Neuberg ${ }^{26}$ mentions from 30 to 36 grammes as the figure which may be reached by the day's excretion, which is far more than twice as much as any other recorded estimate with which I am acquainted.

Exclusion of carbohydrate from the diet has been shown to have no influence upon the pentose output as estimated by reduction tests, nor is the pentosuric less able to burn dextrose and lævulose than a normal subject. Still more remarkable is the fact, observed by Bial and Blumenthal, ${ }^{27}$ that even when 5 grammes of 1 . arabinose were administered to a pentosuric by the mouth, the amount of the optically active arabinose excreted was no greater than when a like dose is administered to a normal man. Just as a cystinuric destroys cystin given by the mouth, so the pentosuric is able to destroy the usual proportion of a dose of l. arabinose when so given. From this it is clear that, even if any treatment of pentosuria is called for, no good purpose is served by restriction of the carbohydrate, nor even of the pentose intake.

Neither is there conclusive evidence that the

28 Pathologie des Stoffwechsels (von Noorden), second edition, 1907, vol. ii, p. 221. $\quad{ }_{27}$ Loc. cit., sub. 24. 
excretion of pentose, as estimated by reduction tests, is influenced by protein food. However $\mathbf{K j}$. O. af Klerker, in the course of an elaborate series of observations, found that the output varied much during the day and that the pentose curve from hour to hour followed that of nitrogen. One of his Jewish patients excreted only half his average output of pentose during the day following the rigid fast of the Day of Atonement, to which an abnormally low nitrogen excretion on the same day also bore witness. Bial and Blumenthal found that the blood of a pentosuric patient gave the orcin reaction, and concluded that pentose was present therein. Thus a renal origin is apparently excluded, and their patient also reacted in the ordinary manner to the phlorhyzin test of renal efficiency.

The conclusion appears to be inevitable that the racemic arabinose of pentose urines is derived from some substance formed within the organism, and that glucose is not this parent substance. C. Neuberg has suggested ${ }^{28}$ that the most likely parent substance is $\mathrm{d}$. galactose, but himself points out that the evidence in favour of this hypothesis is purely circumstantial, and that no direct proof of its correctness is forthcoming.

By a series of changes, with glycuronic acid as an intermediate stage, the pentose of nucleo-proteins, 1. xylose, can be derived from d. glucose, and 1 . arabinose stands in a like relation to $d$. galactose. Moreover, Neuberg quotes Fischer's

${ }^{28}$ Ergebnisse der Physiologie, 1904, vol. iii, 1 Abtheilung, p. 426. 


\section{INBORN ERRORS OF METABOLISM}

observation that, on account of the symmetry of the groupings upon its four middle carbon atoms, $d$. galactose is readily converted into optically inactive derivatives, mucic acid by oxidation, and dulcite by reduction. By converse treatment these products are reconverted into galactose, but into the racemic form. On this account Neuberg finds it easier to suppose that this particular sugar may be the parent substance of the racemic arabinose of pentosuria, which may be supposed to be formed as follows:-(af Klerker)

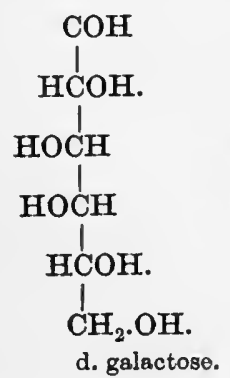

d. galactose.

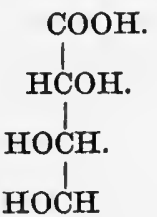

HCOH

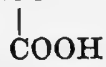

Mucio acid ; inactive in virtue of symmetry.

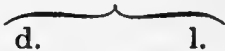

$\mathrm{COH}$<smiles>OCCO</smiles><smiles>[R]OC(C)O</smiles>
HOCH
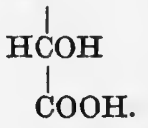

aldehyde-acids, analogous to glycuronic acid.

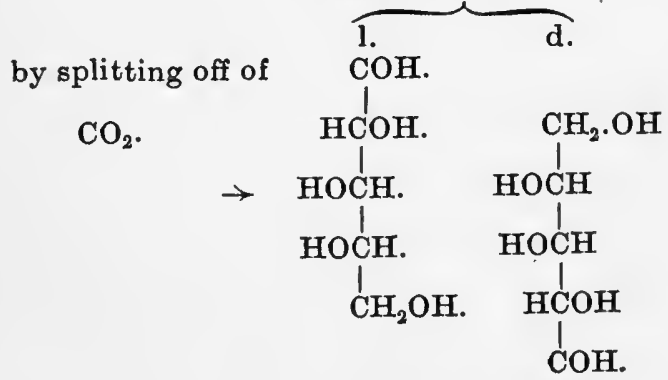

racemic arabinose. 
The formation of $\mathrm{d}$. galactose in the animal body is an undoubted fact; lactose, the disaccharid formed from glucose and galactose, is abundantly formed during lactation, and galactose has also been shown by Thierfelder ${ }^{20}$ to be the sugar yielded by cerebrin.

So far no conclusive evidence is forthcoming that galactose administered as such by the mouth, or in lactose, has any appreciable effect upon the output of arabinose by a pentosuric, nor are there any recorded observations upon a female pentosuric during lactation. Blumenthal and Bial gave to their patient 100 grammes of galactose by the mouth, not with any idea of testing Neuberg's hypothesis, which had not then been put forward, but observed no conspicuous increase of urinary pentose. $\mathrm{Kj}$. $\mathrm{O}$. af Klerker, ${ }^{30}$ who gave 100 grammes of lactose to one of his patients, observed a distinct increase of the hourly output of pentose six or seven hours later, but the total day's excretion was in no way excessive. Tintemann ${ }^{31}$ observed a slight increase of pentose in the urine after 50 grammes of galactose given on an empty stomach.

Obviously much further patient research is necessary before our knowledge of this remarkable anomaly of metabolism can be placed upon a satisfactory footing, and we may hope that to this research British workers will, in due course, contribute their quota.

${ }^{29}$ Zeitschrift für physiologische Chemie, 1890, vol. xiv, p. 209.

so Loc cit., sub. 12.

31 Zeitschrift für klinische Medicin, 1906, vol. lviii, p. 190. 



\section{INDEX}

Abnormalities, chemical, 13; inborn and congenital, 14

See also Malformations

Acetone-

formation of, from fats, 13

formation of, from protein

fractions, by perfusion of liver, 61

Acetone-bodies, rôle of, in diabetes mellitus, 13, 61 Acidosis, protective mechanism against, 4

Albinism, 34 et seq.

absence of melanin pigments in, 35

consanguinity of parents in relation to, 23

harmlessness of, 21

heredity of, 23

injections of melanin in, 36

and intravascular clotting,

from injection of nucleoproteins, 39

as a malformation by arrest, 14

partial, 37

physiological causes of pigmentation inoperative in, 38

rarity of, in man, 20

sex incidence of, 20

theories of, 36

urinary pigments in, 35

Albumin. See Protein

Albumoses, in urine, source of, 12
Alimentary canal-

breaking down of proteins in, 133

excretory products derived from, 9

formation of indol in, 10

formation of urobilin in, 10

products of bacterial action in, 10

Alkapton of Bödeker, 47

Alkaptonuria, 23, 41, et seq. ammonia excretion in, 67

articular lesions associated with, 46

aural wax, characters of, in, 50

completeness of the chemical error in, 61

congenital occurrence of, 17 consanguinity of parents in relation to, 23,24

diet, effects of, in, 55, 59, 63 dysuria, with, 44

effect of administration to alkaptonurics of :benzoyl-phenyl-alanin, 74

$2: 4$ dioxy-benzoic acid, 79 gentisic acid, 79

glycyl-1-tyrosin, subcutaneously, 59

halogen proteins, 76

halogen-tyrosins, 76

homogentisic acid, 69

hydroquinone-pyruvio

acid, 78

metatyrosin, 77 
Alkaptonuria (continued), -

effect of administration to alkaptonurics of (contd.) milk diet, 65

orthotyrosin, 77

paroxy-phenyl-acetic acid, 76

paroxy-phenyl-a-lactic acid, 75

paroxyphenyl pyruvic acid, 76

phenyl-acetic acid, 74

phenyl-alanin, 55 phenyl-glyceric acid, 74 phenyl-a-lactic acid, 74 phenyl- $\beta$-lactic acid, 74 phenyl-propionic acid, 74 phenyl-pyruvic acid, 74 plasmon, 65 protein foods, 55,59 protocatechuic acid, 79 tryptophane, 56 tyrosin, 54

family incidence of, 23-29 harmlessness of, 12 heredity of, 23 history of our knowledge of, 42

H. : N. ratio in, 63

homogentisic acid in urine in, 48

infective theory of, 58 intermittent, 17, 71

intestinal disinfection in, 58 life-long persistence of, 17

Mendel's law in relation to, 26 proportion of alkaptonuric members in families, 29 sex incidence of, 20 temporary, 17, 71 theory of, 66 uric acid, excretion of, in, 54 urine, colour of, in, 41 urine, properties of, in $\mathbf{4 L}$
Alkaptonuria (continued),urine, reducing power of, in, 42

uroleucic - acid, supposed excretion of, in, 50

Amino-acids. See individual amino-acids

Ammonia-

used for neutralization of abnormal acids, 4 excretion of, in alkaptonuria, 67

Arabinose, a pentose sugar, 136 lævo-, dextrorotatory property of, 137

formula of, 137

in pentose urine, 145

in urine in alimentary pentosuria, 138

in vegetable kingdom, 136 racemic, the sugar of pentosuria 149

effect of its administration to normal man, 150 possibly derived from galactose, 153. See also Pentose and Pentosuria

Arginin-

effect of its administration to cystinurics, 125

not found in urine in cystinuria, 127

putrescin derived from, 124 Aromatic sulphates in urine, 9,88

Aspartic acid, effect of its administration to cystinurics, 130

Autolysis of tissues, products of, in urine, 12

Bacterial products, excretion of, in urine, 10 
Bence Jones protein, in urine, 4 in cases of multiple myeloma 8

Benzene ring-

fate of in normal organism, $4,60,79$

not synthesized in animal organism, 54, 59

Benzoyl-phenyl-alanininactive when administered to alkaptonurics, 74

Bial's test for pentose in urine, 146

Bile examination of, in a case of cystinuria, 117, 132

Bile-acids, specific differences of, 2

Biliary fistula, case of cystinuria with, 117

effect of administration of cystin to dogs with, 93

effect of, upon neutral sulphur of urine, 95

Blood, homogentisic acid in, 50

pentose in, 153

proteins of, in alkaptonuria, 59

Brachydactyly, sex incidence of, 20

Brombenzene, effect of administration of to dogs, 90 effect of administration of to $\operatorname{man}, 91$

Cadaverin or penta-methylene diamine-

derivation of from lysin, 124 excretion of, by cystinurics, 101,119

in fæces, 119 in normal urine, 11 See also Diamines
Calculi of cystincomposition of, 82,84 tyrosin in, 85

Chemical specificity and individuality, 2, 3

Cholalic acid-

effect of administration of, to normal man, 93

effect of administration of, to cystinurics, 115

effect of administration of, with cystin, 93

and taurocholic acid formation, 93

Clotting, intravascular, from injection of nucleo-proteins, 39

Consanguineous marriages, frequency of, 25

Consanguinity of parentsof albinos, 23

of alkaptonurics, 23

of cystinurics, 32

and Mendelian recessive characters, 27

Cysteic acid-

an intermediate stage between cystin and taurin 92

Cystein-

relation of to cystin, 83

subcutaneous injection of, into cystinurics, 115

Cystin

absent from fæces in cystinuria, 100

analysis of 83

calculi of, 82,84

composition of, 83

crystalline sediments of, 82

deposition of, in tissues, in cystinuria, 97

discovery of, 82 
Cystin (continued),-

effects of administration of, to cystinurics, 112

effects of administration of, to normal men and animals, 95

effects of administration of, with cholalic acid, 93

estimation of, in urine, 102

excretion of, only one of the phenomena of cystinuria, 101, 119

excretion of, in relation to supply of cholalic acid, 115

excretion of, not maximal in cystinuria, 103

formula of, 84

isomeric forms of, 84

iso-cystin, 84

in kidney of an ox, 86

in human liver, 86

metabolism of, normal, 90

parent substance of taurin

91

partial excretion of, in cystinuria, 103

preparation of, by hydrolysis of hair and albumins, 86

as a product of pancreatic digestion, 86

a primary protein fraction, 86

quantities of, excreted by cystinurics, 104

relation of, to taurin, 92 stone-cystin of Neuberg and Meyer, 84

subcutaneous injection of, into cystinurics, 115

a sulphur compound, 83 synthesis of, 84

Wollaston's test for, 99
Cystinuria, 18, 31, 82 et seq. bile, in a case of biliary fistula with, 117

calculus formation in, 82,85 , 97

in children, 19

congenital occurrence of, question of, 18

consanguinity of parents and, 32

crystalline deposits in urine in, 82, 98, 108

$C: N$ ratio in, 110

day and night excretion of cystin in, 112

derangement of sulphur metabolism in, 96

diamines in fæces in, 101, 119,126

diamines in urine in, 101, 119 in dogs, 22

effect of administration to cystinurics of

arginin, 125

aspartic acid, 130

cholalic acid, 115

cystein, 115

cystin, 112, 115

lysin, 125

polypeptides, 133

proteins, 107

stone cystin, 113

tyrosin, 129

excretion of diamines in, 101 , 119

excretion of neutral sulphur in, 106

excretion of sulphates in, 106 excretion of tyrosin and

leucin in, 101, 128

excretion of undetermined nitrogen in, 131

experimental, 90

family incidence of, 31 
Cystinuria (continued), -

heredity of, 31

history of our $\mathrm{k}$ owledge of, 82

nitrogenous metabolism in, 131

pathogeny of, 132

persistence of, 18

protein diet, effect of, in, 107

quantities of cystin excreted

in, 103

sex incidence of, 20

sweat, presence of cystin in, 100

temporary, 19, 99, 117

tryptophane derivative in

urine in, 130

tyrosin in, urine in, 128

urine in, properties of, 98

varieties of, 101

Desamination, of protein frac-

tions in the organism,

74,133

seats of, in tissues, 134

Developmental errors, classification of, 14

Diabetes mellitus-

as a disorder of metabolism, 7,12

impaired destruction of homogentisic acid in, 68,71

in relation to pentosuria, 142 rôle of the acetone bodies in, 13,61

Di-alanyl-cystin, effect of its administration to normal man, 95

Di-amino-acids. See Lysin and Ornithin

Di-brom-tyrosin, effect of administration of, in alkaptonuria, 76
Diet, effects of, in alkapt onuria 55,62

effects of, in cystinuria, 107

effects of, on diamine excretion, 127

effects of, in pentosuria, 150 , 152

Diamines, detection of, in urine and fæces, 119

in faeces in intestinal disorders, 120,126

in fæces in cystinuria, 119

influence of diet upon excretion of, 127

as metabolic products, 125 , 128

relationship of, to diaminoacids, 124

in urine in cystinuria, 119

in urine in other conditions, 120

in urine, normal, 11. See also Cadaverin and $\mathrm{Pu}$ trescin

Di-leucyl-cystin, effect of administration of, to normal man, 95

$2: 4$ di-oxy-benzoic acid, fate of in normal organism, 79

Di -phenyl - hydrazine, compound of, with arabinose, 149

Diseases of metabolism, 12

Dogs, cystin calculi in, 22

kynurenic acid in urine of, 2

Dysuria as a symptom of alkaptonuria, 44

Enzymes, rôle of, in metabolism, $5,6,7,80,134$

Ethyl-sulphide in urine, 90 
Freces, absence of homogentisic acid from, in alkaptonuria

diamines in, in cystinuria, 119

diamines in, in intestinal disorders, 120,126

Fats, specific differences of, 1

Function, inborn derangements of, 15

\section{Galactose-}

constitution of, 154

effect of its administration to pentosurics, 155

a possible source of urinary pentose, 153

relation of, to arabinose, 153

Gentisic acid, effect of its administration to alkaptonurics, 80

fate of, in normal organism, 67,79

Glycocoll, effect of administration of, to a cystinuric, 133

Glucose, effect of its administration to pentosurics, 152

relation of, to l-xylose, 153

Glycosuric acid, of Marshall, 47

Glycuronic acid, distinction of pentose from, 148

as intermediate product of metabolism, 9

relation of, to l-xylose, 148

in urine, may be mistaken for pentose, 148

Glycyl-1-tyrosin, injection of, in a case of alkaptonuria, 59

Gout, as a disorder of metabolism, 5, 12
Hæmatoporphyrin, in normal urine, 11

Hæmoglobins, specific differences in, 1

Hair, colours of, as evidences of chemical diversity, 3 cystin obtained by hydrolysis of, 86

and nails, tyrosin in, in alkaptonurics, 59

Halogen, benzenes, causing mercapturic excretion, in dogs, 90

proteins, effect of administration of in alkaptonuria, 76

Himalayan rabbit, a partial albino, 37

Hippuric acid, a product of a protective mechanism, 9

Homogentisic acid, 48

in blood, in alkaptonuria, 50 in what combination excreted in urine, 67

constitution of, 48

effect of administration of, to alkaptonurics, 69

to normal man, 68 estimation of, in urine, 49 ethyl-ester of, 46 extraction of, from alkapton urine, 49

fate of, in normal organism, 68

formula of, 48

how formed from tyrosin and phenyl-alanin, 58,78 impaired destruction of, in diabetes, 68,71

increased excretion of, on protein diet, 55, 59

as an intermediate product of normal metabolism, 66 
Homogentisic acid (continued),-

lead salt of, 49

limited destruction of, in normal organism, 68

parents substances of, 54 in plants, supposed formation of, by action of tyrosinase, 72

properties of, 50

reaction of, with ferric chloride, 42

synthesis of, 48

Hydroquinone-acetic acid. See Homogentisic Acid

Hydroquinone- $a$-lactic acid, the supposed uroleucic acid, 51

synthesis of, 53

Hydroquinone-pyruvic acideffect of its administration to an alkaptonuric, 78

Inborn errors of metabolismcharacters of, 13

congenital occurrence of, 17 conspicuous character of those known, 17

heredity of, 22 persistence of, 17

Indol, origin of from tryptophane, 10

Intermediate products of metabolism, excretion of, 7 , 11

Jewish race-

occurrence of pentosuria in, $31,140,143$

Joints, lesions of, in association with ochronosis and alkaptonuria, 46
Kidneys, diseases of, effect of, upon urinary excretion, 10

selective retention of proteins by, 3

Kynurenic acid, in urine of dogs, 2

Lactose, effect of administration of, to pentosurics, 155

Lævulose, not dealt with in organism in same way as dextrose, 6

Leucin, as an acetone yielding substance, 61,81

catabolism of, in alkaptonuria, 81

in urine, in acute yellow atrophy of liver, 12

in urine, in cystinuria, 101, 128

Liver, disease of, effect of, on metabolism, 12

formation of acetone in perfused, 61

desamintion in, 134

Lysin, effect of administration of, to a cystinuric, 125

not found in urine in cystinuria, 127

parent substance of cadaverin, 101,124

Malformations, structural, compared to chemical anomalies, 14

structural, classification of, 14

structural, sex incidence of, 20

Melanins-

absent in albinism, 35

chemistry of, 35 
Melanins (continued), -

effects of injection of, into animals, 36

origin of, 37

rôle of, in animal pigmentation, 35

Mendel's law of heredity, 26

in relation to alkaptonuria, 26

in relation to consanguinity, 27

Mercapturic acids, excretion of, an experimental cystinuria, 90

composition of, 91

Metabolism

by-produots of, 11

in compartments, 6

derangements of, in disease, 11

diseases of, 12

inborn errors of, 15

individual and specific difference of, 1

influence of evolutionary factors upon, 3

intermediate products of, 9 , 11

nature of derangement of, in albinism, 35

nature of derangement of, in alkaptonuria, 59, 80

nature of derangement of, in cystinuria, 103, 133

nature of derangement of, in pentosuria, 154

nitrogenous, disturbance of, in cystinuria, 131

permanency of paths of, 7

of sulphur, disturbance of, in cystinuria, 96, 103

Meta-tyrosin, effect of administration of, to alkaptonurics, 77
Meta-tyrosin (continued), -

fate of, in normal organism 79

Methyl-mercaptan, in urine, 90

Mice, waltzing, 16

Millon's reagent, in detection of tyrosin in urine, 129

Mucic acid, relation of, to galactose and arabinose, 154

Ifuscle proteins, specific differences of, 2

Myeloma, multiple, excretion of Bence-Jones protein with, 8

Neurasthenia, association of, with pentosuria, 141

Neutral sulphur of urine. See Sulphur.

Nitrogen, undetermined, in urine in cystinuria, 131

Nitrogenous metabolism in cystinuria, 131

Norway hare, intravascular clotting in, from injection of nucleo-proteins, 40

Nucleo-proteins, injection of causing intravascular, clotting, 39

Obesity, as a disease of metabolism, 5, 12

Ochronosis, 44

and alkaptonuria, 44

from chronic phenol poisoning, 45

experimental, 46

joint-lesions associated with, 46

Orcin-test, for pentose in urine, 146 
Ornithin, putrescin derived from, 101, 124

Ortho-tyrosin, effect of administration of, to alkaptonurics, 77

fate of, in normal organism, 79

$\beta$-Oxy-butyric acid, rôle of, in diabetes mellitus, 13, 61

Paroxy-phenyl acetic acideffect of administration of, to alkaptonurics, 78

Paroxy-phenyl- $a$-lactic acid, effect of administration of to alkaptonurics, 75

Paroxy-phenyl-pyruvic acid, effect of administration of to alkaptonurics, 76

Pentosanes, in vegetable kingdom, 137, 138

Pentosazones, properties of, 145

Pentoses, in animal tissues, 138 in blood in pentosuria, 153 Bial's test for, in urine, 146 in diabetic urines, 139 discovery of, 136 distinction of, from glycuronic acid, 148

estimation of, in urine, 151

nature of, 136

occurrence of, in nature, 136 optical properties of, 137, 149

orcin test for, 146

origin of urinary, 150

osazones of, 145

phloroglucin test for, 145

possible origin of, from galactose, 153

properties of, 144

quantitative estimation of, in urine, 151
Pentoses (continued), -

tests for, in urine, 144, 145 ureide of, in urine, 151 varieties of, 137

Pentosuria-19, 31, 136 et seq. alimentary or accidental, 138 arabinose, racemic, excreted in, 150

1-arabinose in urine, in a case of, 145

diagnosis of, 143

discovery of, 137

discrimination of, from glycuronic acid excretion, 148 effects of administration, to pentosurics, of l-arabinose, 152

carbohydrate -free diet, 152

galactose, 155

glucose, 142

lactose, 155

proteins, 153

thymus gland, 151

family occurrence of, 31

harmlessness of, 21,141

in Jews, 31, 140, 143

neurasthenia with, 141

persistence of, 19

properties of urine in, 137,144

quantities of pentose excreted in, 151

relation of, to diabetes mellitus, 142

sex incidence of, 20

source of arabinose excreted in, 150

symptoms associated with, 141

theory of, 153

urine in, properties of, 144

urine in, special reactions of, 145 
Phenyl-acetic acid, yields no acetone in perfused liver, 61

Phenyl-alanin,desamination of, 134

effect of its administration to alkaptonurics, 54, 55

fate of, in normal organism, 60

a parent substance of homogentisic acid, 54, 55

yields acetone when perfused through liver, 61

Phenyl-glyceric acid, not converted into homogentisic acid, 74

Phenyl-a-lactic acid, effect of its administration to alkaptonurics, 74

yields acetone when perfused through liver, 61

Phenyl- $\beta$-lactic acid, effect of its administration to alkaptonurics, 74

yields no acetone in perfused liver, 61

Phenyl-pyruvic acid, effect of its administration to alkaptonurics, 74

Phlorhizin test, in Pentosuria, 153

Phloroglucin, test for pentose in urine, 145

Polypeptides, effect of their administration to a cystinuric, 133

Protective mechanisms against chemical poisons, 4, 9, 67,91

Proteins, changes undergone by, in alimentary canal, 133

cystin obtained by hydrolysis of, 86
Proteins (continued),-

effects of administration of, to alkaptonurics, 55,59 effects of administration of, to cystinurics, 107, 127

effects of administration of, to pentosurics, 153 excretion of by kidneys, 3 paths of metabolism of, 6 specific differences among,

1, 2. See also BenceJones Protein and Halogen-Protoing

Protocatechuic acid, fate of, in normal organism, 79 thought to be present in alkapton urines, 47

Putrescin, in fæces in cystinuria $119,120,122$

relation of, to arginin, 124 relation of, to ornithin, 124 in urine in cystinuria, 101 . 119,122 . See also Diamines

Pyrocatechin, thought to be present in alkapton urines, 47

Quinone grouping, a probable step in the change from tyrosin to homogentisic acid, 77

Ratio, $\mathbf{C}: \mathbf{N}$ in cystinuria, 110 $\mathrm{H}: \mathrm{N}$ in alkaptonuria, 62,63 Residual nitrogen, in urine, in systinuria, 131, 132

Sulphates, aromatic in urine, 8,88

urinary, 8,88

urinary, cystin excreted at expense of, in cystinuria, 106 
Sulphates (continued), urinary, ratio of neutral sulphur to, $8,88,106$

Sulphocyanides in urine and saliva, 87,88

Sulphur metabolism normal paths of, 87 in cystinuria, 96

Sulphur, neutral of urine, 88 neutral of urine, constituents of, 11,89

effect of administration of taurin upon, 94

estimation of cystin in urine by increase of, 103 increase of, in cystinuria, 106

not increased by administration of cystin, 95,112 not increased by protein diet, 89,103

products of tissue metabolism, 89

ratio of, to sulphates, normal, 88

ratio of, to sulphates, in cystinuria, 106

Sweat, in alkaptonuria, 50

in cystinuria, 100

Tables illustratingconsanguinity of parents in relation to alkaptonuria, 24

the excretion of cystin in cases of cystinuria, 105 family incidence of alkaptonuria, 29

the uniformity of the $\mathrm{H}: \mathrm{N}$ ratio in cases of alkaptonuria, 64

the variations of the $\mathrm{C}: \mathrm{N}$ ratio in cases of cystinuria, 111
Taurin, effect of administration of, to normal man and animals, 94

origin of, from cystin, 88

relation of, to cystin, 92

Taurin-carbamic acid in urine, 94

Taurocholic acid, formation of, 92,93

Thiosulphates in urine, 90, 95 Thyroid gland, influence of, upon metabolism, 6,12 Tryptophane, derivative of, in urine of a cystonuric, 130

effect of administration of, to alkaptonuries, 56

indol formed from, in intestine, 10

kynurenic acid derived from, 2

Tyrosin, in a cystin calculus, 85 effect of administration of, to alkaptonurics, 54 effect of administration of, to cystinurics, 129

effect of administration of, halogen derivatives of, 76

excretion of, in acute yellow atrophy of liver, 12

excretion of, in some cases of cystinuria, 101, 129

fate of, in normal organism, 60

formation of homogentisic acid from, 57, 78

a parent substance of homogentisic acid, 54, 57, 78

a primary protein fraction, 6,54 .

See also Meta and Orthotyrosin, Dibrom-tyrosin and leucyl-l-tyrosin 
Tyrosinase, suggested formation of melanins by action of, 36

supposed formation of homogentisic acid in plants by action of, 73

Undetermined nitrogen in urine in cystinuria, 131

Uric acid, in blood and tissues in gout, 12

excretion of, in alkaptonuria, 54

excretion of, by birds and reptiles, 2,35

in wings of butterflies, 34

Urine, accidental constituents of, 9

acetone bodies in, 13, 61

1.-arabinose in. 138,145

r.-arabinose in, 150

aromatic sulphates in, 88

Bence-Jones protein in, 8 cadaverin in, 11, 101, 119

cystin sediments in, 82

diamines in, 11, 101, 119

homogentisic acid in, 49

intermediate metabolic products in, 11

kynurenic acid in, 2

leucin in, 12, 128

melanogen in, 36

neutral sulphur in, 88

nitrogen, undetermined in, 131
Urine (continued), -

pentose in, 137

pigments of, in albinos, 35

products of becterial action in, 10

products of protective mechanisms in, $4,9.67,91$ propertics of, in alkaptonuria, 41 in cystinuria, 97

in pentosuria, 137,144 proteins in, 10

putrescin in, 101, 119, 122

sulphates in, 88, 106

tyrosin in, 12, 101, 129

uric acid in, in alkaptonuria, 54

Urobilin, in urine, origin of, 10

Uroferric acid, in urine, 90

Uroleucic acid-

history of, 51

Huppert's views on, 52

of Kirk, impure homogen.

tisic acid, 51

non-existence of, 53

supposed, properties of, 51

Uroproteic acid in urine, 90

Wex, aural, in alkaptonuria, 50

1.-Xylose, or wood sugar

formula of, 137

optical properties of, 137

in pancreas, 138

relation of, to glucose, 153

in vegetable kingdom, 136 
. 



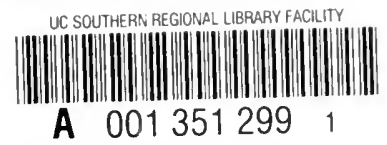


